\title{
BREVISSIMA STORIA DELLA CRITICA INTERPOLAZIONISTICA NELLE FONTI GIURIDICHE ROMANE*
}

["Short History of the Interpolation Critic's in the Sources of Roman Law"]

FRANCISCO J. ANDRÉS SANTOS**

Universidad de Valladolid, España

\section{RESUMEN}

En este artículo se presenta una breve semblanza de la historia del método interpolacionista referido a las fuentes jurídicas romanas, desde sus orígenes en la Escuela Humanista del siglo XVI hasta su decadencia en la segunda mitad del siglo XX, y se apuntan algunas líneas de investigación recientes que apuntan a una recuperación de la preocupación por los problemas de crítica textual en los estudios romanistas.

PALABRAS CLAVE

Interpolaciones - Crítica textual - Humanismo Neohumanismo - Textstufenforschung - Konservativismus - Traducción juridica.

\begin{abstract}
This article draws a brief history of interpolationism concerning the Roman legal sources, from its very beginning in the Humanist Legal Scholarship to its fall in the second half of 20 th century. Some of the recent lines of research in the Romanist studies pointing out a new rendering of the problems of textual criticism are also discussed here.
\end{abstract}

\section{KEYWORDS}

Interpolations - Textual Criticism - Humanism Neo-Humanism -Textstufenforschung - Konservativismus - Legal Translation.

RECIBIDO el 14 de julio y ACEPTADO el 29 de julio de 2011

\section{IL CONCETTO DI INTERPOLAZIONE E DI CRITICA INTERPOLAZIONISTICA. GLI INIZI DELLA CRITICA TESTUALE DELLE FONTI GIURIDICHE ROMANE: LA SCUOLA UMANISTA}

La parola interpolazione deriva del latino "interpolatio", sostantivo deverbativo dal verbo interpolare che indica propriamente un procedimento diretto a rabberciare vecchi abiti, a rimettere a nuovo vestiti malconci; p. es. già Plauto adopera interpolare per "mutare i connotati" a furia di pugni ${ }^{1}$. Questo può accadere anche con intenzione fraudolenta, come si può vedere pure in D. 18,1,45 (Marci., 4 reg.): “si vestimenta interpola quis pro nobis emerit". La parola si presta, quindi, assai bene ad esprimere l'opera di manipolazione, di rabberciatura e di cucitura

* Il testo corrisponde in essenza alla mia lezione nel corso "Interpretare il Digesto. Storia e metodi", organizzato nel CEDANT (Centro di Studio e ricerche sui Diritti Antichi) dell'Istituto Universitario di Studi Superiori di Pavia nel gennaio di 2011 sotto la direzione dei professori Dario Mantovani (Pavia) e Antonio Padoa Schioppa (Milano). Vorrei ringraziare qui gli organizzatori del corso per l'invito a far parte come docente in quella interessante esperienza didattica e di ricerca, e anche i partecipanti del corso per le osservazioni critiche al mio testo. ** Catedrático de Derecho Romano de la Universidad de Valladolid. Dirección postal: Facultad de Derecho, Universidad de Valladolid, Plaza de la Universidad, s/n, 47002, Valladolid, España. Correo electrónico: fjandres@der.uva.es ${ }^{1}$ PLAUT. Amph.317; cfr. anche Most.262 
compiuta, sui testi antichi, nelle epoche successive a quella in cui furono scritti.

Questa parola oggi ha soltanto un significato tecnico, non è una parola di uso comune. Ma anche in senso tecnico è una parola polisemica, avente diversi significati. Se facciamo una semplice ricerca in Internet attraverso Google, vedremo che la maggioranza delle ocurrences del termine "interpolazione" corrisponde a un significato matematico: si parla d'interpolazione in riferimento alla costruzione di un modello della funzione $\mathrm{f}(\mathrm{x})$ valido al interno dell'intervallo del punti $\left[\mathrm{x}_{1}, \mathrm{x}_{\mathrm{n}}\right]$ per calcolare il valore del punto $\mathrm{x}^{1} \mathrm{x}_{1}, \mathrm{x}_{2}, \ldots \mathrm{x}_{\mathrm{n}}$. Ma questo non è ovviamente l'oggetto del nostro presente testo, bensì un altro significato dell'espressione che oggi non è così comune, nemmeno nell'ambito delle scienze umane, ma che ha avuto un importante ruolo nella storia delle discipline filologiche, così come nello svolgimento della romanistica moderna.

Come ci informa il grande filologo Giorgio Pasquali nella Enciclopedia Italiana ${ }^{2}$, nell'ambito della critica testuale il termine "interpolazione" è adoperato dagli studiosi moderni in due significati, più stretto l'uno, più largo l'altro.

Secondo il primo, si suole comunemente chiamare "interpolazione" qualunque consapevole alterazione del testo tramandato che non si confessi tale. Le interpolazioni, in questo senso del termine, sono comunissime nella tradizione di qualsiasi classico. I moderni sono troppo inclinati a concepire qualunque alterazione dei testi come meccanica; copiati meccanicamente sono invece per lo più soltanto i testi che l'amanuense non intende, o testi che sono difesi da particolarità della loro forma. Ogniqualvolta l'amanuense comprende quello che trascrive, egli è proclive a rendere il suo autore "migliore". "Migliore" in questo senso può significare più facile: il formarsi di una lectio facilior, il progressivo prevalere di questa sulla lectio difficilior, il formarsi di una vulgata, è, in questo senso, un procedimento interpolatorio. L'interpolatore, se intende un testo nel suo complesso, ma non lo intende in un punto particolare, congettura, e pone la sua congettura arditamente nel testo. Ma "migliore" può significare qui più conforme al gusto del tempo. S'intende dunque che tali interpolazioni sono più sistematiche là dove il testo doveva essere ridotto alla lettura scolastica. Questo indirizzo è caratteristico dei periodi storici caratterizzati da una sensibilità umanista, periodi che tendono maggiormente all'interpolazione.

$\mathrm{Ma}$ "interpolazione" si usa dagli studiosi più severi in un significato più particolare, d'inserzione in un testo di elementi che gli erano originariamente estranei. In questo significato più stretto e più tecnico l'interpolazione non è caratterizata come nel primo dalla volontà, quanto da una caratteristica materiale, l'accrescimento: l'interpolazione è sempre aggiunta.

Le più innocenti e comunque le più recenti di tali interpolazioni sono "glossemi", cioè spiegazioni marginali per distrazione di amanuensi penetrate nel testo. Ma anche intere note marginali (cd. scoli) possono per inavvertenza penetrare nel testo.

Ma ci sono anche interpolazioni di tutt'altra fatta, oppure più estese, e queste intenzionali. Testi destinati alla recitazione vengono ampliati a volta a volta, come é accaduto p. es. con i poemi omerici. Testi destinati alla lettura sono interpolati più di rado, quasi mai, se non v'è un forte interesse, p. es. religioso, com'è successo con parecchi testi della Bibbia. Ma casi di tale genere sono in complesso rari, e lo stesso Pasquali ci informa che la filologia nel suo tempo era meno proclive di quella di cinquant'anni prima a stabilire interpolazioni per ragioni di poco conto o non evidenti, ed essa tendeva forse allora anzi all'eccesso oposto ${ }^{3}$.

\footnotetext{
2 s. v. 'Interpolazione', nella Enciclopedia Italiana di Scienze, Lettere ed Arti (Roma, 1939, rist. 1949-50), XIX, pp. 398 ss.

${ }^{3}$ Deve notarsi che questo si dice nello stesso momento in cui nella romanistica ancora dominava una tendenza a vedere una grande copia d'interpolazioni nei testi giuridici romani, come si può osservare nel testo parallelo di Albertario nello stesso volume citato sopra della Enciclopedia Italiana (v. nota seguente): la romanistica avrebbe avuto bisogno ancora di trent'anni per fare un simile percorso come la filologia degli anni 30' del XX secolo.
} 
Esposta all'interpolazione, anche in senso più ristretto della parola, è particolarissimamente la letteratura scolastica, in specie trattati grammaticali e commenti, per adattare i libri scolastici ai bisogni sempre nuovi della scuola. Ma qui l'interpolazione si combina con altri procedimenti (abbreviazioni e sostituzioni), cosicché è ben difficile che l'analisi possa restituire il testo originale. Come vedremo, questa è la stessa problematica dei testi giuridici.

In effetti, nell'indagine delle interpolazioni c'è quasi sempre bisogno di delicati procedimenti analitici, dato che è raro il caso che l'interpolazione si trovi ancora allo stato grezzo, ci dice Pasquali. Di solito la parte del testo originale che la precede e la segue è stata rielaborata per accoglierla più facilmente. Onde non è sempre agevole determinare il confine di un'interpolazione. E questo non è del resto che un secondo stadio d'indagine: prima di tutto occorre accorgersi che un certo gruppo di parole non può essere se non interpolato. Stranezza e sconcordanze e specialmente contraddizioni possono destare il sospetto; ma a una risposta definitiva non si giunge se non mediante un'analisi penetrante. Anche lo stile può rivelare a un conoscitore sottile della lingua l'interpolazione; ma anche qui la certezza non può essere data se non da un'indagine approfondita, ché spesso condizioni speciali possono giustificare quella che è veramente un' anomalia linguistica, onde certi filologi moderni hanno la pretesa che dallo stile si prescinda in tale ricerca.

Questa problematica della critica testuale è arrivata anche nella scienza giuridica, e particolarmente nella disciplina romanistica, dal momento che il problema dell'autenticità dei testi procedenti dal passato, con i quali è possible ricostruire scientificamente i profili del diritto romano storico, soprattutto i testi del Corpus iuris civilis, e in specie i testi dei giuristi classici contenuti nei Digesa giustinianei, questo problema è diventato uno degli scopi fondamentali della romanistica, particolarmente fin dalla metà dell'Ottocento, ed è considerato un presupposto necessario per la considerazione della scienza del diritto romano come una disciplina d'indole veramente storica.

Nella romanistica si designano col nome complessivo d'interpolazione in specie tutte le alterazioni introdotte dai compilatori nei frammenti delle opere dei giureconsulti o delle costituzioni imperiali inseriti nel Corpus iuris. Qualunque genere di alterazioni chi hanno sofferto i testi giuridici dell'antichità romana nel corso dei secoli per le vie più diverse e per le più diverse cagioni, particolarmente quelle eseguite di forma intenzionale da loro commentatori e interpreti, si solevano designare col nome di glossemi; ma posteriormente è stato anche presso il nome di interpolazioni per significare le modificazioni pregiustinianee dei testi anche non eseguite da commissioni legislative, bensí volutamente, ma sempre con uno scopo innovativo. Anzitutto, il termine non sarebbe adatto a designare propriamente se non le aggiunte intercalate nel testo dalla commissione (o dal commentatore), ma per estensione si usa pure dai romanisti per esprimere le omissioni, nonchè le sostituzioni operate: l'interpolazione, insomma, esprime non solo l'interpolare, bensí anche il demere (tagliere, sosttrarre) e il mutare (cambiare) $)^{4}$.

Dunque, la cosidetta "critica interpolazionistica" s'intende comunque, come ci dice Orestano, come "l'attività che, attraverso un insieme di criteri e di procedimenti per lo più congetturali, mira a ristablire quale sarebbe stato il dettato 'genuino' dei testi (scritti di giuristi e costituzioni imperiali) utilizzati per la formazione del Corpus iuris". Che nella compilazione esistono interpolazioni in copia è cosa che non si può mettere in dubbio, poiché Giustiniano

\footnotetext{
${ }^{4}$ Albertario, E., s. v. 'Interpolazione (Diritto)', nella Enciclopedia Italiana di Scienze, Lettere ed Arti, cit. (n. 2), XIX, p. 399.

${ }^{5}$ OReSTANO, R., “Diritto”: Incontri e scontri (Bologna, 1981), p. 217.
} 
medesimo aveva dichiarato le profonde manipolazioni cui i testi antichi erano stati sottoposti, per suo ordine, dai commissari incaricati della composizione del Codex e dei Digesta ${ }^{6}$. Nella cost. Deo auctore (15 dec. 530), al $\ 7$, l'imperatore porge ai commissari la seguente istruzione: "Sed et boc studiosum nobis esse nolumus, ut, si quid in ueteribus non bene positum libris inueniatis uel aliquod superfluum uel minus perfectum, superuacua longitudine semota et quod imperfectum est repleatis et omne opus moderatum et quam pulcherrimum ostendatis. Hoc etiam nibilo minus observando, ut, si aliquid in veteribus legibus vel constitutionibus, quas antiqui in suis libris posuerunt, non recte scriptum inveniatis, et hoc reformetis et ordini moderato tradatis: ut hoc videatur esse verum et optimum et quasi ab initio scriptum, quod a vobis electum et ibi positum fuerit, et nemo ex comparatione veteris voluminis quasi vitiosam scripturam arguere andeat' ${ }^{7}$.

Più energicamente nella cost. Tanta (16 dec. 533), al \$10, l'imperatore dice: "Tanta autem nobis antiquitati habita est reverentia, ut nomina prudentium taciturnitati tradere nullo patiamur modo: sed unusquisque eorum, qui auctor legis fuit, nostris digestis inscriptus est. boc tantummodo a nobis effecto, ut, si quid in legibus eorum vel supervacuum vel imperfectum aut minus idoneum visum est, vel adiectionem vel deminutionem necessariam accipiat et rectissimis tradatur regulis. Et ex multis similibus vel contrariis quod rectius babere apparebat, hoc pro aliis omnibus positum est unaque omnibus auctoritate indulta, ut quidquid ibi scriptum est, hoc nostrum appareat et ex nostra voluntate compositum: nemine audente comparare ea quae antiquitas habebat his quae nostra auctoritas introduxit, quia multa et maxima sunt, quae propter utilitatem rerum transformata sunt. Adeo ut et si principalis constitutio fuerat in veteribus libris relata, neque ei pepercimus, sed et hanc corrigendam esse putavimus et in melius restaurandam. Nominibus etenim veteribus relictis, quidquid legum veritati decorum et necessarium fuerat, hoc nostris emendationibus servavimus" ${ }^{8}$.

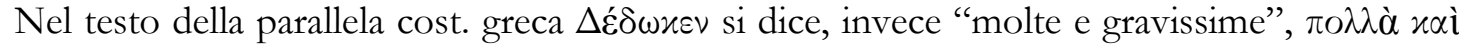

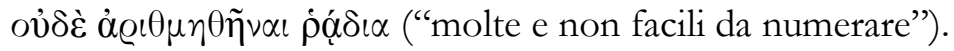

Similmente nella cost. Haec quae necessario (13 feb. 528), la prima prefazione al Codex, al $₫ 2$, si dice: "Quibus specialiter permisimus resecatis tam supervacuis, quantum ad legum soliditatem pertinet, praefationibus quam similibus et contrariis, praeterquam si iuris adqua divisione adiuventur, illis etiam, quae in desuetudinem abierunt, certas et brevi sermone conscriptas ex isdem tribus codicibus, novellis etiam constitutionibus leges componere et congruis subdere titulis, adicientes quidem et detrabentes, immo et mutantes verba earum, ubi hoc rei commoditas exigebat, colligentes vero in unam sanctionem, quae in variis

\footnotetext{
${ }^{6}$ Vedasi sul tema, da ultimo: LAMBertini, R., Interpolazioni nei Digesta. Dichiarazioni di Giustiniano, esperienza di recerca, in M. MiglietTA, M - SANTUCCI, G. (a cura di), Problemi e prospettive della critica testuale. Atti del seminario di Diritto romano a Trento, 14-15 dicembre 2007 (Trento, 2011) (opera in corso di stampa).

7 "Vogliamo che abbiate cura che, se negli antichi libri voi trovate qualque cosa di inopportuno o di superfluo o di imperfetto, voi, tolte la superfluità e riempite le lacune, abbiate a presentar tutta l'opera armonica e perfetta. Abbiate anche questa osservanza, che se nelle vetuste leggi o costituzioni che gli antichi posero nei loro libri, ritrovate qualque cosa di inopportuno, anche questo dovete riformare ed in buon ordine ridurre; di guisa che ciò che da voi sarà scelto e posto, quello dovrà apparire il vero e l'ottimo, come se fosse la scrittura originaria, e nessuno osi dalla comparazione dell'antica opera impugnare come viziosa la nuova scrittura" [Trad. ital. di BONFANTE, P., Storia del Diritto romano, (4ª edizione, Roma, 1934, rist. a cura di G. BONFANTE e G. CRIFÒ, Milano, 1959), II, pp. 139 s.].

8 “Abbiamo avuto tanta riverenza all'antichità da non soffrire di passar sotto silenzio i nomi dei giureconsulti: ma ciascuno dei giureconsulti, che fu autore della legge, serba nei nostri Digesti l'iscrizione: noi non facemmo se non questo, di aggiungere o togliere, ove era necessario, o corregere nel miglior modo, quando nelle leggi vi fosse qualque cosa di superfluo o di imperfetto o di meno acconcio, e ridurre tutto a perfezione. $\mathrm{E}$ in molte spece autorità, di guisa che tutto ciò che è scritto quivi appare nostro e composto di nostro volere; e nessuno osi porre a raffronto il dettato antico e le modificazioni introdotte da noi, perché sono molte e gravissime le modificazioni apportate per utilità. Tanto che se anche una costituzione imperiale veniva riferita nei libri antichi, noi non l'abbiamo risparmiata, ma reputammo che fosse anch'essa da corregere o da migliorare; insomma, lasciati i nomi antichi, noi abbiamo con le nostre emendazioni sancito ciò che era conforme alla realtà ed alle necessità odierne" [Trad. ital. BONFANTE, Storia, cit. (n. 7), II, p. 140].
} 
constitutionibus dispersa sunt, et sensum earum clariorem efficientes, ita tamen, ut ordo temporum earundem constitutionum non solum ex adiectis diebus et consulibus, sed etiam ex ipsa compositione earum clarescat, primis quidem in primo loco, posterioribus vero in secundo ponendis et, si quae earum sine die et consule in veteribus codicibus vel in his, in quibus novellae constitutiones receptae sunt, inveniantur, ita his ponendis nullaque dubietate super generali earum robore ex hoc orienda, sicut et illas vim generalis constitutionis obtinere palam est, quae ad certas personas rescriptae vel per pragmaticam ab initio datae eidem novo codici propter utilitatem sanctionis inditae fuerint"'.

Finalmente, nella cost. Cordi (16 nov. 534), terza prefazione nel codice, al $\$ 3$ abbiamo: "Supra dictis itaque magnificis et prudentissimis viris permisimus baec omnia facere et, si qua emendatione opus fieret, banc facere non titubante animo, sed nostra auctoritate fretos, constitutiones vero superfluas vel ex posterioribus sanctionibus nostris iam vacuatas, vel si quae similes vel contrariae invenirentur, circumducere et a prioris codicis congregatione separare et tam imperfectas replere quam nocte obscuritatis obductas nova elimationis luce retegere, ut undique non solum institutionum et digestorum via dilucida et aperta pateret, sed etiam constitutionum nostri codicis plenum iubar omnibus clareat, nulla penitus nec simili nec diversa nec inusitata relicta" ${ }^{\prime 10}$.

La ricerca delle interpolazioni nella Compilazione giustinianea appare però soltanto nel XVI secolo, col sorgere delle Scuola Umanista (o Scuola dei Culti), cioè degli studi storici nel campo del diritto romano: prima di questo momento non aveva senso una ricerca cosí, poiché, mentre il Corpus iuris era stato considerato, in varia guisa, come diritto positivo 'vigente', un 'problema critico' dei testi non aveva -sotto questo profilo- una ragione pratica di porsi, anzi sarebbe andato contro la proibizione dello stesso Giustiniano di mettere in evidenza le alterazioni ${ }^{11}$. Prima del XVI secolo soltanto isolatamente si trova il rilievo di qualche interpolazione nei glossatori (come per es. la gl. exaequata di Accursio ad D. 30,1: "vel dic quod aliquid est bic detractum

9 “Abbiamo permesso a costoro in modo speciale di tagliar vie le declarazioni superflue quanto al dispositivo legal, le prefazioni, le norme simili o contrarie, salvo che fossero giustificate da una distinzione giuridica, e similmente le norme andate in desuetudine; e con queste avvertenze mettere insieme leggi precise, ridotte in breve dettato, dai tre codici e anche dalle nuove costituzioni, ordinarle sotto titoli acconici aggiungendo e togliendo, anzí mutando le parole, quando lo esigesse la comodità, raccogliendo in una sola disposizione quanto era disperso in varie costituzioni e rendendone più chiaro il senso; con questo tuttavia che fosse chiaro l'ordine dei tempi nelle costituzioni, non solo mediante l'aggiunzione dei giorni e dei consoli, ma altresì della stessa disposizione, collocando le più antiche in primo luoco, le susseguenti nel secondo posto e se ve n'è senza giorno e console nei codici antiqui e nei codici, in cui sono raccolte le nuove costituzioni, collocando queste così come si trovano, senza che sorga nessun dubbio sulla validità generale; come è chiaro che ottengono il valore di una costituzione generale anche quelle che sono dirette a persone determinate" [Trad. ital. BONFANTE, Storia, cit. (n. 7), II, p. 140 s.].

10 “Ai sopradetti personaggi magnifici e prudentissimimi noi abbiamo permesso di fare tutto ciò e se v'era bisogno di correzioni, eseguirle senza esitazione, forti della nostra autorità; e se v'erano costituzioni superflue o abrogate da nostre costituzioni posteriori o simile o contrarie, di cancellarle e separarle dal codice precedente, e così integrare le costituzioni imperfette, come chiarire quelle oscure, di guisa che non solo i Digesti e le costituzioni appaiano chiari ed aperti, ma anche sia chiaro ad ognuno lo splendore pieno del nostro codice, sfuggendo le ripetizioni, le contradizzioni e le norme disusate" (Trad. ital. BONFANTE, Storia, cit. (n. 7), II, p. 141].

${ }^{11}$ Const. Deo auctore $\$ 7: "Sed et hoc studiosum nobis esse nolumus, ut, si quid in ueteribus non bene positum libris inueniatis uel aliquod superfluum uel minus perfectum, superuacua longitudine semota et quod imperfectum est repleatis et omne opus moderatum et quam pulcherrimum ostendatis. Hoc etiam nibilo minus observando, ut, si aliquid in veteribus legibus vel constitutionibus, quas antiqui in suis libris posuerunt, non recte scriptum inveniatis, et hoc reformetis et ordini moderato tradatis: ut hoc videatur esse verum et optimum et quasi ab initio scriptum, quod a vobis electum et ibi positum fuerit, et nemo ex comparatione veteris voluminis quasi vitiosam scripturam arguere audeat"; const. Tanta/ $\Delta \dot{\delta} \delta \omega x \varepsilon v \rrbracket 10:$ "Et ex multis similibus vel contrariis quod rectius habere apparebat, hoc pro aliis omnibus positum est unaque omnibus auctoritate indulta, ut quidquid ibi scriptum est, hoc nostrum appareat et ex nostra voluntate compositum: nemine audente comparare ea quae antiquitas habebat his quae nostra auctoritas introduxit'; $\mathbb{S}$ 21: "Alias autem legum interpretationes, immo magis perversiones eos iactare non concedimus, ne verbositas eorum aliquid legibus nostris adferat ex confusione dedecus". 
a compilatoribus novi iuris, et illud detractum induxit novitatem"). Nel secolo XVI -e non senza scandalo- si cominciò nell'indirizzo umanistico a non rispettare la veneranda intangibilità dei testi giustinianei, ricercando attraverso i 'materiali' della compilazione il pensiero originario degli antichi giureconsulti e imprecando contro l'operato dei commissari giustinianei, contro l'imperatore medesimo che li aveva ispirati e suppratutto contro il suo principale collaboratore, Triboniano, l'uno e l'altro accusati di ogni nefandezza ${ }^{12}$. Queste alterazioni si dissero emblemata Triboniani (cioè "intarsi di Triboniano") o addiritura facinora Triboniani ("scelleraggini di Tribonano"). La critica all'opera di Giustiniano e di Triboniano si trova espressa nella forma più aspra e articolata in un libro di uno dei più cospicui rappresentanti della Scuola Culta, François Hotman (Hotomanus, ovvero Ottomanus) (1524-1590), chi fu avvocato al Parlamento di Parigi e professore a Valençes e a Bourges, prima di andare in esilio in Germania e Svizzera, e che scrisse moltissimo nel campo della critica interpolazionistica ${ }^{13}$. Il suo libro cui ci riferiamo è il significativamente intitolato Antitribonianus sive dissertatio de studio legale, scritto nel 1567, ma pubblicato postumo nel 1604. In questo libro, Hotman non esita a introdurre motivi di polemica personale contro Giustiniano, imperatore rozzo, vizioso e ignorante, e suprattutto contro il suo ministro Triboniano, avido di denaro ed anticlericale: quel "graeculus semilatinus proletarius in iurisprudentia", con emplastra e flagritia, aveva adulterato i testi degli antichi giuristi e imperatori; gli sembra inconcepibile che uomini simili abbiano potuto permettersi di riordinare le fonti del diritto romano: progetto che lo stesso Giulio Cesare aveva avuto una volta, ma che aveva rinunciato a realizzare perché troppo difficile. Questa prima parte dell'Antitribonianus è evidentemente poco seria: come sempre, gli argomenti polemici di tipo personale sono strumentali, allo scopo di rafforzare reali motivi critici. Questi ultimi sono sintetizzati da Franca de Marini ${ }^{14}$ così: "1) La commissione incaricata di compilare il Corpus Iuris non era preparata al lavoro, perché si trattava di greci che non avevano la necessaria conoscenza della lingua latina e del diritto della prima età imperiale; inoltre l'affermazione di Giustiniano, secondo cui la commissione avrebbe letto in soli tre anni più di duemila libri antichi per scegliere i brani da inserire nel Digesto, è una prova della mancanza di attenzione con cui necessariamente fu fatto lo spoglio. 2) La conseguenza della scarsa preparazione scientifica della commissione preposta alla compilazione è palese in tutto il Digesto: invece di trovarvi le antiche leges, i senatusconsulta, gli edicta praetorum, noi vi troviamo soltanto i commentari a quei testi fatti da giuristi posteriori, e anche tali commentari sono conservati non nella loro forma originaria, ma frammentariamente ed alterati dai commissari che si proponevano (senza nemmeno riuscirvi) di coordinarli tra di loro e di aggiornarli al diritto del loro tempo".

In questa opera di $\operatorname{Hotman}^{15}$ si possono vedere, dunque, i principali scopi cercati dai Culti riguardo dei testi giuridici romani, in genere, e al Corpus iuris civilis in particolare: la scoperta del vero diritto romano antico, la ricostruzione del diritto dei giuristi classici dei secoli I-III d. C., che, a loro avviso, Giustiniano aveva religiosamente raccolto nella Compilazione, ma che era stato adulterato, deformato o misconosciuto dagli compilatori. Le modifiche dei commissari giustinianei devono essere individuate al fine di conoscere nella loro forma originaria $i$ testi della giurisprudenza romana, e quindi la storia del diritto romano nei vari periodi del suo sviluppo. E in questo atteggiamento non erano mossi soltanto da un fanatico amore per la

\footnotetext{
${ }^{12}$ GUZMÁn BRITO, A., Introducción a los juristas de los siglos XVI y XVII (de Zasio a Montesquieu), in DOMINGO, R. (editore), Juristas universales, II: Juristas modernos (Madrid - Barcelona, 2004), p. 28.

${ }^{13} \mathrm{Su}$ questo autore vedasi da ultimo: DOMINGO, R. - DOMínguEZ, V., François Hotman (Francisco Otomano; Franciscus Hotomanus), in DOMINGO, R. (editore), Juristas universales, cit. (n. 12), II, pp. 227 ss.

${ }^{14}$ DE MARINI, F. - LANZA, C., Critica testuale e studio storico del Diritto (3a edizione, Torino, 2001), p. 153.

${ }^{15}$ Nello stesso senso vedasi anche, ad es., HUBERT van GIFFEN (OBERTUS GIPHANIUS), Commentarius de imperatore Iustiniano (Ingolstadt, 1591).
} 
antichità, ma anche da un desiderio consapevole di restaurare per il loro tempo i monumenti giuridici della antichità e i loro ideali. Questa necessità è scorsa suprattutto dopo la invenzione della stampa e il bisogno di fare nuove edizioni delle fonti giuridiche per i nuovi tempi. La ricerca delle interpolazioni nel Corpus iuris è quindi uno strumento funzionale, vi funge un ruolo sussidiario perché possa riuscire l'impegno essenziale dei Umanisti di scoprire il vero pensiero giuridico romano-classico occulto sotto le macerie, le "inutili scorie" del diritto giustinianeo. Sebbene gli Umanisti si fossero impegnati molto nella scoperta di manoscritti di opere giuridiche anteriori a Giustiniano, e fossero riusciti a restituire e fare la edizione critica e la pubblicazione di parecchie di queste opere (Epitome Gai [1517], Pauli Sententiae [1517], Tituli ex corpore Ulpiani [1549], Codex Theodosianus [1566], Collatio Legum Mosaicarum et Romanarum [1573], Fragmentum Dositheanum [1573], Consultatio veteris ciusdam iurisconsulti [1577], Edictum Theodorici [1579], etc. $)^{16}$, la Compilazione giustinianea tuttavia forniva l'unico strumento veramente esteso e assai denso per discernere le sottigliezze e le sfumature del pensiero della giurisprudenza classica.

Questo lavoro di scoperta d'interpolazioni giustinianee fu un compito collettivo della Scuola dei Culti dagli inizi del movimento umanista con Lorenzo Valla o Angelo Poliziano fino gli ultimi rappresentanti nel XVIII secolo. Questo è stato ampiamente studiato da Luigi Palazzini Finetti in una monografia pubblicata a Milano nel 1953, il cui titolo (Storia della ricerca delle interpolazioni nel Corpus iuris civilis) dà l'impressione che l'opera abbia un scopo più ampio del suo contenuto reale. Si tratta, senza dubbio, di un'opera utile e meritevole, che apporta interessanti informazioni sulla letteratura umanistica e sui problemi moderni della critica testuale, ma è una mera storia esterna dell'impostazione interpolazionistica, che non mette in rilievo le ragioni interne che la spieghino storicamente e la conessione con il suo contesto storico-istituzionale.

L'opera degli Umanisti era, però, frammentaria e saggistica: in genere, non si trovano presso di loro grandi ricostruzioni sistematiche delle istituzioni, e, precisamente per il carattere per loro puramente accessorio della ricerca interpolazionistica, nemmeno hanno fatto un elenco delle interpolazioni trovate nel testo della Compilazione, bensì sogliono indicare sporadicamente l'esistenza di un'alterazione testuale mentre fanno un commento più ampio su un altro argomento.

L'atteggiamento critico degli Umanisti era tuttavia debole, poiché, come consumati filologi che essi erano, la loro indagine critica si esauriva in un'esigenza stilistica, il loro oggetto era suprattutto l'espressione formale. La ricerca delle interpolazioni, secondo la loro premesse filologiche, fu basata in specie su confronti testuali con opere trasmesse al di fuori della compilazione giustinianea: la conoscenza della storia delle istituzioni giuridiche dei romani (grazie a un superbo dominio della letteratura non giuridica) e, suprattutto, l'esame della lingua e degli stili degli scrittori antichi, divengono premesse per lo studio storico-critico della compilazione giustinianea e strumenti per diagnosticare la presenza dei tribonianismi. La loro assoluta padronanza della lingua latina e dello stile dei classici, che gli umanisti sembravano sapere distinguere da quello delle commissioni bizantini, li faceva essere convinti della loro capacità d'individuare l'esistenza di una interpolazione giustinianea in un testo attribuito a un giureconsulto classico. Secondo Palazzini Finetti, gli Umanisti avevano sviluppato già praticamente tutti $\mathrm{i}$ canoni euristici adibiti alla scoperta d'interpolazioni secondo le classificazioni moderne, ma questo pare più o meno un anacronismo, visto che, da un lato, per loro l'indagine delle interpolazioni non è stata mai un argomento centrale del loro lavoro

${ }^{16}$ Sulla storia delle edizioni di queste opere pregiustinianee, vedasi da ultimo, esaustivamente: COMA FORT, J. $\mathrm{M}^{\mathrm{a}}$, Índice comentado de las colecciones de fuentes del Corpus iuris civilis (Cizur Menor, 2008), pp. 79 ss. 
(come sì è stato per molti moderni che hanno profilato tali criteri di ricerca rigorosamente distinti), e, dall'altro, il criterio linguistico ovvero stilistico è così dominante nei loro scritti che non si può distinguere facilmente da altre tecniche d'individuazione dell'alterazione giustinianea. In qualsiasi modo che sia, i resultati di questa ricerca furono numerosi: infatti, le indicazioni delle interpolazioni rilevate dalla Scuola Culta prendono 57 pagine di stampa nell'opera di Palazzini Finetti, e questo elenco non può dirsi che sia per niente definitivo. E, in genere, si dice che questi risultati furono buoni, poiché le alterazioni testuali individuate dagli Umanisti sono state considerate, in massima parte, definitivamente accertate.

La scoperta dei tribonianismi non divenne un compito esclusivo di alcuni giuristi eruditi, ma fu assunto da quasi ogni studioso che abbia scritto seguendo l'indirizzo umanistico fra i secoli XVI e XVIII, e non soltanto in Francia, dove il mos Gallicus s'impose, ma anche daperttutto in Europa. Sono parecchie decine i nomi dei giuristi che vi contribuirono. Ma fra questi nomi risaltano su tutti in Francia, oltre al nome sopraddetto François Hotman, le figure di Iacopus Cuiacius (Jacques Cujàs, Iacopo Cuiacio) e Antonius Faber (Antoine Favre, Antonio Fabro).

Iacopo Cuiacio (1522-1590) ${ }^{17}$ è riconosciuto come il maggiore esponente della Scuola Culta francese nel secolo XVI. Il suo proposito scientifico e fine ultimo di tutti i suoi studi non era altro che restituire al diritto romano la sua classica forma originaria, riconducendo all'antica purezza e intergrità quelle opere che i compilatori bizantini avevano alterato e disperso in mille frammenti, con una visuale del Corpus iuris esclusivamente storico-critica, come un monumento che conservava l'antico e genuino diritto di Roma che doveva essere riscoperto. Onde, nel corso della sua vasta produzione scientifica, l'esegesi delle fonti assume preminente importanza nel metodo di studio da lui seguito, che cerca di riprendere la via iniziata dai Glossatori di una vera conoscienza del sapere giuridico romano conservato nel Corpus iuris. Cuiacio, oltre che un fine filologo, era un acuto giurista del suo tempo, e quindi i criteri di indagine da lui seguiti per l'individuazione degli emblemata Triboniani furono più estesi che in altri rappresentanti della Scuola, poichè egli non si limitava alla forma delle espressioni apparse nel testo del Corpus iuris, ma penetrava anche nella loro sostanza giuridica. Le interpolazioni scoperte da Cuiacio sono stati studiate da Emilio Albertario ${ }^{18}$ e anche parzialmente da Luigi Lusignani ${ }^{19}$ e Luigi Palazzini Finetti ${ }^{20}$.

Antonio Fabro (1557-1624) ${ }^{21}$ era originario della Savoia, studiò diritto a Torino e si dedicò sempre alla vita pubblica al servizio del duca Carlo Emanuele I, prima come giudice nella sua circoscrizione natale, poi come presidente del senato a Ginevra e a Chambéry, ed infine di quello della Savoia. Pur svolgendo una intensa attività pubblica, non perse mai l'interesse per lo studio delle fonti giuridiche romane e poté comporre una serie di opere di grandissimo valore nell'ambito degli studi storico-critici sul Corpus iuris, fra cui si possono citare, in merito al tema della critica interpolazionistica, le principali: De erroribus pragmaticorum et interpretum iuris (Lyon, 1597), Rationalia in Pandectas (Lyon, 1604), Iurisprudentiae papinianeae scientia (Lyon, 1607) e Coniecturarum iuris civilis libri XX (Genève, 1609). Fabro è senza dubbio il più attivo e audace ricercatore di tribonianismi della Scuola, nelle cui opere vi sono interi capitoli dedicati allo studio delle interpolazioni da lui avvertite valendosi di numerosi e diversi criteri di indagine, sempre nell'ambito della considerazione storico-testuale della Compilazione giustinianea. Per

\footnotetext{
${ }^{17}$ Sull'autore si veda da ultimo: VArELA, E., Jacques Cujas (Jacobus Cuiacius; Cuyacio), in DOMINGO, R. (editore), Juristas universales, cit. (n. 12), II, pp. 221 ss.

${ }^{18}$ I Tribonianismi avvertiti dal Cuiacio, in ZSS., 31 (1910), pp. 158 ss.

19 Saggio di una raccolta delle interpolazioni presso gli antichi (Parma, 1898).

20 Storia della ricerca delle interpolazioni nel "Corpus iuris civilis" (cit. nel testo), pp. 188 ss.

21 Sull'autore vedasi da ultimo: GÓMEZ-IGLESIAS, Á., Antoine Favre (Antonius Faber, Antonio Fabro), in DOMINGO, R. (editore), Juristas universales, cit. (n. 12), II, pp. 303 ss.
} 
lui, come una conseguenza della sua attività come giudice, il diritto giustinianeo mancava di tutto valore pratico come ius commune e, al suo avviso, il Corpus iuris era soltanto utilizzabile come strumento per ricondurre le fonti romane alla loro purezza originaria con un puro spirito erudito. Il contributo del Fabro alla storia della dottrina interpolazionistica è stata molto spesso esaltata come un precedente dell'“oltranzismo interpolazionista" del secolo XX e le sue opere sono estate studiate da Di Medio ${ }^{22}$, Baviera ${ }^{23}$, e parzialmente Lusignani ${ }^{24}$ e Palazzini Finetti ${ }^{25}$.

Con la decadenza della Scuola francese alla fine del secolo XVI, il lavoro d'indagine di interpolazioni va a ridursi progressivamente, ma non scompare fino alla fine del XVIII secolo. Non ci sono però nei secoli XVII e XVIII nomi così significativi come gli anteriori, ma si possono menzionare qui gli autori dei primi tentativi di sistemazione dei criteri sino ad allora invalsi per la diagnosi dei "tribonianismi”, cioè Jan Jacob Wissembach (1604-1665), giurista di origine tedesca ma attivo in Olanda, che trattò degli emblemata Triboniani in un'opera speciale con questo titolo, pubblicata a Franecker nel 1642, in Germania, Christian Heinrich Eckard (1716-1751) e Georg Meister (1718-1782), chi in piccoli trattati speciali su questo argomento cercarono di fissare il metodo della ricerca interpolazionistica. Questi, e molti altri nomi, sono stati raccolti da Palazzini Finetti nella sua opera, con moltissimi dati eruditi e citazioni testuali delle loro opere ${ }^{26}$.

Insomma, da un lato, l'antistoricismo degli Umanisti, che, a causa della loro condanna di tutta la storia trascorsa fra l'età classica di Roma e il tempo del Rinascimento, non potevano comprendere il complessivo valore storico della Compilazione giustinianea, era evidente; dall'altro, i “tribonianismi”, sebbene potessero disturbare la eleganza e la purezza degli scritti dei classici, erano un indice chiaro della evoluzione del diritto e la sua essenziale storicità. Ma i resultati raggiunti dai Culti nel campo della storia della critica testuale e della storiografia giuridica sono incontestabili e sono spesso messi in rilievo dagli studiosi, dal momento che hanno superato le concezioni del diritto prima circolanti che vedevano il Corpus iuris come qualcosa di perfetto e di intoccabile. Di questa guisa essi hanno aperto la porta ai lavori storiografici sul diritto romano che soltanto alla seconda metà del XIX secolo poterono essere compiuti.

\section{PRIMA FASE DELL'INTERPOLAZIONISMO MODERNO (1884-1917): LA RISCOPERTA DELLE INTERPOLAZIONI GIUSTINIANEE IN ITALIA E IN GERMANIA. LA “CACCIA ALLE INTERPOLAZIONI”}

La ripresa di questo indirizzo scientifico avviene sul finire del XIX secolo in consonanza con il rapido affirmarsi del c.d. metodo storico-critico per lo studio del diritto romano, cercando uno scopo simile a quello della Scuola Umanista, ma, stranamente senza alcun collegamento esplicito con la vecchia tradizione dei Culti. I romanisti dell'Ottocento presero a porre il problema e a svolgere l'indagine interpolazionistica totalmente ab ovo, ignorando le analoghe esigenze e le soluzioni dei giuristi dell'Umanesimo e del Rinascimento, forse perché, nel clima "storicistico" e "positivista" dell'epoca, essi erano sospinti da una esigenza diversa da quella precipuamente "stilistica" dei Culti. Ma, come se voglia che fosse, l'aspirazione di questi studiosi moderni era così tanto come per gli Umanisti la ricostruzione ideale di un momento

${ }^{22}$ I Tribonianismi avvertiti da Antonio Fabro, in BIDR, 13 (1900), pp. 208 ss.; Di nuovo sui Tribonianismi avvertiti da Antonio Fabro, in BIDR., 14 (1901), pp. 276 ss.

23 Ancora sui Tribonianismi avvertiti da Antonio Fabro, in Archivio Giuridico, 69 (1902), pp. 398 ss.

${ }^{24}$ Saggio di una raccolta delle interpolazioni presso gli antichi, cit. (n. 19).

${ }^{25}$ Storia della ricerca delle interpolazioni, cit. (n. 20), pp. 216 ss.

${ }^{26}$ Si veda: Storia della ricerca delle interpolazioni, cit. (n. 20), pp. 233 ss. 
storico essenziale: quello cd. "classico", cioè, il diritto romano del secoli I-III d. C., per via dell'esame critico, con gli strumenti e mezzi tecnici e filologici più moderni del loro tempo, delle fonti dell'Antichità romana a noi pervenuti, suprattutto la Compilazione giustinianea, ma anche molte altre fonti che man mano durante il secolo erano state scoperte, restaurate e pubblicate. Tuttavia, a differenza del tempo scorso, nella Modernità la critica interpolazionistica si è sviluppata in modo compiuto, rivolgendosi, almeno in un primo tempo, quasi esclusivamente a quella 'ricostruzione' degli scritti e del pensiero degli antichi giureconsulti attraverso $\mathrm{i}$ frammenti del Digesto giustinianeo, ma poi estendendosi alle costituzioni del Codex, e infine investendo tutto il problema della tradizione testuale delle fonti pregiustinienee e di quelle utilizzate dai commissari di Giustiniano.

I postulati di base del nuovo metodo sono stati formulati da Álvaro d'Ors in questi punti programmatici ${ }^{27}$ : i) Non allontanarsi mai dalle fonti; ii) Sottomettere queste fonti alla critica più stretta possibile; iii) Porre qualsiasi fenomeno in relazione con i fenomeni coevi, senza anacronismi; iv) Distinguere le cause storiche che hanno determinato questi fenomeni; v) Collegare i dati certi per ricostruire l'evoluzione storica delle istituzioni.

In questa breve descrizione si possono vedere i due aspetti che articolano questo metodo: la "Textgeschichte" ("storia dei testi") e la "Dogmengeschichte" ("storia delle strutture dogmatiche"), che, come diceva Franz Wieacker ${ }^{28}$, formano oggetti pure complementari, ma diversi, poiché entrambi sogliono stare vincolati, ma c'è la possibilità che certe variazioni d'uno di questi aspetti non abbiano necessariamente un reflesso nell'altro.

Entrambi gli aspetti fondamentali di questo metodo sono stati benissimo sintetizzati dal Wieacker in questi termini: "Das Rohmaterial der Schriftquellen bedarf der kritischen Bearbeitung, der Textkritik. Traditionsgemäß unterscheidet man hierbei 'niedere' und 'höhere' Kritik. Die 'niedere' sucht die ursprüngliche Gestalt eines Zeugnisses herzustellen (Konstitution des Textes, recensio); die 'höhere' prüft die Glaubwürdigkeit seiner inhaltlichen Mitteilungen ('Berichte'), seine Herkunft von den Urheber, den der Text selbst (oder denn eine andere Quelle) ihm zuschreibt (Authentizität), sowie die absichtlichen Veränderungen (Interpolationen) des Textes durch einen anderen als seinen Urheber. Die Herstellung eines Textes geht sinngemäß dieser höheren Kritik voraus"29.

Secondo questa interpretazione, quindi, i due scopi centrali cercati dagli studiosi di questo indirizzo metodologico fin dal suo inizio sono stati, precisamente, la edizione critica delle principali fonti di conoscenza della storia giuridica di Roma e l'analisi critica (nel livello "superiore") dei testi trasmessi dall'Antichità, ciò che all'epoca significava giustamente la critica interpolazionistica.

Infatti, alla fine del Ottocento la critica interpolazionistica cominciava ad affacciarsi nello studio delle fonti giuridiche romane come l'ultimo ambito degli studi sull'antichità classica cui era rimasta fin allora sostanzialmente estranea. Prima di loro, da quando Karl Lachmann aveva rifondato la critica testuale come scienza verso la metà del secolo mediante il metodo

${ }^{27}$ D’ORS, Á., Presupuestos críticos para el estudio del Derecho romano (Salamanca, 1943), pp. $40 \mathrm{~s}$.

${ }^{28}$ Textstufen klassischer Juristen (Göttingen, 1960), pp. 25 ss.

29 "Il materiale greggio delle fonti scritte bisogna di una refundizione critica, cioè, della critica del testo. Secondo la tradizione, si distingue qui fra una critica testuale di livello inferiore o basilare ("niedere Textkritik") e un'altra di livello superiore ("höhere Textkritik"). La critica inferiore cerca di fissare la forma originaria di un documento (la 'costituzione' del testo, o recensio). La critica superiore esamina la credibilità del suo contenuto (l'informazione), dell'origine del autore a cui si attribuisce il testo dalla fonte medesima, ovvero da un'altra, cosí come le alterazioni del testo (interpolazioni) compite da ognuno che non sia il suo autore. La 'constituzione' del testo precede, logicamente, alla critica superiore” [WIEACKER, F., Römische Rechtsgeschichte, I: Einleitung, Quellenkunde, Frühzeit und Republik (München, 1988), pp. 112 s.]. 
stremmatico, tanto la Bibbia quanto gli autori letterari erano stati passati per un vaglio che si manifestava più agevole per una maggiore congenialità tra la natura dell'opera passata al vaglio critico e la scelta dei criteri formali prevalentemente adoperati. La giurisprudenza s'impossessava della critica del testo come l'ultima onda di questa marea critica, ma anche dopo la scoperta, non tanti anni prima, di importantissime nuove fonti, come il manoscritto veronese delle Istituzioni di Gaio (dovuta a Niebuhr, nel 1816) e i Fragmenta Vaticana (dovuta al Cardinale Angelo Mai, nel 1823), che gettavano nuova luce sull'immagine del diritto romano classico, e l'apparire di nuove scienze storico-filologiche, come l'epigrafia, la papirologia e la paleografia scientifica, che contribuivano in genere alla rinascita e rivitalizzazione degli studi sull'Antichità. E anche questo accadeva come naturale conseguenza dei principi della Scuola Storica di Gustav Hugo e di Friedrich Karl von Savigny, ancorché questi suoi fondatori non pensassero a riprendere l'esame critico dei testi direttamente, e appunto nel momento dell'estinguersi del vigore positivo del diritto romano nell'ultimo suo grande territorio europeo, la Germania, quando il Codice civil tedesco (BGB.), dopo una lunga vicenda, stava con tutta evidenza entrando in dirittura d'arrivo.

Per queste ragioni, o forse per altre più recondite che non possiamo scorgere (p. es. Carlos Petit ha suggerito che forse questa visuale interpolazionistica che ricupera l'onore di Triboniano può essere vista come un sottile apoggio al compito dei codificatori tedeschi, ovvero un riflesso ideologico del nuovo tempo codificato della Civilistica tedesca ${ }^{30}$, la cosa certa è che questo nuovo indirizzo metodologico partì dalla Germania, in fermo confronto con la tendenza dominante in Italia nel contempo, cioè, la scuola di Filippo Serafini ${ }^{31}$, che difendeva una visione nazionale e attualizante nello studio del diritto romano dopo l'unificazione d'Italia (per cui il diritto romano doveva, più o meno direttamente o scopertamente, servire di modello del diritto civile italiano attuale); cioè, una tendenza che, allorchè avesse un ruolo di primo piano nella "sprovincializzazione" della scienza giuridica italiana (le parole sono di Mario Talamanca ${ }^{32}$ ), e, con essa, del diritto romano, ancora rimaneva ancorata ad una metodologia antiquata, perfino collegata con la vigenza positiva del ius commune. L'unica eccezione significativa era Ilario Alibrandi (1823-1894) ${ }^{33}$, professore nella Università Gregoriana di Roma, chi, malgrado il ruolo pratico che il ius commune continuava a svolgere nello Stato della Chiesa col Regolamento Gregoriano, fece dello strumento della critica testuale un uso, secondo Pietro Bonfante ${ }^{34}$ (ma contro l'opinione di Talamanca ${ }^{35}$ ) più largo e felice degli iniziatori tedeschi del movimento. In ogni caso, il suo nome è rimasto come un fenomeno isolato nelle origini e, in sé, senza eco presso i suoi contemporanei e senza séguito nella posterità. L'indirizzo critico arrivò in Italia propriamente solo nelle generazioni seguenti, per influsso della dottrina tedesca, quando alla fine degli anni 90' dell'Ottocento,

30 PETIT, C., Estudio y edición, con una nota de lectura sobre 'California y el derecho romano', in RADIN, M., Cartas romanísticas (1923-1950) (Napoli, 2001), p. cii.

${ }^{31}$ Si veda: TAlamancA, M., La romanistica italiana fra Otto e Novecento, in Index, 23 (1995), pp. 164 ss. Sull'autore, vedasi: LANDUCCI, F., Filippo Serafini, in Archivio Giuridico, 85 (1921), pp. 9 ss.; AlBERTARIO, E., s. v. Serafini, Filippo, en Enciclopedia Italiana, cit. (n. 2), (Roma, 1936; rist. 1949-50), XXXI, pp. 408 s.

32 TALAMANCA, La romanistica italiana, cit. (n. 31), p. 165.

${ }^{33}$ Sull'autore, v. SCIALOJA, V., Ilario Alibrandi, in BIDR., 7 (1895), pp. 120 ss.; ID., Prefazione a Opere giuridiche e storiche del Prof. Ilario Alibrandi, (Roma, 1896), I, pp. iii-viii; ARANGIO-RuIZ, V., s. v. 'Alibrandi, Ilario', in Enciclopedia Italiana.., cit. (n. 2), II (Roma, 1936; rist. 1949-1950).

34 BONFANTE, Storia del Diritto romano, vol. II, cit. (n. 7), p. 138.

35 TAlamanca, M., La ricostruzione del testo dalla critica interpolazionistica alle attuali metodologie, in Centro di Studi Romanistici Vincenzo Arangio-Ruiz, Opuscula XVIII (a cura di A. ADAMO, Napoli, 1996) (in corso di ristampa in MiglietTA - SANTUCCI (a cura di), Problemi e prospettive della critica testuale, cit. (n. 6), p. 7. 
membri della scuola di Vittorio Scialoja ${ }^{36}$ (come Pietro Bonfante, Siro Solazzi, Gino Segrè, Salvatore Riccobono, Carlo Longo, pure, in parte, lo stesso Scialoja) abbracciarono la causa dell'interpolazionismo, e alla fine (per ragioni che non si possono spiegare agevolmente) la critica interpolazionistica è stata in Italia complessivamente più lunga e più radicalizzante che nella stessa Germania.

Come si voglia che fosse, il punto di partenza del movimento in sé si pone nel 1887, quando apparve la acuta monografia di Otto Gradenwitz (1860-1935) ${ }^{37}$ Interpolationen in den Pandekten, un vero "manifesto fondazionale" dell'interpolazionismo moderno: qui si appuntavano alcuni criteri di ricerca di interpolazioni nel Digesto giustinianeo, si sottoponevano a penetrante esegesi critica numerosi testi giurisprudenziali considerati come adulterati dai commissari giustinianei, cercando di individuare le interpolazioni effettuate, e si esponevano i principali lineamenti ideologici del movimento. Infatti prima di questa opera lo stesso Gradenwitz aveva pubblicato un articolo omonimo nella Zeitschrift der Savigny-Stiftung del 1886, accanto a un altro articolo di Fridolin Eisele (1837-1920) intitolato Zur Diagnostik der Interpolationen in den Digesten und im Codex ${ }^{38}$, ma entrambi erano ancora piuttosto moderati. Allora, veramente un punto di partenza ancora non così ideologico, ma sì molto pratico, era stato anzi la pubblicazione in 1883 dell'Edictum Perpetuum di Otto Lenel (1849-1935) ${ }^{39}$, dove il giovane erudito tedesco faceva già un abbondantissimo uso delle congetture d'interpolazione per fare la ricostruzione delle clausole edittali attraverso una valutazione critica dei resti a noi pervenuti dei commentarii ad edictum dei giuristi del Principato. Il metodo fu anche utilizzato da lui nella sua Palingenesia Iuris Civilis (Leipzig, 1889), suprattutto nelle note esplicative delle ipotetiche alterazioni sofferte dai frammenti giurisprudenziali estratti dal Digesto. Il pronto successo ottenuto da queste opere nella romanistica tedesca e internazionale fu, senza dubbio, una spinta decisiva per spingere l'intensificazione e l'approfondimento nell'uso della critica del testo sulle fonti giuridiche romane, e particolarmente sul Digesto giustinianeo ${ }^{40}$. Tanto Lenel come Gradenwitz e Eisele continuarono a scrivere numerosi contributi sotto questo profilo critico negli anni seguenti, e a costoro si aggiunsero poi molti altri studiosi, prima tedeschi (come Pernice, Krüger, Bekker, Kalb, Wölfflin, Grupe, Kalinka, Rechnitz, Mitteis, etc.), dopo anche italiani (oltre ai nomi già dinanzi accennati di Scialoja, Bonfante, Segrè, Riccobono, Solazzi, Longo, anche i nomi di Ascoli, De Medio, Di Marzo, Baviera, Vassalli, e pure alcuni più maturi della generazione anteriore come Perozzi o Pampaloni) e di altri paesi (come Henri Appleton in Francia). La critica interpolazionistica diventò in poco tempo il più innovatore e il più dinamico degli indirizzi metodologici nella romanistica internazionale.

Bonfante, nella sua Storia del Diritto romano ${ }^{41}$, ha messo in risalto i due punti principali ove la critica testuale moderna differisce dalla ricerca di tribonianismi della Scuola Culta: i) in primo luogo, si tengono più fermi i criterii direttivi, anzi è forse esclusivamente in quest'epoca che si ebbero studii aventi per scopo il metodo e la ricerca dell'interpolazione per sè stessa,

${ }^{36}$ Sull'autore vedasi, da ultimo: TAlamanca, M., Vittorio Scialoja, en DOMINGO, R. (editore), Juristas universales, III: Juristas del siglo XIX (Madrid/Barcelona, 2004), pp. 672 ss.

${ }_{37}$ Sull'autore vedasi, da ultimo: CASTRESANA, A., Otto Gradenwitz, in DOMINGO, R. (editore), Juristas universales, III, cit. (n. 36), pp. 740 ss.

38 ZSS., 7 (1886), pp. 15 ss. Sull'autore, vedasi: ZEILER, F., Biographische Skizzen zum Lebrkörper der Freiburger Rechtsfakultät in den Jahren 1860-1918 (Freiburg, 2008), pp. 39 ss.<http://www.freidok.unifreiburg.de/volltexte/5871/pdf/Biographische_Skizzen.pdf > [10 luglio 2011].

${ }^{39}$ Sull'autore si veda, da ultimo: BEHRENDS, O., Otto Lenel, in DOMINGO, R. (editore), Juristas universales, III, cit. (n. 36), pp. 574 ss.

${ }^{40}$ Si veda: BEHRENDS, O., Das Werk Otto Lenels und die Kontinuität der romanistischen Fragestellungen. Zugleich ein Beitrag zur grundsätzlichen Überwindung der interpolationistischen Methode, in Index, 19 (1991), pp. 169 ss.

${ }^{41}$ Op. cit. (n. 6), pp. 138 s. 
indipendentemente dall'analisi di un determinato istituto; ir) in secondo luogo, si rende più giustizia all'imperatore Giustiniano, e non gli si muove più l'accusa, come usavano gli Umanisti dinanzi accenati, di avere spogliato l'eredità dell'Antichità romana: Giustiniano voleva e doveva fare principalmente un codice di diritto vigente; se egli ha scelto questo sistema di comporre a mosaico frammenti classici, noi dobbiamo essergli grati di avere conservato documenti storici preziosi, rispettando pur sempre l'iscrizione dei singoli frammenti; ma per costruire un corpo di leggi vigenti egli doveva trattare liberamente i testi classici, aggiungere e sopprimere senza scrupolo, neanche era tenuto ad avvertire delle modificazioni. Ma se si rende giustizia a Giustiniano, ancor più se ne rende a Triboniano, poiché non gli ripete più l'accusa di avere deturpato l'eleganza dei classici cogli ampollossi barbarismi bizantini: l'uomo allora ironicamente chiamato bonus Tribonianus, o compassionevolmente miser Tribonianus, o giudicato proletarius in iurisprudentia, corruptus et corruptor, viene adesso equamente valutato, e in un'interpolazione non si scorge un flagitium o un facinus, ma la necessità di adattazione di un testo classico alle esigenze del diritto vigente nel suo tempo.

Come si è detto, uno scopo basico di questi primi rappresentanti del metodo fu l'individuazione di criteri per la diagnosi delle interpolazioni. Già Gradenwitz ${ }^{42}$ appuntò tre criteri nel riguardo: i) criteri esterni ("questo non lo ha scritto il classico"); ii) criteri interni ("questo non lo può avere scritto il classico"); iii) criteri filologici ("questo non lo può avere detto il classico cosi”). Gli interpreti posteriori li hanno via via affinati e moltiplicati e hanno raggiunto quei limiti di perfezione che sono compatibili con l'intrinseco carattere prevalentemente congetturale proprio dell'intero metodo. Bonfante, prima, nell'opera dinanzi accennata $^{43}$, e dopo Emilio Albertario $^{44}$ hanno fatto un elenco completo di tali criteri d'individuazione. Questi sono i seguenti:

a) Criterio testuale ("comparazione diretta"). L'interpolazione emerge dall'esame del testo quale l'abbiamo nelle fonti giustinianee e quale ci è pervenuto attraverso le opere pregiustinianee, oppure dall'esame del testo referito in due diverse sedi nelle fonti giustinianee (lex geminata) (v. g. FV. 283/CI. 8,54(55),2; FV. 12/D. 18,6,19(18),1; PS. 3,6,43/D. 33,7,18,9; Coll. 10,8,1/CI. 4,34,1; CTh. 2,25,1/D. 50,17,206). Questi casi sono purtroppo rari nelle fonti, $\mathrm{e}$, in altri casi, bisogna dedurre l'esistenza dell'interpolazione altrimenti.

b) Criterio storico ("anacronismi”). L'interpolazione risulta dall'incompatibilità di un principio enunciato da un giureconsulto con lo stato del diritto classico in generale o con lo stato del diritto all'epoca di quel giureconsulto (v. g. D. 30,1; D. 3,5,46(47),1; D. 43,31,1,1; D. 26,1,1 pr.; D. 26,1,1/CI. 5,35,1-2),

c) Criterio logico ("illogismi"). L'interpolazione è dimostrata dalla contraddizione tra le diverse parti del medesimo testo o tra le diverse parti del medesimo periodo o con altri testi dello stesso autore (v. g. D. 16,3,26,1; D. 18,1,62,1).

d) Criterio logico-giuridico ("inelegantia iuris"). L'interpolazione è lumeggiata dall'enunziazione di una norma, seguita da restrizioni che la annientano o la invertono, oppure dalla enunziazione di una norma vigente in una specie, seguita da un'appendice che la deforma, perchè la estende ad una categoria più larga in cui quella specie rientra (v. g. D. 50,16,243; D. $10,2,25,9)$.

e) Criterio legislativo ("sententia imperativa"). L'interpolazione è resa evidente dal modo con

\footnotetext{
${ }^{42}$ Interpolationen in den Pandekten (cit. nel testo), pp. 36 ss., 43 ss.; anche ID., Interpolationen in den Pandekten, in ZSS., 7 (1896), pp. 45 ss.

43 Storia del Diritto romano, II, cit. (n. 6), pp. 141 ss.

44 Albertario, E., Introdurione storica allo studio del Diritto romano giustinianeo, Parte Prima (Milano, 1935), pp. 43 ss.; cfr. anche ID., s. v. 'Interpolazione (Diritto)', nella Enciclopedia Italiana., cit. (n. 4), XIX, p. 400.
} 
cui il legislatore si intromette nel discorso del giurista, sia per l'uso dello stile imperativo o della forma verbale rivolta al futuro (sciat, faciat) o del tono autoritario, sia per l'uso dei generali enunciati o del nos maiestaticum (ad. es. definimus, constituimus, generaliter sancimus, generaliter definiendum est, placet nobis, etc.) (v. g. D. 24,2,6/D. 24,2,1).

f) Criterio sistematico o metodologico ("iscrizioni, rubriche edittali"). L'interpolazione è affermata per la non corrispondenza dell'istituto a quello che sappiamo esser stato trattato dal giurista in quel determinato libro della sua opera: v. g. si sono scoperte molte sostituzioni di pignus a fiducia, di actio pigneraticia ad actio fiduciae, di competens iudex a consul o a consules, etc.

g) Criterio filologico o linguistico (“solecismi, grecismi, secentismi"). L'interpolazione è fatta o da locuzioni speciali ai commissari giustinianei (sed melius est ut dicamus, satis inbumanum est, etc.), da verbi (malle per velle, suggere per suadere, promere, protelare, subiugare, adimplere, etc.), da sostantivi (cumulus per summa, sacramentum per iusiurandum, indevotio, cautela, solacium, moderamen, opitulatio, medietas, mediocritas, posteritas, etc.), da aggettivi (favorabilis, absimilis, rationabilis, resupinus, etc.) propri dei complilatori; dall'uso dei pronomi e di particelle a loro speciali (ipse per is, iste per hic, super o pro per de, etc.) o dall'uso di costruzioni grammaticali insuete nei testi classici (si quidem sin vero o sin autem; nisi-tunc enim; licet-attamen, etc.) o dall'uso di modo o costrutti assolutamente errati (sciendum est, quod; permittendum est utilem actionem; senatores accipiendum est eos; etc.), o dall'uso

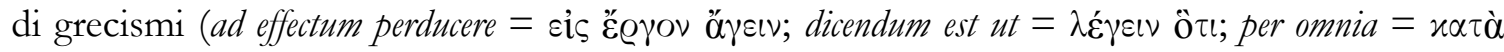

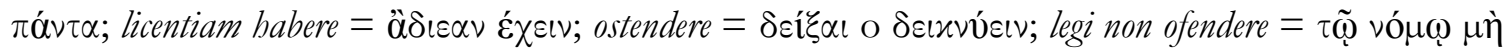

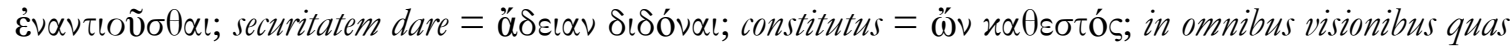

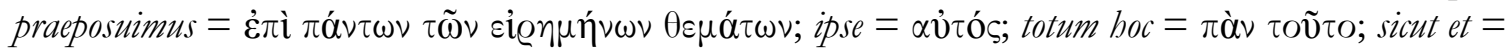

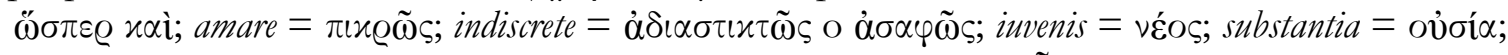

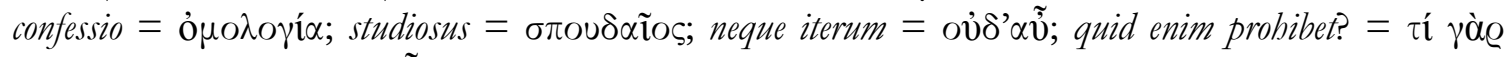

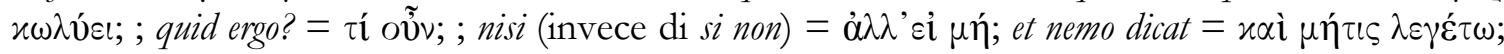

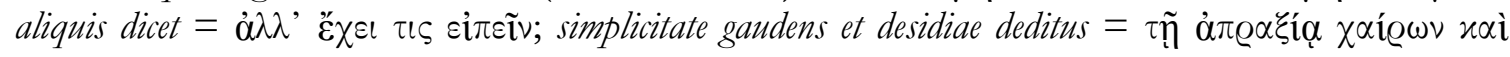

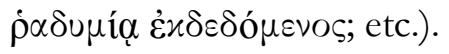

b) Criterio exegetico ("antinomie"). L'interpolazione balza fuori dalla incongruenza o contraddizzione tra due testi o due serie di testi: i compilatori spesso hanno mutato soltanto alcuni testi e serbato gli altri con valore storico.

Questo criterio fa scorgere l'interpolazione del testo, quando il richiamo a un istituto, diverso da quello di cui il giurista si sta occupando, è inserito saltuariamente, non continuamente, sì da sembrare anche ad un superficiale osservatore un elemento estraneo al testo stesso (v. g. Inst. 1,26,12; CI. 5,43,7).

i) Criterio diplomatico ("lezioni della Fiorentina"). L’interpolazione è facilmente supponibile nel testo della Fiorentina quando è gravemente scorretto: la scorretezza può spesso derivare dalla difficoltà in cui si imbatte l'amanuense, che doveva copiare il testo classico con le annotazioni e cancellazioni dei compilatori, soprattutto quando questi indicavano di trasportare nel testo commenti postclassici marginali (v. g. D. 21,1,35).

Riccobono ${ }^{45}$ aggiunse anche un decimo criterio, il criterio della duplex interpretatio: costituisce una "duplice interpretazione" -legislativa e storica nel medesimo tempo- quella a cui si prestino espressioni usate in un determinato testo. In questo caso, l'interpretazione storica consente in intendere il testo nel significato e nel valore che esso aveva in epoca classica; l'interpretazione legislativa ne coglie, viceversa, il suo adeguamento all'epoca giustinianea.

Esistono anche interpolazioni tipiche, indice del fatto che Giustiniano aveva trasformato od eliminato una serie di istituzioni e regole giuridiche classiche: v. gr. dotis dictio, espressione soppressa o sostituita da dotis promissio; mancipatio, mancipare, mancipio dare, interpolate in traditio,

\footnotetext{
${ }^{45}$ Cf. bibliografia in WENGER, L., Die Quellen des römischen Rechts (Wien, 1953), \89 IX, pp. 850 s. sub n. 30.
} 
tradere, per traditionem accipere; usucapio delle res soli interpolata in longa, diutina, per longum tempus possessione capio degli immobili; sponsio, interpolata in stipulatio; cernere, cretio in adire, aditio; recuperatores, decemviri, centumviri o altri giudici, interpolati in iudex, iudices, etc.

Si ammetteva che, naturalmente, non tutti i criteri hanno un valore uguale. Strumento estremamente pericoloso è il criterio filologico, e strumento di precisione, ammesso da tutti, è invece spesso il criterio testuale, ma in genere si concludeva che non di rado l'interpolazione si sarebbe dimostrata col concorso di piú criteri.

Questa prima fase della critica interpolazionistica conosceva, per l'attribuzione dei testi, solo l'alternativa classico-giustinianea: ciò che non è giustinianeo, è classico; o meglio all'inversa: ciò che si prova non essere classico, è giustinianeo. Come diceva in una plastica immagine Max $\mathrm{Kaser}^{46}$, c'era una pittura fatta solo di bianco o nero: si riconosceva soltanto l'antitesi fra diritto classico e giustinianeo e si riportava l'origine di ogni interpolazione a Triboniano, cioè ai compilatori giustinianei. Questo bipolarismo si fondava in un presupposto basico: il "mito" della ricostruzione scientifica del "diritto classico" (cioè il diritto romano dei secoli I-III d. C.), diverso e in ampio senso opposto al diritto della Compilazione giustinianea, e con la visuale ideale del diritto classico come un tutto compatto e sistematico, in conformità con l'idea della sistematicità razionalistica leibniziana e, poco dopo, pandettistica. Il "diritto classico" viene, dunque, a prendere in sostanza, presso i romanisti della fine del Ottocento e gli inizi del Novecento, il posto che, sulla scala dei valori non soltanto formativi, aveva avuto ancora il diritto giustinianeo (non solo in Germania, ma anche nei territori di diritto civile codificato). I fondatori del metodo critico (e anche i suoi seguaci) pativano, come dire, una specie di "complesso di sistematicità", che veniva inconsciamente trasferita dal soggetto ricercatore all'oggetto della ricerca. Come insegna M. Talamanca ${ }^{47}$, su questo processo, in un rapporto circolare con la stessa terminologia di "diritto classico", ha indubbiamente influito, pur nei cambiamenti dovuti al diverso contesto politico e culturale, la lunga tradizione che vedeva nel Corpus iuris civilis la ratio scripta, un valore che, in quel momento storico, venne trasferito al diritto classico, sulla ricostruzione del quale ebbero così ad incidere le convizioni e le ideologie che gli interpreti nutrivano per il presente. $\mathrm{Si}$ era così portati a ricostruire in modo tendenzialmente monolitico il "Diritto classico", non soltanto nella sincronia, bensì anche in una diacronia. Su ciò influivano, muovendo da punti di partenza diversi, almeno altri due fattori, ad avviso di Talamanca ${ }^{48}$ :

a) Dall'una parte, più intrinseca, una residua impostazione giuspositivistica, che si radicava nei secoli, che si era espressa, al livello della Scuola Storica e della metodologia dell'epoca della Pandettistica, nel "heutiges römisches Recht", e che, entro certi limiti, ancora fra di noi alligna. In sostanza, non si cercava tanto di vedere quale fosse per i romani, più esattamente per $\mathrm{i}$ giuristi romani, il diritto vigente, ma di costruire quello che sarebbe dovuto essere il diritto vigente, ipostatizzando questo ultimo, quasi che, indipendentemente da quello che ne pensavano i giuristi, esso potesse avere un'esistenza propria ed astratta: presupposto questo ultimo che era, alla fine del Ottocento, molto più facilmente accettabile, in quanto il prevalere dell'ideologia codicistica dava ulteriore vigore all'idea di un ordinamento giuridico di per sé esistente, quasi un quid medium fra il significato letterale delle norme e l'interpretazione dei giuristi.

b) D'altro canto, l'idea del carattere sostanzialmente omogeneo e unitario del "diritto

\footnotetext{
${ }^{46}$ Zur heutigen Stand der Interpolationenforschung, in ZSS., 69 (1952), pp. 60 ss.

${ }^{47}$ Otto Lenel e la Palingenesia, Prefazione alla riedizione (a cura di L. CAPOGROSSI COLOGNESI) di LENEL, O., Palingenesia iuris civilis (Roma, 2000), I, p. VII.

${ }^{48}$ Op. ult. cit., p. viii.
} 
classico" agiva in sinergia con la critica interpolazionistica. Muovendosi, infatti, con un classico andamento a spirale fra criteri formali e sostanziali, la critica tendeva all'ottimizzazione del risultato: in quella che poteva sembrare un'irresistibile spinta alla radicalizzazione volta a "depurare" in via massimale (secondo lo stile degli Umanisti) il diritto classico delle "scorie" che vi si vedevano apportate da Giustiniano. Una volta individuato quello che, secondo le visuali degli interpreti, era il "diritto classico", un'ipostasi del tutto irreale, si giungeva con una sorta di "metodo d'inversione" ad attribuire questo contenuto alle opere dei giureconsulti romani, i quali non avrebbero mai potuto pensare in modo diverso.

Questa idea, naturalmente, presumeva la considerazione dei giuristi classici come persone "fungibili", cioè senza sostanziali differenze fra loro di visione del diritto e di stile di scrittura: la paternità di questo "slogan" è stata fatta risalire, forse un po' ingiustamente, a Friedrich Karl von Savingy ${ }^{49}$, ma è stata raccolta da Rudolf von Ihering ${ }^{50}$ e, suprattutto, da Fritz Schulz ${ }^{51}$ in quest'epoca dell'interpolazionismo. Questa considerazione coinvolgeva una visuale rigidamente "unitaria", monoliticamente "statica" del diritto classico, che non ammetteva sviamenti derivatisi dalle specifiche personalità individualizzate di ogni giurista cui si attribuiva il testo nel Digesto. Questa presunta "staticità" del diritto privato classico era tale che si arrivò pure alla conseguenza, invero alquanto paradossale, che laddove ci si è trovati in presenza di elementi non riducibili essattamente all'unità dei paradigmi preconcetti e che tuttavia non si poteva attribuire all'età postclassica, si è parlato di "possibili glossemi”, i quali però esprimerebbero aspetti non classici della dottrina classica e, alla fine, posti su questa via, si è persino teorizzata una "non classicità" di alcuni giuristi classici, specialmente rispetto a Gaio e alle sue Istituzioni (un atteggiamento in cui risaltò sopra tutti Siro Solazzi con le sue Glosse a Gaio ${ }^{52}$ ).

Così, all'opposto della visuale che è stata finora assai estesa nella storiografia romanistica, invece di essere una, benché rozza e rudimentale, prima manifestazione della "storicizzazione" dello studio del diritto romano in reazione alla tradizione "attualistica" dell'Usus Modernus Pandectarum e del "heutiges römiches Recht" della Pandettistica, nel momento del cambio di secolo, con il metodo critico si pervenne infatti ad una "pandettizzazione del diritto classico", come ha detto a ragione R. Orestano ${ }^{53}$. Con ne l'irrigidimento a sistema la bipolarizzazione classico-giustinaneo era dunque solidale con questa impostazione sistematica: la suggestione della perfezione e dell'unità della giurisprudenza serviva bene a fornire un criterio pressoché costante per rompere il circolo: dottrina della giurisprudenza romana era quella che si supponeva più rispondente ad una visione preformata di perfezione "ideale", e dottrina recenziore e giustinianea ciò che apparisse in contrasto con questa visione o comunque ne divergesse. In questo modo, nell'irrigidimento a sistema si perdeva non solo l'identità del periodo che va da Diocleziano a Giustiniano, ma si smarriva suprattutto la ricchezza di spunti della giureprudenza classica. Questo modello ideale dell'unità monolitica del diritto classico era

${ }^{49}$ SAvignY, F. K. von, De la vocación de nuestro siglo para la legislación y la ciencia del Derecho (trad. spagnola di A. G. POSADA, Buenos Aires, s. d. [ma 1977]), pp. 62 s.

${ }^{50}$ IHERING, R. von, El Espiritu del Derecho romano en las diversas fases de su desarrollo (trad. esp. di E. Príncipe y Satorre, Madrid, 1895; rist. Granada, 1998), pp. 532, 581 ss.

51 SCHUlZ, F., Prinzipien des römischen Rechts (Berlin, 1934; rist. 1954), pp. 72 s.; ID., History of Roman Legal Science (2 edizione, Oxford, 1953), pp. 125 s.

${ }^{52}$ In Studi in onore di S. Riccobono nel XL anno del suo insegnamento (Palermo, 1936), pp. 73 ss. [= SOLAZZI, S., Scritti di Diritto romano (Napoli, 1972), VI, pp. 153 ss. ]; vedasi anche ID., Appunti di critica gaiana, in Studi in onore di V. Arangio-Ruiz nel XLV anno del suo insegnamento (Napoli, 1953), pp. 83 ss. (= ID., Scritti, cit. ibi, V, pp. 441 ss.), fra altri studi. Si v. sul punto anche TALAMANCA, La ricostruzione del testo, cit. (n. 35), pp. 3 ss.

${ }^{53}$ ORESTANO, R., Introducción al estudio del Derecho romano (trad. spagnola M. Abellán Velasco, Madrid, 1997), pp. 583 ss. 
una struttura concettuale quant'altre mai lontana dall'essenziale "controversialità" dei iura populi Romani e del ius controversum giurisprudenziale. In questa visuale rigidamente sistematica, giuspositivisticamente constituitasi, non vi era, insomma, luogo per la storia dell'esperienza giuridica romana, soltanto per il "sistema", dove, come dicevano Leibniz o Savigny, i giuristi pensavano come geometri, calcolavano con loro concetti giuridici. La critica interpolazionistica assunse a suo compito principale di eliminare "testualmente" o rimuovere "storicamente" gli ostacoli alle moderne costruzioni sistematiche: eliminare le asimmetrie, cancellare le disarmonie, ridurre ad unità era infatti il compito ampiamente perseguito nella "ricostruzione" del diritto classico con il metodo critico. Il paradosso sta giustamente nel fatto che la via seguita dalla critica era precisamente contraria a una vera impostazione storicizzante: il ridurre in unam consonantiam era stata però la pratica adoperatasi dagli imperatori, prima, e da Giustiniano e dai suoi commissari poi: la compilazione giustinianea si realizzò tagliando e segando i rami e le fronde della giurisprudenza casistica e problematica, per produrre un corpus legale singolare, dove fisonomie, individualità e divergenze scolorano, si appiattiscono e tendono a fondersi. Il vero compito della romanistica storica sarebbe, dunque, di scavare dentro la consonantia per andarvi a ricercare il multiforme, onde ripercorrere all'incontrario il processo di riduzione e di livellamento attuato per esigenze di una unità legislativa e dommatica dai compilatori. Come dice Orestano, "la tecnica chirurgica dell'interpolazionismo ha spesso maggiormente alterato le linee del diritto c.d. 'classico' di quanto avessero fatto per le loro ragioni i compilatori, ${ }^{24}$.

Nonostante queste evidenti debolezze di entrambi i presupposti epistemologici di questa visuale della critica interpolazionistica (cioè, tanto il bipolarismo stretto di diritto classicodiritto giustinianeo quanto il modello di sistema rigido e chiuso del "diritto classico"), il metodo continuò a prosperare e a guadagnare terreno, cattivandosi sempre più militanti, fino a diventare il più importante indirizzo metodologico della romanistica (non solo in Germania, ma in quasi tutta Europa, e singolarmente in Italia) nei primi anni del secolo XX. C'era, però, non solo uno sviluppo del metodo estensivo, ma anche intensivo: non solo cresceva progressivamente il numero di difensori dell'utilizzazione del metodo critico, bensì che anche gli attacchi interpolazionisti contro i testi compilatori (e pure anche contro altri testimoni della tradizione testuale della giurisprudenza classica) erano sempre più profondi ed energici, fino al punto che, in soltanto alcuni anni, praticamente nessun testo del Digesto era assolutamente libero del sospetto d'essere stato interpolato. Questo si vede bene attraverso le pagine dell'Index Interpolationum (cioè, l'Index Interpolationum quae in Iustiniani Digestis inesse dicuntur), una raccolta di tutte le interpolazioni riscontrate dalla dottrina nei testi del Digesto fino ad 1936, promossa all'inizio da Ernst Immanuel Bekker e Ludwig Mitteis nel 1909, ma edita finalmente da Ernst Levy e Ernst Rabel tra il 1929 e il $1935^{55}$. In questa opera, e già prima in virtù di certe convenzioni adoperate dalla scienza filologica, sono entrati in uso determinati segni per l'indizazione dei sospetti d'interpolazione, in particolare le parentesi quadre [--] per le parole del testo sospettate di non genuinità e le parentesi acute $<->$ per il sopposto testo classico, cancellato al momento dell'interpolazione.

Si cadde, quindi, nei primi anni del Novecento, in una sorta d'ipercriticismo che è stato detto, simbolicamente, come la "caccia alle interpolazioni", un nome adoperato a partire del titolo omonimo di una monografia del filologo tesdesco Wilhelm Kalb (Die Jagd nach Interpolationen der Digesten, Nürnberg, 1897), che suscitò la rigorosa reazione critica di Lenel mediante un articolo

\footnotetext{
54 ORESTANO, “Diritto": Incontri e scontri, cit. (n. 5), p. 230.

55 Vedasi una storia del testo in VALVUENA GARCÍA, E., Cien años del Index interpolationum, in e-Legal History Review, 8 (2009) (http://www.iustel.com).
} 
con questo titolo (Interpolationenjagd) nel numero 45 (1925) della Savigny Zeitschrift. Con questa denominazione si è preteso significare che la ricerca d'interpolazioni nelle fonti giustinianee (e singolarmente nelle Pandette) era diventata un fine a sè stesso, al di là dell'idea d'origine di fare una ricostruzione razionale di quello che dovrebbe essere stato il "diritto classico" en vertù di argomenti materiali. I criteri filologici e linguistici d'indagine delle interpolazioni avevano rimossi quasi affatto i criteri d'indole materiale, un po' come nell'epoca dell'Umanesismo, ma in una direzione molto più radicalizzante che allora. Ciò nonostante, al di là delle corruttele formali, questo indirizzo (non solo nella romanistica, ma in genere in tutti gli studi sull'Antichità) mirava essenzialmente ad incidere sui contenuti sostanziali delle fonti, portando a ricostruzioni storiche che tendevano tutte a proporre uno svolgimento delle vicende antiche in modo diverso dagli -spesso ingenui- racconti contenuti nelle fonti. Il campione di questo indirizzo nella romanistica tedesca fu senza dubbio Gerhard von Beseler $(1878-1947)^{56}$, che pubblicò il primo fascicolo dei suoi Beiträge zur Kritik der römischen Rechtsquellen nel 1910, momento che per convenzione fissa l'inizio di questa tendenza oltranzista nell'ambito della critica interpolazionistica. Attentissimo e preparatissimo studioso delle fonti (secondo le parole di Antonio Guarino ${ }^{57}$ ), Beseler ha dato il più forte impulso alla critica formale dei testi romani (e pure alla critica estetica e impressionistica) in numerosi saggi e articoli pubblicati da quel momento, forse ancora di più dal 1923 in poi, spesso con uno stile espositivo estremamente conciso e quasi ai limiti dell'ermetico. Il punto di partenza di questo autore era che la lingua dei giuristi romani, per tutta l'età classica, si sia mantenuta in una posizione di completo isolamento rispetto della lingua letteraria e parlata, e quindi si può tracciare una acuta differenza fra il linguaggio dei giuristi e quello dei compilatori. Onde egli si segnala, oltre tutto, per l'iniziativa, che ha largamente coltivata, di scrivere "Wortmonographien" (monografie di parole), cioè di dedicare raffiche di critiche (spesso molto azzardate) ai testi giuridici in cui figurano certe parole da lui ritenute in uso solo nell'età postclassica (ad esempio: 'bodie', oppure 'atquin'), cercando di farli fuori tutti, dal primo all'ultimo, senza eccezione alcuna ${ }^{58}$.

Queste tendenze oltranziste furono diffuse in Germania, ma forse magari di più in Italia, perfino dopo l'apparizione di evidenze (documentali e filologiche) dell'esistenza di numerose alterazioni dei testi classici accadute prima di Giustiniano, cioè interpolazioni pregiustinianee, che hanno le caratteristiche delle rielaborazioni postclassiche, ma contenuisticamente contrastano con le innovazioni giustinianee: queste alterazioni testuali si usa designarle in senso tecnico col nome di glossemi, se sono scivolate inavvertitamente nel testo per svista dell'amanuense, derivate in generale dalle chiose e note marginali o interlineari eseguite dagli studiosi e passate nel testo; ma se l'alterazione del testo classico è stata voluta (per es., se il testo genuino è parafrasato e riformato in guisa di costruire quasi un nuovo e diverso testo), si tratta di vere e proprie interpolazioni pregiustinianee. Il sospetto che molti testi giustinianei fossero stati alterati anteriormente alla Compilazione fu avanzato da Pietro Cogliolo, in un articolo del $1888^{59}$, poi da Ernst Immanuel Bekker ${ }^{60}$, e poi ammesso da tutti. Queste scoperte mettevano in evidenza pure l'illegittimittà di molti sospetti di tribonianismi ma, suprattutto, del rigido schematismo bipolare classico-giustinianeo per l'analisi delle fonti giurisprudenziali romane: qualora troviamo un testo compilatorio che, per cagioni di forma o di contenuto, dovrebbe considerarsi non classico, non si può ipotizzare pure che si tratta di una

\footnotetext{
${ }^{56}$ Sull'autore vedasi: VILLERS, R., Gerard de Beseler: Miseres et grandeurs de l'bypercritique, in Mélanges offerts au professeur Louis Faletti. Annales de la faculté de droit et des Sciences Économiques de Lyon (Paris, 1971), pp. 545 ss.

${ }^{57}$ Giusromanistica elementare (Napoli, 1989), p. 168.

${ }^{58}$ GUARINO, loc. ult. cit.

${ }^{59}$ La storia del Diritto romano e le interpolazioni delle Pandette, in Archivio Giuridico, 41 (1888), pp. 188 ss.

${ }^{60}$ Sub rec. di Cicerus Rede pro Q. Roscio Comedo (ed. H. H. Pflüger, Leipzig, s. d.), in ZSS., 25 (1904), p. 395.
} 
interpolazione giustinianea, bensì si deve cercare di distinguere fra alterazioni giustinianee e pregiustinienee.

Non per questo si spaventarono però i critici piú radicali: semplicemente cambiarono lo schema. Al posto del quadro precedente, in bianco e nero, subentrò ora un'ulteriore differenziazione fra classico, postclassico e giustinianeo. S'imponeva pertanto il problema di differenziare le interpolazioni aventi origine pregiustinianea dalle giustinianee. Il compito degli studiosi sarebbe allora tracciare le frontiere, determinare quali alterazioni sono interpolazioni giustinianee e quali glossemi ed interpolazioni anteriori alla Compilazione, fissando alcuni criteri che, una volta accertata l'alterazione di un testo classico, valessero a far scorgere in esse più l'origine pregiustinianea che l'origine legislativa. In questo compito risaltò su tutti Emilio Albertario (1885-1948) ${ }^{61}$ in molte pubblicazioni, ma suprattutto in una relazione metodologica intitolata Glossemi e interpolazioni pregiustinianee, offerta nel Congresso Internazionale di Diritto Romano di Roma di $1933^{62}$, dov'egli cercò di sistematizzare parecchi criteri da seguire per discernere le alterazioni pregiustinianee dei testi. Questi criteri in breve sono $\cos ^{61^{63}}$ :

a) Le aggiunte esplicative fatte con espressioni come $i d$ est, hoc est, scilicet, videlicet, sicut, veluti, le aggiunte con vel, sive sono in grandissima parte di origine pregiustinianea: esse sono l'indice dell'opera elementare del più modesto annotatore ed interprete in qualunque luogo e tempo.

b) Il richiamo dell'istituto greco accanto al corrispondente istituto romano, quando non sia classico (e assai spesso non lo è), è spiccatamente scolastico e, quindi, postclassico.

c) Sono da considerare piuttosto di origine dottrinale e non legislativa le interpolazioni fatte con parole o forme che non s'incontrano nelle costituzioni giustinianee: ad es. con finge, fingamus (adoperate per posizioni di casi), oppure fortasse, fortassis (che non sono mai nell'uso classico).

d) Le soluzioni dubbiose; le motivazioni incerte, espresse principalmente con forte, forsan, forsitan, fortasse, fortassis; i quesiti lasciati senza risposta, sono opera inverosimile di un legislatore: costituiscono pertanto interpolazioni dottrinali postclassiche e non legislative di Giustiniano.

e) Le avvertenze espresse con la forma notandum est quod od altra simile; le obbiezioni prevenute, frequentemente concretate in una forma grecizzante (fortassis quis dicat, fortassis quis possit dicere, illud fortasse, quesiturus sit aliquis, fortassis quis dixerit, fortassis quis recte dixerit, forsitan

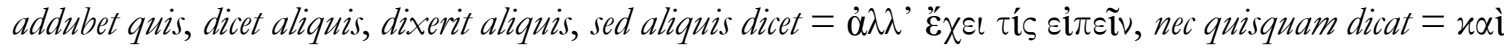
$\mu \eta \dot{\tau \iota \varsigma} \lambda \varepsilon \gamma \varepsilon \dot{\varepsilon} \tau \omega)$; i ragionamenti diluiti in forma interrogativa (quare non dicemus? quare non dicas?) combinata anche e soggiunta ad altra forma interrogativa (quid enim si? Cur ei non consulatur, cur non possit, cur absolute diximus, cur non dicamus?), oppure svolti con quid ergo est? (= $\tau i ́$ oũv;); le posizioni di casi, fatte con ut puta, ut ecce, verbi gratia, pone, ponamus, soprattutto con finge, fingamus; le conclusioni poste con ex quo apparet, ex quo colligi potest, secundum hoc, secundum baec, etc, sono avvertenze, obbiezioni, ragionamenti, distinzioni, delucidazioni, ripetizioni, posizioni di casi, conclusioni, che costituiscono l'ampio tessuto più volte secolare intorno al testo classico: sono quindi lavoro scolastico, non opera legislativa di Giustiniano.

f) Le generalizzazioni espresse con et ceteri, et omnes, et alii, et similes, sono pur esse caratteristico prodotto scolastico anche se più volte furono i giustinianei a trasportarle nel testo e senza molta attenzione.

g) Le discordanze grammaticali fra le varie parti di un testo; le parole o frasi inserite nel testo

${ }^{61}$ Sull'autore, vedasi: DE FRANCISCI, P., Emilio Albertario, in SDHI., 15 (1949), pp. 355 ss.

${ }^{62}$ Atti del Congresso (Pavia, 1934), I, pp. 385 ss. [= AlBERTARIO, E., Studi di Diritto romano, V: Storia. Metodologia. Esegesi (Milano, 1937), pp. 377 ss.].

${ }_{63}$ V. ALBERTARIO, Introduzione storica, cit. (n. 44), pp. 57 ss.; cfr. anche ID., s. v. 'Interpolazione (Diritto)', in Enciclopedia Italiana, cit. (n. 4), XIX, pp. 400 s. 
senza alcun appoggio grammaticale e sospese, derivano assai spesso da una glossa, talvolta da varie glosse, entrate per svista di amanuense o per errore dei compilatori malamente nel testo.

b) La ripetizione stemperata in un frammento di ciò che il giurista dice in altro frammento derivato dallo stesso libro della stessa opera non è che una parafrasi scolastica al testo, utilizzata anch'essa dai compilatori e posta nella sede più acconcia.

i) Le costatazioni di fatto di principi giuridici invalsi nella prassi, diversi da quelli che insegnava il testo romano, espressi soprattutto con hodie (e così bodie aliter observatur, bodie in usu servatur, quid quidem hodie magis usurpatur, hodie non dubitatur, hodie solet, etc.) sono naturali in un commentatore o maestro, che vuole aggiornare il suo testo o il suo insegnamento.

j) L'adattamento dei testi classici in conformità della mutata legislazione romano-ellenica era un lavoro di revisione necessario per l'uso di quei testi nella scuola, e quindi è prodotto dei maestri nell'epoca postclassica.

k) Le alterazioni dovute alle nuove costruzioni dommatiche (p. es. l'assunzione dell'usufrutto nelle servitù, l'estensione del concetto di successio a qualunque acquisto derivativo, la configurazione della hereditas come universitas) hanno sicura origine scolastica, e queste costruzioni i compilatori trovarono già penetrate nel testo classico o collocate attorno a questo testo.

b) I brevi testi, allacciati con altri da cui si fanno dipendere, e interamente alterati, non possono esere altro che elementi spuri che già trovavansi nel testo classico o intorno al testo classico, e che, avulsi da questo, furono attribuiti in buona o mala fede all'autore classico del testo stesso.

n) L'interpolazione è pregiustinianea se appaia che il testo che la contiene non risulti nella restante parte aggiornato con nuovi principii che nella legislazione giustinianea sono dominanti e che i compilatori sogliono inserire nei testi classici.

n) Le interpolazioni dove manca un'obbligata alterazione giustinianea sogliono essere postclassiche.

o) Devono essere anche postclassiche le alterazioni di testi contrarie alle innovazioni giustinianee.

I limiti di questi criteri li vedremo poi, quando esamineremo gli ulteriori sviluppi nella ricerca della storia dei testi classici nell'epoca postclassica. Ma la questione principale qui è il fatto che la scoperta delle interpolazioni pregiustinianee non fece scomparire le tendenze oltranziste della critica interpolazionistica, ma soltanto introdurre alcune sfumature nel metodo. L'evidenza però della inconsistenza di un argomento ideologico di base del metodo, come era l'opposizione radicale classico/giustinianeo, così come i medesimi eccessi ed esagerazioni delle proposte ipercriticiste, fecero pure apparire presto una reazione anticritica, che venne infine sbocciare nel 1917. Infatti, come dice ancora Orestano ${ }^{64}$, la maggior parte delle affermazioni interpolazionistiche più radicali e le "scoperte" più sconvolgenti sono anteriori al 1917 o di poco dopo, cioè l'“età aurea" della critica interpolazionistica è compresa fra l'ultimo decennio del XIX secolo e i primi due decenni del XX.

\section{SECONDA FASE (1917-1967): LA CRITICA DELLA CRITICA INTERPOLAZIONISTICA. LA POLEMICA RICCOBONO VS. ALBERTARIO. LA SCOPERTA DEI GLOSSEMI E DELLE INTERPOLAZIONI PREGIUSTINIANEE E LA RICOSTRUZIONE DELLA STORIA DEI TESTI GIURISPRUDENZIALI CLASSICI NEL PERIODO POSTCLASSICO}

In effetti, nell'anno 1917 due eventi sono accaduti per introdurre una certa cesura in questo

64 "Diritto": Incontri e scontri, cit. (n. 5), p. 227. 
sviluppo finora lineare della moderna critica d'interpolazioni. Il primo di questi fenomeni fu una conferenza col titolo di Antike Rechtsgeschichte und römische Rechtsstudium ("Storia del diritto antico e studio del diritto romano"), tenuta il 3 giugno di quell'anno alla Societá di amici del Gymnasium umanistico di Vienna dall'insigne romanista Ludwig Mitteis (1859-1921) ${ }^{65}$. Là, oltre a fare alcune osservazioni critiche sulla strada percorsa dagli studi romanistici negli anni recenti, egli pronosticava che la critica interpolazionistica non sarebbe sopravvissuta al di là del secondo decennio del secolo XX, e additava agli futuri studiosi, come terreno dal tutto nuovo da esplorare "l'importante compito di seguire il sorgere graduale dei concetti giuridici e la loro evoluzione di generazione in generazione, mostrare con ciò l'attività dei singoli giuristi e presentare in tal modo una storia giuridica biografica dell'antichità romana, nello stesso modo come si revelano le individualità nella storia dell'arte"66. Queste affermazioni, soprattutto in bocca di uno dei maggiori esponenti dell'indirizzo interpolazionistico, dovettero suonare agli orecchi dei romanisti contemporanei come una vera palinodia e come un'autentico torpedo sparato contro la linea di galleggiamento della nave critica.

Ma sicuramente un maggiore impatto e un più profondo influsso (almeno nell'ambito della romanistica italiana a partire degli anni 30 del secolo XX) ebbe l'altro evento che si produsse nello stesso anno 1917. In questo anno (infatti la stampa dell'opera fu iniziata nel 1915, ma soltanto nel 1917 fu ultimata) si publicò nel numero doppio (3-4) degli Annali Palermo un lunghissimo saggio, anch'esso un'autentica palinodia, di Salvatore Riccobono (1864-1958) ${ }^{67}$, intitolato Dal Diritto romano classico al Diritto moderno ${ }^{68}$, dove egli propone un'interpretazione e spiegazione affatto diversa dell'intero svolgimento del diritto romano e della sua trasformazione nelle ultime fasi, e si fa quindi banditore di una vera e propria crociata contro l'oltranzismo interpolazionista, benché egli fosse stato avanti uno dei primi e maggiori difensori del metodo storico-critico in Italia. In questa opera caotica, ma geniale, il maestro siciliano si opponeva all'opinione dominante nel suo tempo solo per quanto concerne la valutazione delle interpolazioni accertate e, soprattutto, il giudizio che va dato sulla loro origine storica. Questo lavoro fu seguito da una ampia serie di studi che si susseguono con un ritmo incesante per circa un quarantennio ${ }^{69}$.

Nella sua produzione si devono distinguere due parti: l'una ricostruttiva, l'altra -che segue ad essa- critica ${ }^{70}$.

La prima inizia compendiando la storia del diritto romano in due grandi periodi: dalle origini di Roma alla prima metà del secondo secolo a. C., cioè, il periodo del c.d. diritto quiritario; e poi dalla seconda metà del secondo secolo a. C. a Giustiniano. Questo secondo va

\footnotetext{
${ }^{65}$ Sull'autore: D’ORS, Á., Ludwig Mitteis, in DOMIngO, R. (editore), Juristas universales, cit. (n. 36), III, pp. 715 ss.

${ }^{66}$ Cit. da ORESTANO, "Diritto": Incontri e scontri, cit. (n. 5), pp. 226 s. Riguardo a questa conferenza di Mitteis, con trad. ital. del testo, si veda: RICCOBONO, S., Punti di vista critici e riscostruttivi, a proposito della disertazione di $\mathrm{L}$. Mitteis 'Storia del Diritto antico e studio del Diritto Romano', in Annali Palermo, 12 (1929), pp. 500 ss.

${ }^{67}$ Sull'autore vedasi da ultimo: DOMINGO, R., Salvatore Riccobono, in ID. (editore), Juristas universales, cit. (n. 36), III, pp. 813 ss.

${ }_{68}$ Rist. nella raccolta RICCOBONO, S., Scritti di Diritto romano (Palermo, 1964), II.

${ }^{69} \mathrm{Si}$ veda: Riccobono, S., Fasi e fattori dell'evoluzione del Diritto romano, in Mélanges de Droit romain dédiés à G. Cornil (Paris, 1926), II, pp. 237 ss.; ID., Punti vi vista critici e ricostruttivi, in Annali Palermo, 12 (1929), pp. 500 ss.; ID., La formazione della teoria generale del contractus nel periodo della giurisprudenza classica, in Studi in onore di P. Bonfante (Milano, 1930), I, pp. 125 ss., fra altri tanti. Un'esposizione complessiva della sua dottrina, in cui sono riassunti i risultati particolari, si trova nel suo Corso di Diritto romano: Formazione e sviluppo del Diritto romano dalle XII Tavole a Giustiniano (Milano, 1934), Parte II; cfr. anche, infine, i suoi Lineamenti della storia delle fonti e del Diritto romano (Milano, 1949). Un buon riassunto delle posizioni di Riccobono si può vedere nell'opera del suo allievo CHIAZZESE, L., Introdurione allo studio del Diritto romano ( $3^{\text {a }}$ edizione, Palermo, rist. 1952), pp. 322 ss.

${ }^{70}$ Cfr. Cosentini, C., Lezioni di Esegesi delle fonti del Diritto romano (rist. riv., Catania, 1995), pp. 332 ss.
} 
suddiviso in due fasi: quella classica (che si protrae fino a tutto il terzo secolo d. C.), e la susseguente postclassica. Due fasi, però, che non stanno in un rigido rapporto antitetico, come le raffigurava la dottrina dominante, bensì in un intimo rapporto evolutivo. In entrambe, infatti, il diritto procede unitario e gli sviluppi che esso raggiunge nel periodo postclassico si compiono nel senso già tracciato dal processo di rinnovamento maturatosi nel periodo anteriore. L'età postclassica viene così a continuare e ad integrare il travaglio giuridico di quella classica, che aveva trovato già la sua chiara espressione nei vari ordinamenti giuridici sorti al di fuori del campo del ius civile quiritario. Numerosi fattori (ad es. la normazione e la procedura imperiale, l'influenza del Cristianismo o la prassi giudiziaria postclassica) e suprattutto sviluppi e germi già operanti nella età classica avrebbero portato ad una modificazione principalmente "interna" allorchè, cadute le forme solenni e scomparsa la procedura formulare su cui si basava il dualismo tradizionale ius civile-ius honorarium, si venne attuando una progressiva "fusione" fra $\mathrm{i}$ vari ordini giuridici espressi dall'esperienza romana nel corso della sua storia, fusione che culmina in epoca bizantina e viene affatto espressa nella compilazione giustinianea.

Con questi presupposti si svolge, quindi, la parte critica, cioè, il problema della valutazione delle interpolazioni giustinianee, che l'autore raggruppa in due categorie: formali e sostanziali (una divisone che ebbe un grande successo nella critica posteriore). Interpolazioni "formali" sono dette quelle che modificano il testo solamente dal lato della redazione esteriore, cioè della forma, senza alterarne il contenuto intrinseco. Interpolazioni "sostanziali" sono, invece, quelle che mutano il senso del testo e la dottrina in esso enunciata. Nell'ambito di queste ultime è necessario, però, porre una suddistinzione tra interpolazioni sostanziali "innovative" e "non innovative". Le prime sono quelle che modificano il testo, introducendovi un principio del tutto estraneo ai principi del diritto romano classico, considerato nel complesso dei suoi ordinamenti. Le interpolazioni sostanziali "non innovative" sono, invece, quelle che, pur modificando il contenuto del testo, non introducono un principio nuovo al diritto classico. L'interpolazione può, p. es., consistere nel sostituire ad un principio di ius civile, enunciato nel testo, un altro principio, anch'esso classico, ma tratto, ad es., dal ius honorarium. La tesi fondamentale di Riccobono è che le interpolazioni pregiustinianee e giustinianee, sebbene siano molte, raramente hanno carattere "sostanziale" e più raramente ancora hanno carattere "innovativo". Lo stesso Triboniano, largamente interpolando, non ha creato in realtà nuovo diritto, ma, il più delle volte, ha unificato in un sistema unitario i separati e concorrenti sistemi giuridici dell'età classica. In altre parole: le interpolazioni (pregiustinianee e giustinianee) dei testi classici sono da presumere meramente formali e solo sulla base di prove o di indizi consistenti sono da qualificare come sostanziali o addirittura innovative.

Questo indirizzo riccoboniano significa, ad avviso di Orestano ${ }^{71}$, la rottura di una concezione monolitica, statica e quindi astratta del diritto classico e la proposta documentata di una visione pluralistica, dinamica e quindi concretamente storica dell'intero arco di tempo che dalla fine della Republica va ai Severi e da questi a Giustiniano. Ma questo indirizzo rimase lungo tempo come una posizione di minoranza nella romanistica italiana, e pure europea, ormai sotto la salda direzione di Emilio Albertario che, suprattutto dopo il suo trasferimento a Roma nell'anno accademico 1931/1932, ebbe il maggior influsso sulla giovane romanistica italiana, posizione che a partire da quella data ebbe a mantenere fino al secondo dopoguerra. Albertario impersonava l'ala estremistica della critica interpolazionistica, non molto lontano da Beseler in Germania, e pubblicò una rigorosa replica al lavoro di Riccobono negli Studi Bonfante (1930) con il titolo di La cosidetta crisi del metodo interpolarionistico ${ }^{72}$, e poi continuò a fare nuove

\footnotetext{
${ }^{71}$ Introducción, cit. (n. 53), p. 592.

72 Studi in onore di P. Bonfante, cit. (n. 69), I, pp. 611 ss. (= ALBERTARIO, Studi di Diritto romano, V, cit. n. 62, pp.
} 
risposte contro le posizioni anticritiche di Riccobono ${ }^{73}$. Infatti, Albertario discrepava dalla interpretazione di Riccobono non solo nella sua valutazione delle interpolazioni, ma anche (e principalmente) nella parte ricostruttiva della storia del diritto romano. Per lui, fra il diritto classico (che finisce alla fine del III secolo) e il diritto postclassico e giustinianeo c'era una differenza abissale, a causa dell'influsso degli nuove circostanze politiche, delle elaborazioni delle scuole postclassiche, della pressione dei istituti orientali e delle dottrine filosofiche greche, cosí come pure del Cristianesimo. L'effettività di questi influssi esterni sul diritto romano si concentra, a suo avviso, soltanto nei tre secoli ultimi del Tardo Impero, mentre prima il diritto romano aveva conservato la purezza e l'isolamento scientifico nello sviluppo della elaborazione giuridica. Quindi, le interpolazioni ebbero ad essere moltissime e molto sostanziali e innovative per adattare i testi giurisprudenziali classici a questo ordine giuridico cosí diverso dal loro originale.

Questa polemica tra tali grandi romanisti era, secondo l'opinione di Talamanca ${ }^{74}$, più che altro un confronto accademico oltre che scientifico fra la scuola di Pietro Bonfante (rappresentata al riguardo da Albertario) e la scuola minoritaria che si riconosceva nello stesso Riccobono. Ma la posizione anti-interpolazionista di Riccobono è rimasta nell'epoca un fenomeno abbastanza circoscritto alla sua scuola e più una reazione ideologica che scientifica: infatti, i presupposti ideologici della recensio riccoboniana non erano così lontani da quelli degli interpolazionisti radicali, poiché entrambi avevano quella visione sistematica del diritto classico come un ordine giuridico unitario, perfetto e intemporale. La reazione anticritica di Riccobono era in sostanza una "battaglia di retroguardia" (in parole di Talamanca ${ }^{75}$ ) in difesa dei "valori eterni" contenuti nel diritto romano e insidiati dalla critica formale delle fonti. La reazione si collocava, in un certo qual modo, nella tradizione che vedeva le fonti romane come la ratio scripta, tradizione la quale, a ben vedere, aveva influito profondamente sulle vicende della critica interpolazionistica: al di là del rilievo della critica formale, le dispute più forti sul piano sostanziale derivavano infatti del desiderio di trasferire alla giurisprudenza classica la valenza di ratio scripta che, nutrita fortemente degli interessi del presente, un tempo era attribuita alla compilazione giustinianea nel suo complesso. É ovvio, dunque, che la ricerca storica veniva così influenzata illegittimamente dagli interessi dal presente, dato che lo stesso Riccobono era partecipe dell'ideologia che voleva trovare nella giurisprudenza classica il metro della validità delle soluzioni degli attuali problemi sostanziali. I tempi non erano, dunque, assai maturi per vedere trionfare un'impostazione come quella.

Uno dei principali elementi di questa discussione fu la domanda sull'origine geografica delle interpolazioni ${ }^{76}$. Oltre che cercare le alterazioni testuali eseguite dai commissari giustinianei, la questione fondamentale era cercare dove fossero state introdotte le modificazioni testuali pregiustinianee, che ebbero anche un decisivo influsso sui compilatori giustinianei. A partire dall'apparizione del molto influente lavoro di Ludwig Mitteis, Reichsrecht und Volksrecht in den

67 ss.).

${ }^{73} \mathrm{Si}$ veda, ad es., Il Diritto privato romano nella sua formazione storica e nella sua elaborazione giustinianea, nel Anuario della Università Cattolica di Milano (1926-27) e in MT (1927), e Da Diocleziano a Giustiniano, in Conferenze per il XIV Centenario delle Pandette (15 dicembre 530-15 dicembre 1930) (Milano, 1931), pp. 391 ss. (entrambe opere ristampate in AlBERTARIO, Studi di Diritto romano, V, cit. n. 62, pp. 53 ss. e 205 ss., rispettivamente, insieme ad altri tanti scritti opposti alle tesi di Riccobono). Un riassunto della sua posizione si può vedere nella sua Introdużione, cit. (n. 44), 83 ss.

${ }^{74}$ Otto Lenel e la Palingenesia, cit. (n. 47), p. v; cfr. anche, id., La ricostruzione del testo, cit. (n. 35), pp. 5 ss.

${ }^{75}$ Op. ult. cit., p. 8.

${ }^{76} \mathrm{Si}$ veda. FUENTESECA, P., Oriente y Occidente en la Compilación de Justiniano, en Información jurídica. Revista del Ministerio de Justicia, 109 (1952), pp. 547 ss. [= ID., Estudios de Derecho romano (Madrid, 2009), pp. 781 ss.]. 
östlichen Provinzen des römischen Kaiserreichs (Leipzig, 1891), e particolarmente per conseguenza delle importanti scoperte di nuovi documenti, molti dei quali in papiri egizi, fatte nei primi decenni del XX secolo, gli autori si risolvero a cercare quelle alterazioni suprattutto presso le scuole giuridiche romano-orientali. Nella misura in cui non potevano essere riportate a leggi di riforma giustinianee o agli interventi necessari per la messa in opera della compilazione, le trasformazioni erano attribuite ai maestri giuridici orientali, i quali furono fatti responsabili non solo delle delucidazioni scolastiche e delle forme di stile retoriche, ma anche di molteplici innovazioni sostanziali. In proposito si cercò di provare che essi, grazie alla loro elevata erudizione, introducevano nelle fonti giuridiche anche concetti filosofici e teologici (come p. es. la dottrina della colpa e dell'interpretazione degli atti giuridici), e che anzi, talora, lasciavano influire sul diritto dell'impero romano perfino quegli istituti dei diritti locali ellenistici, i quali ci apparivano nei papiri egizi. Da questa visuale il diritto romano tardo fu inteso come "diritto elleno-orientale", "romano-ellenico", "romano-bizantino" o diritto "romeo", come disse il Bonfante per significare, attraverso l'impiego del termine greco, il nuovo assetto in cui si sarebbe "tradotto" il diritto romano classico. In questo indirizzo, in cui la ricerca interpolazionistica si congiungeva alla papirologia giuridica, emesero Josef Partsch (1882$1925)^{77}$ e Fritz Pringsheim (1882-1967) ${ }^{78}$, e sopra tutti Paul Collinet (1869-1938) ${ }^{79}$, che nei suoi eruditi studi sulle scuole giuridiche di Berito e Costantinopoli e sull'evoluzione del diritto romano nel Basso Impero, cercò di disegnare un complesso quadro storico dove la compilazione giustinianea è una funzione diretta degli sviluppi scientifici di queste scuole orientali, senza escludere anche un certo influsso della prassi postclassica e l'origine occidentale di alcune innovazioni sostanziali. Albertario, malgrado fosse un avvezzo ricercatore delle alterazioni testuali postclassiche, rappresentava questo punto di vista dominante nella sua epoca, ciò che Pablo Fuentesec ${ }^{80}$ ha chiamato il "prejuicio orientalista". Riccobono, però, si oppose energicamente a questa visuale: al suo avviso, malgrado l'opinione dominante, non solo non vi era alcuna testimonianza diretta che potesse provare, in merito alla redazione del Digesto, la influenza dei lavori dovuti ai grandi maestri bizantini del quinto secolo, bensì, invece, ci sono prove che la trasformazione delle dottrine e dei testi era avvenuta nel mondo occidentale, ad opera della prassi e delle scuole occidentali, e su basi perfettamente romane. La sua idea era, ancora una volta, la difesa della stretta romanità della Compilazione e dei fattori responsabili del processo evolutivo del diritto romano tardo: sono le prassi e le scuole dell'Occidente che sollecitano, sotto la spinta delle mutate condizioni ambientali, la maturazione di elementi presenti già in germe nel diritto classico; le modificazioni apportate ai testi classici rispecchiano, a suo avviso, la flessione della coscienza giuridica romana in senso moderno.

${ }^{77}$ Sull'autore, si veda, da ultimo: BALDUS, C., Josef Partsch, in DOMINGO, R. (editore), Juristas universales, IV: Juristas del siglo XX (Madrid/Barcelona, 2004), pp. 76 ss.

${ }^{78}$ Sull'autore, da ultimo: HONORÉ, T., Fritz Pringsheim (1882-1967), in BEATSON, J. - ZIMMERMANN, R. (editori), Jurists Uprooted. German-speaking Emigré Lanyers in Twentieth-century Britain (Oxford, 2004), pp. 205 ss. (si veda anche: http:/ / users.ox.ac.uk/ alls0079/fritz2.pd> [10 de luglio 2011]), con larga bibliografia.

${ }^{79}$ Sull'autore, da ultimo: DOMINGO, R., Paul Collinet, in ID. (editore), Juristas universales, III, cit. (n. 36), pp. 859 ss. Si veda suprattutto i suoi lavori: Études historiques sur le Droit de Justinien, I: Le caractère orientale de l'cuvre legislative de Justinien et les destinées des Institution classiques en Occident (Paris, 1912); e Études historiques sur le Droit de Justinien. II: Histoire de l'école de droit de Beyrouth (Paris, 1925). Sebbene progressivamente l'autore avesse lasciato man mano molte delle sue posizioni iniziali, ancora si può vedere questa tendenza nella sua opera postuma intitolata: La genèse $d u$ Digeste, du Code et des Institutes de Justinien (a cura di R. MONIER e E. VOLTERRA, Paris, 1952). Contro l'ipotesi 'orientalista', contemporaneamente a Collinet, vedasi: CHIAZZESE, L., Nuovi orientamenti nella storia del Diritto romano, in Archivio Giuridico, 103 (1930), pp. 87 ss e 165 ss.

${ }^{80}$ Oriente y Occidente en la Compilación de Justiniano, in ID., Estudios, cit. (n. 76), p. 787. 
Anche questa visione riccoboniana è rimasta, naturalmente, in minoranza nel suo tempo e non ebbe un forte influsso sui lavori contemporanei. Tuttavia, pur in base ad argomenti diversi da quelli del maestro siciliano, le ricerche posteriori sulla storia della tradizione dei testi giuridici classici nell'epoca postclassica hanno finito per dargli sostanzialmente la ragione. $\mathrm{Ma}$ questo accadde speciamente dopo la Seconda Guerra Mondiale.

In effetti, la polemica Albertario-Riccobono (che ancora si dilungò durante vari decenni) simbolizza, in un certo qual modo, la fine dell'epoca della "caccia alle interpolazioni". Verso la metà del XX secolo la critica interpolazionistica diventa più calma: l'ipercriticismo radicale cominció ad abbandonarsi e a trionfare una nuova tendenza favorevole alla revisione degli anteriori sospetti sui testi e a fornire una maggiore credibilità alla verità delle inscriptiones dei testi. Questa nuova fase è ben rappresentata da un lavoro di Fritz Schulz pubblicato nel 1951: Die Ulpianfragmente des Papyrus Rylands 474 und die Interpolationenforschung ${ }^{81}$. In quest'opera, lo studioso tedesco analizzava il frammento di Ulpiano $(26 \mathrm{ed}$.) D. 12,1,1, riprodotto anche nel Papiro Rylands III, 474 (giá pubblicato in 1937 dal Roberts e studiato da Francis De Zulueta ${ }^{82}$ ), frammento che era stato considerato interpolato dai compilatori, ma in realtà si dimostrava essere stato alterato veramente poco dopo la morte di Ulpiano, nella prima metà del III secolo d.C. Questa importante scoperta fu generalmente vista come il vero colpo di grazia all'oltranzismo interpolazionista. Ma questa svolta era, propriamente, una conseguenza non solo degli eccessi della ipercritica, ma anche, in specie, dei progressi eseguiti dalla ricerca (particolarmente in Germania) sulla storia della letteratura giuridica classica nell'epoca postclassica, che, in virtù della informazione raggiunta dai Fragmenta Vaticana e dalla Collatio, si vedeva come sottoposta a un'ampia rielaborazione già nell'epoca proto-postclassica (cioè, fra il 250 e il 330). Di conformità con questo indirizzo, Schulz segnava contemporaneamente in questo lavoro quali erano -a suo avviso- i nuovi canoni delle indagini sulle fonti che dovevano rispettarsi di poi (la c.d. dottrina dei "Werktypen”).

Schulz chiama "ipotesi di lavoro vecchia" ("ältere Arbeitshypothese") il punto di partenza del metodo critico dominante fino ad allora, cioè, la considerazione che i testi dei giuristi classici erano arrivati ai compilatori giustinianei scevri di manipolazioni, salvo errori meccanici e glossemi: quindi, qualora un testo del Digesto non possa essere attribuito a un giurista classico, per cagioni formali o materiali, deve essere ascritto ai compilatori; invece, se un testo non può considerarsi interpolato dai compilatori, la sua classicità non può mettersi in dubbio. Secondo Schulz, infatti il principale difetto della critica interpolazionistica tradizionale non era il "radicalismo", ma anzi il suo "conservatorismo" in seguito alla sua accettazione acritica della classicità della tradizione postclassica. La scoperta dell'esistenza di alterazioni postclassiche dei testi obbligò dunque a formulare una "ipotesi di lavoro nuova" ("neue Arbeitshypothese"), che Schulz riassume così: i compilatori ridussero drasticamente e interpolarono in diversa misura i brani conservati delle opere dei giuristi classici; queste alterazioni furono, in effetti, numerose, ma nè così tante nè così profonde ed importanti come si credeva nella vecchia critica; se si dispone del materiale necessario, si può accertare che i compilatori furono radicali tagliando e riducendo i testi, ma agirono in modo comunque conservatore riguardo ai loro modelli; quindi le loro interpolazioni cercano, in generale, adattare il diritto del testi ai nuovi tempi bizantini e sono, dunque, agevolmente identificabili.

Molto più numerose sono, invece, e formalmente più incisive furono -a suo avviso- le trasformazioni dei testi nell'epoca pregiustinianea, e precipuamente dalle modeste scuole giuridiche dell'Occidente dell'Impero. Gli anonimi maestri di queste scuole si sarebbero

\footnotetext{
${ }^{81}$ ZSS., 68 (1951), pp. 1 ss.

${ }^{82}$ Bibl. in WIEACKER, Textstufen klassischer Juristen, cit. (n. 28), p. 250 n. 155.
} 
impadroniti dell'eredità classica poco dopo la fine della classicità (alla fine del III secolo e inizi del IV) e, principalmente per scopi d'insegnamento, l'avrebbero accorciata, semplificata, resa più grossolana e vi avrebbero frammischiato chiarimenti scolastici. Questi testi così rimaneggiati avrebbero raggiunti i compilatori giustinianei.

Questa impostazione del problema da parte di Schulz coinvolgeva, infine, non solo la definitiva demolizione del vecchio e fallace schema bipolare classico-giustinianeo, ma anche una seria messa in questione dell'interpretazione "orientalista" della storia della trasmissione dei testi classici e delle alterazioni postclassiche. $\mathrm{Ma}$ in questa linea sono rese anzitutto decisive le ricerche sulle stratificazioni testuali ("Textstufenforschung"), le quali volevano scoprire le vicissitudini attraverso le quali sarebbero passati i testi dei giuristi classici, dalla loro pubblicazione da parte dell'autore, fino all'assetto finale della compilazione giustinianea. Questo indirizzo ottenne i suoi migliori frutti nei lavori di Ernst Levy e Franz Wieacker alla metà del XX secolo, ma fu iniziato già da Hans Niedermeyer con una relazione tenuta nel Congresso Internazionale di Diritto Romano di Roma del 1933 intitolata Vorjustinianische Glossen und Interpolationen und Textüberlieferung ${ }^{83}$, dove egli, osservando la coincidenza di gravi errori meccanici nelle versioni del libro 18 ad edictum di Ulpiano raccolti nel Digesto e nella Collatio, conclude che entrambi i testi provengono da un archetipo comune, e fissa la data di questo archetipo intorno all'anno 300, poichè, dovendo essere il detto archetipo necessariamente anteriore alla Collatio, la importanza delle alterazioni significa che esse non potevano essere state introdotte in una data prossima alla morte di Ulpiano. In conseguenza, a suo avviso, i maggiori attacchi ai testi classici dovettero prodursi nella seconda metà del III secolo, mentre dalla prima metà del IV secolo fino a Giustiniano gli attacchi, se proprio non scomparvero del tutto, certamente ebbero molto minori possibilità di verificarsi.

Non molto tempo dopo il lavoro di Niedermeyer, nel 1945, Ernst Levy pubblicò un lavoro di ricerca sulle Pauli Sententiae svolgendo il metodo di Niedermeyer ${ }^{84}$. Levy analizza qui le successive revisioni cui il testo sarebbe andato soggetto attraverso il succedersi delle generazioni per stabilire una palingenesia degli suoi primi titoli. L'interesse delle Sentenze di Paolo risale al fatto che la loro evoluzione nell'epoca postclassica può essere assunta come documento provativo dell'evoluzione graduale del diritto nell'epoca postclassica e dell'attività innovatrice delle scuole giuridiche occidentali, sicché i risultati potrebbero estendersi ad altre fonti coeve.

Ma il definitivo successo di questo metodo della ricerca delle stratificazioni testuali nella romanistica internazionale è unito giustamente al nome di Franz Wieacker (1908-1994) ${ }^{85}$, il cui libro col titolo di Textstufen klassicher Juristen, pubblicato nel anno 1960 (e significativamente dedicato a Hans Niedermeyer), segnò un punto essenziale nello svolgimento degli studi romanistici e marcò una nuova cesura nella storia del metodo critico-storico. In questa opera il professore di Göttingen intendeva fornire una più ampia dimostrazione delle cause e delle entità delle modificazioni subite dai testi della giurisprudenza nella seconda metà del III sec. inizio del IV, seguendo, particolarmente, attraverso la storia dei testi ("Textgeschichte") e non la storia dei contenuti giuridici ("Sachgeschichte"), la vita degli scritti della giurisprudenza

83 Atti del Congresso, I, cit. (n. 62), pp. 351 ss.

${ }^{84}$ LEVY, E., Pauli Sententiae. A Palingenesia of the Opening Titles as a Specimen of Research in West Roman Vulgar Law (New York, 1945). Già prima, nel 1928, in una comunicazione nel Congresso storico internazionale di Oslo col titolo: Westen und Osten in der nachklassischen Entwicklung des römischen Rechts, aveva ammesso Levy largamente lo sviluppo organico del Diritto romano durante il Basso Impero, ponendo in gran risalto il contributo dell'Occidente all'evoluzione giuridica postclassica.

${ }^{85}$ Sull'autore, da ultimo: WOLF, J. G., Franz Wieacker, in DOMINGO, R. (editore), Juristas universales, IV, cit. (n. 77), pp. 538 ss. 
classica, dal loro apparire fino all'epoca di Giustiniano ${ }^{86}$.

Non è qui il luogo per riassumere il contenuto di un'opera così piena di erudizione e così ricca di informazioni, idee ed argomenti. Ma forse vale la pena fare qui una rassegna del suo significato nel riguardo alla critica interpolazionistica e della sua rilevanza nella storia della metodologia della ricerca romanistica ${ }^{87}$.

In questa opera l'autore propone un metodo di studio dei testi giurisprudenziali classici a noi pervenuti abbastanza diverso dal metodo interpolazionistico tradizionale. Si tratta di lumeggiare la vita dei singoli scritti della giurisprudenza classica dalla loro prima pubblicazione fino alla vigilia della compilazione giustinianea. A suo avviso, i testi classici avrebbero attraversato, idealmente, in tutto cinque stadi di sviluppo: i) l'originale classico; ii) la rielaborazione proto-postclassica (fine III-inizio IV secolo); iii) la volgarizzazione del IV-V secolo; iv) l'enunziazione teoretica da parte delle scuole romano-orientali; $v$ ) l'adattamento, infine, nella compilazione giustinianea. Secondo l'opinione di Wieacker, il maggior numero di alterazioni testuali si è verificato negli anni di transizione dal III sec. al IV sec. d. C. (cioè, nell'epoca proto-postclassica o c.d. epiclassica), allorquando nella storia di tutte le edizioni antiche si realizzò un profondo cambiamento, si lasciarono cioè da parte i vecchi e costosi (e poco durevoli) rotoli di papiro (volumina) e si adottarono, al loro posto, i più economici e duraturi codici fatti di fogli di pergamena (codices). I redattori amanuensi di nuovi codici pergamenacei, nel trascrivere i contenuti dei papiri a loro pervenuti, non fecero gran caso alle glosse marginali ed interlineari di cui questi testi erano zeppi, e riprodussero il tutto, più o meno alla meglio rabberciato, come se provenisse genuinamente dall'originale. Per questa via, le molte alterazioni di ogni tipo che i testi classici avevano subito già nel corso del III secolo andarono a finire nelle edizioni postclassiche tanto di Occidente quanto di Oriente. Ma la complessa opera di modificazione delle forme librarie e dei testi ebbe luogo, secondo Wieacker, ad ogni caso, in Occidente; l'Oriente, invero, non diede affatto, nella trasformazione dei testi, il contributo che la "teoria orientalista" sosteneva.

$\mathrm{Al}$ riguardo della critica interpolazionista, Wieacker respinge qui energicamente il presupposto fondamentale della medesima, cioè il bipolarismo classico-giustinianeo: questo principio, secondo lui, sembra essere un canone sbagliato, poiché si tratta di un canone che non lascia nessun margine ai problemi della storia del testo e in particolare salta a piè pari il destino degli scritti nell'epoca postclassica. Wieacker intende anzitutto mettere in evidenza il circolo vizioso entro il quale vennero a chiudersi con il proprio povero strumentario critico gli interpolazionisti. Questo strumentario in definitiva si riduce, secondo Wieacker, a tre principî: i) i compilatori per le loro alterazioni poco appariscenti si servono in realtà di artifizi stereotipati; ii) vi è un vocabolario proprio ai pochi uomini e ai pochi anni ai quali si deve la Compilazione; iii) i motivi sostanziali di alterazioni sono dovuti alle riforme di Giustiniano stesso e sono facilmente determinabili attraverso le costituzioni di questo imperatore. Avvalendosi di questi tre criteri si possono seguire le alterazioni operate dai commissari di Giustiniano.

Una critica cosí condotta si dimostra per Wieacker affatto deficiente, e la sua insufficienza si manifesta ancora maggiore quando (come si vede p. es. nelle opere di Albertario) si è preteso di studiare le interpolazioni pregiustinianee con gli stessi canoni critici adottati per

${ }^{86}$ Le sue idee sono state ribadite anche, ancora in modo dettagliato, nel primo volume della sua imponente Römische Rechtsgeschichte, cit. (n. 29), pp. 139-183.

${ }^{87}$ Una prospettiva dell'influsso di questa opera un cinquantennio dopo la sua pubblicazione si veda in: CASCIONE, C., "De nuptiis philologiae et iuris". La storiografia wieackeriana dalle "Textstufen" al rapporto tra Diritto romano e "Nachbarndisziplinen der Altertumswissenschafe", e BALDUS, C., ¿Hacia un nuevo concepto de "Textstufen"?, entrambi in Seminarios Complutenses de Derecho Romano, 23-24 (2010-2011), pp. 59 ss. e 75 ss., rispettivamente. 
diagnosticare quelle dovute ai commissari giustinianei. Nella sua opinione, non esistono, a stretto rigore, indizi unitari applicabili anche per la stessa opera di un giureconsulto, di modo che sbaglia chi, senza distinguere i vari strati e i vari tempi, applica indifferentemente agli uni e agli altri gli stessi canoni metodologici.

Wieacker oppone dunque, in questa opera, al metodo interpolazionistico classico un altro metodo storico-critico che consiste in esaminare la questione dell'individualità delle singole opere e della loro autenticità in base alla ricerca degli strati storici dei testi tramandati, in specie di quelle opere per le quali è possibile accertare una doppia tradizione manoscritta, sia entro la stessa compilazione giustinianea, sia confrontando il testo utilizzato dai giustinianei con resti pervenuti per altra via ${ }^{88}$. Si tratta, insomma, di inserire il problema delle interpolazioni pregiustinianee e, in conseguenza, di quelle giustinianee, nel quadro assai più ampio della cultura e della storia editoriale della Tarda Antichità.

L'opera di Wieacker ebbe subito un saldo impatto nell'ambito di tutta la romanistica europea e richiamò l'attenzione di un gran numero di qualificati studiosi, sollevando un'accesa polemica $^{89}$. Nonostante che non tutti quanti fossero d'accordo con la totalità degli argomenti forniti dall'autore tedesco ${ }^{90}$, oppure con la stessa impostazione metodologica del lavoro (specialmente criticatasi nella romanistica italiana ${ }^{91}$ ), la maggioranza consentì però che questa opera coinvolgeva un punto senza ritorno, cioè, una svolta definitiva nella metodologia romanistica. Questa opera non solo lasciava definitivamente nel passato il primo presupposto della critica interpolazionistica moderna, cioè, la visione schematicamente bipolare della storia dei testi giurisprudenziali romani, ma anche metteva seriamente in questione il secondo, cioè, la fede nella unità, sistematicità e, supprattutto, conoscibilità del diritto classico, nella misura in cui le ricerche di Wieacker dimostrano la conclusione scettica che nessuna opera della letteratura classica è pervenuta a noi nella forma, nella quale essa fu scritta o fu pubblicata per la prima volta, e nella migliore delle ipotesi si tratta di esemplari di nuove edizioni risalenti al periodo postclassico. La ricostruzione del diritto classico, quindi, se è possibile, avverà soltanto faticosamente e ipoteticamente attraverso l'indagine del percorso testuale degli scritti attribuiti ai giuristi classici. Come diceva Gian Gualberto Archi riguardo all'opera di Wieacker: "d'ora in avanti non sarà più possibile lavorare sui testi dei giureconsulti classici servendosi degli schemi fin qui seguiti. Essi sono ormai troppo elementari, meglio, rudimentali, per poter pretendere di mantenerlii" ${ }^{\prime \prime 2}$.

Le conseguenze ultime di questa posizione critica saranno tratte dalla romanistica del

${ }^{88}$ Prima di Wieacker il metodo della confrontazione di testi già era stato utilizzato di solito dalla romanistica nella critica d'interpolazioni, si veda ad es. specialmente l'opera monumentale di CHIAZZESE, L., Confronti testuali. Contributo alla dottrina delle interpolazioni giustinianee, in Annali Palermo, 16 (1931) pass. Ma soltanto Wieacker fu capace di mutare questa tecnica in una attività scientifica rigorosa.

${ }^{89}$ Si veda le recensioni critiche di MAYER-MALY, T., in ZSS., 77 (1960), pp. 494 ss.; D’ORS, Á., in SDHI., 26 (1960), pp. 366 ss. [= ID., Crítica romanistica (Santiago de Compostela, 1999), pp. 73 ss.]; GAUDEMET, J., in TR., 28 (1960), p. 211; ARANGIO-RUIZ, V., in BIDR., 64 (1961), pp. 351 ss.; ARCHI, G. G., in Iura, 12 (1961), pp. 428 ss.; AMIRANTE, L., Per la storia dei testi giurisprudenziali classici, in Labeo, 7 (1961), pp. 390 ss., fra altri.

${ }^{90}$ Sulle difficoltà concettuali della sua metodologia, v. i commentari, ad es., e soltanto nella dottrina spagnola, di ÁlVAREZ SUÁREZ, U., La jurisprudencia romana en la hora presente (Madrid, 1966), pp. 143 ss.; TORRENT, A., Introducción metodológica al estudio del Derecho romano (Oviedo, 1974), pp. 128, 137 ss.; D’ORS, X., Posiciones programáticas para el estudio del Derecho romano (Santiago de Compostela, 1979), pp. 65 ss.

${ }^{91}$ Vedasi, ad es., una sintesi in: GUARINO, Giusromanistica elementare, cit. (n. 57), pp. 27 ss. Una interessante cronaca di un seminario tenuto a Firenze il 4 aprile di 1962 nel "Circolo toscano di Diritto romano" fra Wieacker e alcuni dei suoi critici italiani (Arangio-Ruiz, Archi, Coli, Frezza, Pugliese, Di Sarlo, Luzzato, Biscardi, Amirante, Bartoletti e altri) si può vedere in GARCÍA GARRIDO, M., Las actuales orientaciones romanisticas, en Revista de Derecho Notarial, IX, 39 (Madrid, 1963), pp. 47 ss.

${ }^{92}$ ARCHI, rec. in Iura, 12 (1961) cit. (n. 89), p. 428. 
periodo seguente, che può considerarsi la fase finale e liquidatrice del metodo interpolazionistico in sè considerato.

\author{
IV. TERZA FASE (1967-1997): LA CONSUMAZIONE DELLA ANTICRITICA. IL \\ “KONSERVATIVISMUS” DE KASER E LE REAZIONI. LO SVILUPPO DELLA CRITICA \\ INTERPOLAZIONISTICA DOPO LA IMPOSTAZIONE KASERIANA
}

In effetti, l'apparizione dell'opera di Wiacker cedè il passo, a partire dei anni 60' del XX secolo a una nuova fase nella storia della critica interpolazionistica, che subì una nuova svolta imponendosi una direzione sempre più "conservatrice" nell'analisi dei testi giuridici romani, cosicchè soltanto un numero limitato d'interpolazioni giustinianee e pregiustinianee erano ammesse: quelle, in ogni caso, di scarsa importanza nel conenuto giuridico-sostanziale dei testi. $\mathrm{Al}$ capo di questo nuovo "Konservativismus" risalta su tutti Max Kaser (1906-1997) ${ }^{93}$, la cui prima visuale del fenomeno interpolazionistico è chiaramente esposta nel suo articolo intitolato Zum heutigen Stand der Interpolationenforschung, pubblicato nella Zeitscbrift der Savigny-Stiftung del $1952^{94}$, solo due anni dopo il primo lavoro di Franz Wieacker dove egli dava una prima approssimazione alla sua Textstufenforschung. ${ }^{95}$. Questa nuova (e ultima) fase della romanistica all'insegna del interplazionismo è caratterizzata dalla polemica tra le tesi di questi due grandi romanisti germanici ("freundschaftliche Klingenwechsel", cioè, amichevole scambio di opinioni, in parole di Franz Wieacker), nella mesura che Wieacker sembra essere ancora un po' più affezionato al metodo critico-storico, laddove Kaser mostra un atteggiamento più dommatico-sistematico verso i testi romani; ma questa nuova fase è anche improntata dalla critica di una parte della romanistica italiana ad ambedue le posizioni.

Il punto di partenza simbolico di questa nuova fase si trova nel "II Congresso Internazionale della Società Italiana di Storia del Diritto", appunto sul tema della critica del testo, svoltosi a Venezia dal 18 al 22 di settembre 1967. In questo congresso, significativamente, Gerardo Broggini ${ }^{96}$ presentò il suo rapporto sullo stato dei lavori d'attualizzazione dell'Index interpolationum di Levy e Rabel fino allora, dove constatò non solo le enormi difficoltà di edizione di tale opera, in vista dell'esaggerato numero di sospetti d'interpolazione nelle fonti pubblicate dal 1935 fino a quell'anno, bensí suprattutto il dubbio metodologico sul "criptostoricismo" che, al suo avviso, è alla base dell'ipercriticismo. Questo rapporto significava infatti una vera dichiarazione d'impotenza per andare avanti.

Ma anche Max Kaser e Franz Wieacker tennero ambedue una relazione per ciascuno allo stesso congresso, dove ciascuno impostò la sua posizione metodologica riguardo alla problematica della critica testuale dei testi giuridici romani. La relazione di Kaser era spiccatamente intitolata Sulla credibilità delle fonti giuridiche romane (sui limiti della critica interpolazionistica) ${ }^{97}$, dove si distaccava fortemente della sua posizione anteriore (ben rappresentata nella prima edizione del suo famosissimo $H_{a n d b u c b^{98}}$ ) e quella di Wieacker, Sulla

\footnotetext{
${ }^{93}$ Sull'autore vedasi, da ultimo: WACKE, A., Max Kaser, in DOMINGO, R. (editore), Juristas universales, IV, cit. (n. 77), pp. 476 ss.

${ }_{94}$ Cit. (n. 46).

${ }^{95}$ Lebensläufe klassischer Schriften in nachklassischer Zeit, in ZSS., 67 (1950), pp. 360 ss.

${ }^{96}$ Rapporto sull'Index Interpolationum, in La critica del testo. Atti del II Congresso Internazionale della Società Italiana di Storia del Diritto (Venezia, 18-22 di settembre di 1967) (Firenze, 1971), I, pp. 117 ss.

${ }_{97}$ Zur Glaubwürdigkeit der römischen Rechtsquellen (über die Grenzen der Interpolationenkritik), in La critica del testo, cit. (n. 96), I, pp. 291 ss.

${ }^{8}$ Das römische Privatrecht, I: Das altrömische, das vorklassische und klassische Recht (München, 1955); II: Die nachklassischen Entwicklungen (München, 1959).
} 
situazione attuale della critica testuale romanistica ${ }^{99}$. Kaser, dopo la pubblicazione in estratto della sua relazione e alcune critiche subite (su tutti da Antonio Guarino ${ }^{100}$ ) ritoccò la sua posizione nel libro Sulla metodologia della ricerca sulle fonti giuridiche romane ${ }^{101}$, e Wieacker, a sua volta, fece qualcosa simile nella sua accurata recensione di questo ultimo libro kaseriano pubblicata nella Savigny Zeitschrift del anno $1974^{102}$. Kaser avrebbe dato un'ultima valutazione della questione nel suo contributo finale sull'argomento nel 1986 (Un secolo di ricerca d'interpolazioni nelle fonti giuridiche romane $)^{103}$, benchè fino alla fine della sua vita scientifica facesse ancora osservazioni su questa problematica, sempre in un senso più "conservatore"104.

Fra entrambe le posizioni ci sono molti punti d'accordo, per es.: $\imath$ ) Nei motivi del fallimento di un metodo interpolazionistico ipercritico; ii) Nella limitata portata degli interventi epiclassici sui testi classici; iii) Nella scarsa misura delle modificazioni testuali operate dalle scuole orientali e da Giustiniano; $i v)$ Nel bisogno di non attribuire ai giuristi classici un livello esageratamente alto di pensiero e di stile, così come nel predominio delle alterazioni formali sulle sostanziali dei testi (anche se Wieacker è opposto a questa distinzione, a suo avviso troppo superficiale, fra interpolazioni "sostanziali" e "formali"105).

Nondimeno i loro atteggiamenti su certe questioni centrali sono in parte diversi.

In poche parole può dirsi che la polemica tra i due autori attinge al fatto che Wieacker è più fidato della possibilità di fare una ricerca concreta dei motivi delle alterazioni giustinianee attraverso una migliore comprensione della Compilazione negli aspetti di stile linguisticoletterario e della politica legislativa, mentre considera $i$ metodi della critica testuale i più adatti all'indagine delle alterazioni testuali pregiustinianee. Kaser, invece, si mostra difensore dell'opinione che vuole dare priorità all'argomento giuridico-sostanziale nei confronti dell'argomento critico-testuale nella valutazione della genuinità dei testi giuridici, in base ad una sorta di "presunzione", di una "congettura di verosimiglanza" ("Wahrscheinlichkeitsschluß") ${ }^{106}$, secondo la quale bisogna presumere che il giurista classico indicato nella inscriptio del testo è anche autore del suo contenuto giuridico-sostanziale, sennonché si forniscano prove capaci di rifiutarlo; le cose stanno così, specialmente tenendo in conto che in un diritto casuistico come era il romano classico c'erano molte controversie (ius controversum) e punti di vista diversi negli stessi giuristi classici che sono stati eliminati o

99 Zur gegenwärtigen Lage der romanistischen Textkritik, in La critica del testo, cit. (n. 96), II, pp. 1099 ss. [= WIEACKER, F., Ausgewählte Schriften, I: Methodik der Rechtsgeschichte (a cura di D. Simon, Frankfurt am Main, 1983), pp. 103 ss.].

100 Sulla credibilità della scienza romanistica moderna, in Atti dell'Accademia Pontaniana, N. S., 20 (1971), pp. 61 ss. [= Guarino, A., Pagine di Diritto romano (Napoli, 1993), I, pp. 403 ss.. C'è ora una traduzione spagnola di questo testo, a cura di E. RUIZ FERNÁNDEZ: Sobre la credibilidad de la ciencia romanística moderna (Granada, 1998).

${ }_{101}$ Zur Methodologie der römischen Rechtsquellenforschung (Wien - Köln - Graz, 1972).

102 Textkritik. und Sachforschung, in ZSS., 91 (1974), pp. 1 ss. [= WIEACKER, Ausgewählte Schriften, (n. 99), I, pp. 122 ss.].

${ }^{103}$ Ein Jahrbundert Interpolationenforschung an den römischen Rechtsquellen, in KASER, M., Römische Rechtsquellen und angewandte Juristenmethode (Wie - Köln - Graz, 1986), pp. 112 ss. (testo di una relazione tenuta alla seduta della Gesamtakademie di Vienna il 9 di marzo di 1979, pubblicato prima nell'Anzeiger der phil.-hist. Klasse der Österreichischen Akademie der Wissenschaften, 116, 1979, pp. 83 ss., con l'aggiunta del piccolo testo intitolato Über Rechtsreglen, literarischen Juristenstil, justinianische Streichungen und Kürzungen, presso dall'articolo Die actio furti des Verkäufers, in ZSS., 96, 1979, pp. 89 ss.). C'è ora anche una traduzione spagnola di questo testo, a cura di COMA FORT, J. Ma GALLENKAMP, G., Las interpolaciones en las fuentes jurídicas romanas (Granada, 1998).

104 Per es. nella sua ultima monografia (Ius gentium, Wien - Köln - Graz, 1993, pp. 94 ss.), Kaser difende vigorosamente la classicità delle Res cottidianae (sive aurea) di Gaio, un'opera considerata finora senza discussione come postclassica.

${ }_{105}$ Röm. Rechtsgeschichte, cit. (n. 29), I, p. 160 n. 27.

${ }^{106}$ Sul concetto, vedasi: KASER, Ein Jabrbundert Interpolationenforschung, cit. (n. 103), pp. 131 ss. 
circostritti dai compilatori. Secondo lui, si deve partire dal fatto che le opere classiche sono state alterate dagli autori postclassici e giustinianei solo nella forma testuale esterna, sia per fare raccorciamenti che per riassumere argomenti ed eliminare controversie e ripetizioni. Ma la sostanza giuridica storico-reale continuò ad essere fondamentalmente la stessa. Insomma, magari da un testo che formalmente non è classico non può scaturire necessariamente, senza altre prove ed argomenti, che il suo contenuto non è classico, ma anzi al contrario: si deve partire da un assunto favorevole alla classicità del testo, in virtù di una "congettura di verosimiglanza" sul contenuto giuridico sostanziale del testo in questione: cioè, anche nella veste postclassica, un testo può affermare diritto classico. Nel senso accennato, si deve prendere in considerazione che nell'epoca postclassica le necessità giuridiche furono mutate e le nuove edizioni, i florilegi e sunti cercavano di rendere più accessibili ai nuovi lettori lo stesso materiale giuridico dell'epoca classica, e questo non si può considerare affatto un'alterazione del diritto classico ${ }^{107}$.

Insomma, il programma metodologico di Max Kaser ${ }^{108}$ si centrava in due punti: il primo è la "konservative Textbehandlung", contropposta alla "radikale Textkritik" vigente fin alla metà del XX secolo ${ }^{109}$; il secondo, sottolineare l'importantza delle controversie fra i medesimi giuristi classici, rifiutando così la visione monolitica di un diritto classico sistematicamente chiuso ${ }^{110}$ : cioè, il secondo presupposto essenziale del metodo critico-interpolazionistico. Questo secondo punto implica tuttavia una critica frontale alla "Textstufenforschung" nel caso di divergenze nei testi occorre pensare a differenti impostazioni degli stessi giuristi classici, prima che ad alterazioni postclassiche o giustinianee.

Accanto a queste asserzioni, Kaser sottolinea appunto che, allorchè si voglia utilizzare la "Textstufenforschung" per lo studio dei testi proto-postclassici, cioè il periodo nel quale si concentra la maggioranza delle alterazioni pregiustinianee, così come dei testi per i quali non si può accertare una doppia trasmissione testuale (cioè, la maggioranza dei testi giuridici romani), il metodo della comparazione testuale non vale più, e bisogna ritornare alla critica interpolazionistica classica, in base ad indizi formali e sostanziali adoperati a partire dagli Umanisti.

Contro questo punto di vista Wieacker oppone la constatazione che l'unica informazione sui fatti si apprende attraverso $i$ testi $e$, anche se a volte non c'è un'altra possibilità per valutare un testo sospetto che fare ricorso alle "congetture di verosimiglianza" raggiunte per mezzo di ciò che è già conosciuto, non si può parlare propriamente di prevalenza degli indizi sostanziali sopra quelli formali, poiché questo implicarebbe sempre la continuità dell'ordinamento giuridico, malgrado si ammetta qualunque alterazione formale. La conessione fra testi e istituzioni è più intima di quello che era supposto da Kaser, dal momento che soltanto dallo studio dei testi può farsi un’idea sugli istituti giuridici, e le alterazioni testuali sono di rado

${ }^{107}$ Kaser, Zur Glaubwürdigkeit, cit. (n. 97), p. 366; ID., Zur Methodologie, cit. (n. 101), pp. 60 ss.

${ }^{108}$ Vedasi sul punto: KNÜTEL, R., Nicht leichter, aber um so reizvoller'. Zum methodologischen Vermächtnis Max Kasers, in ZSS., 115 (1998), pp. 34 ss., e gli estesi commenti da GIARO, T., Über methologische Werkmittel der Romanistik, in ZSS., 105 (1988), pp. 180 ss.; e ID., Max Kaser (1906-1997), in Rechtshistorisches Journal, 16 (1997), pp. 231 ss. Vedasi anche da ultimo: ZIEGLER, K.-H., Max Kaser e la revisione della critica romanistica di lingua tedesca dopo il 1967, in MIGLIETTA - SANTUCCI (a cura di), Problemi e prospettive della critica testuale, cit. (n. 6). Un buon riassunto delle teorie kaseriane in lingua spagnola si può vedere in: GARCíA CAMIÑAS, J., Posiciones metodológicas en el estudio del Derecho romano: el pensamiento de M. Kaser, in Anuario da Facultade de Dereito da Universidade da Coruña, 7 (2003), pp. 337 ss.

${ }^{109}$ Wieacker, invece, risponde che la contrapposizione fra tendenze "radicali" e "conservative" è più legata alla lotta politica che alla scienza (cfr. ZSS., 91, 1974, p. 22).

${ }^{110}$ I giuristi romani classici non sono "fungibili" (cfr. n. 51), né anche infallibili individualmente considerati: vedasi: KASER, Zur Methodologie, cit. (n. 101), pp. 47 ss. 
indifferenti alla storia delle istituzioni ${ }^{111}$.

Non si può dire, però, che Wieacker difendesse puramente una "storia dei testi" ("Textgeschichte") e Kaser una "storia di contenuti giuridici" ("Sachgeschichte"), poichè ambedue sono consapevoli che entrambi gli atteggiamenti non sono contradittori, ma complementari. Infatti, Kaser ha scritto palesemente, riguardo ad un'affermazione di Franz Wieacker che "non possiamo riportare indietro la critica testuale"112, questa asserzione: "Das kann ich nur aus vollem Herzen unterschreiben. Ich habe mich bereits energisch gegen Forschungsarbeiten der jüngsten Zeit gewandt, die das Pendel in das entgegengesetzte Extrem ausschlagen lassen und die gesamte textkritische Literatur kurzerhand mit Nichtachtung übergehen im Glauben, die meisten der überlieferten Wortlaute ohne weiteres als Zeugnisse des klassischen Rechts annehmen zu dürfen". ${ }^{113}$ Il dissenso si trova soltanto nel fatto che Wieacker pone più di fiducia nei criteri della critica testuale per valutare sulla genuinità $\mathrm{o}$ credibilità, mentre Kaser, a sua volta, da maggiore importanza all'argomento sostanziale.

A prima vista, l'atteggiamento di Wieacker sembra essere più forte, ma è ammesso che la c. d. "höhere Textkritik" ha un'assai limitata portata nell'ambito degli studi romanistici, dato che, nella maggioranza dei casi, manca la possibilità di mettere a confronto diversi manoscritti della stessa opera, almeno in genere (ciò che lo medesimo Wieacker aveva ritenuto come una seria limitazione del suo metodo della "Textstufenforschung"). Quindi, nella pratica, la sua applicazione può essere solo limitata e, in conseguenza, i criteri formali non traggono vantaggio sui criteri sostanziali, e si trovano de facto sullo stesso piano. Se vi si aggiunge il fatto che oggi non si può sostenere più la vecchia visuale statica e schematica del diritto classico del primo interpolazionismo moderno, ma si è imposta in generale la considerazione del diritto classico come un vero diritto giurisprudenziale, dove il pensiero e l'attività dei giuristi erano occasione di un ampio ius controversum, risulterà chiaro che i criteri e gli argomenti giuridicocontinuistici, sottolineatisi da Kaser, saranno infine determinanti. Questo significa infine la rottura definitiva del secondo presupposto di base del metodo interpolazionistico. Ciò nonostante, ambedue i grandi romanisti sono d'accordo che si trata di un terreno dove tutto dipende del giudizio prudente del ricercatore e che questa nuova impostazione del percorso storico non deve dare motivo per una rinnovata schematicità del classico.

Questi punti di vista "conservatori" nell'analisi delle fonti giuridiche romane hanno finalmente vinto e sono diventati un nuovo paradigma dominante nello studio storico-critico del diritto romano, suprattutto nell'ambito della romanistica tedesca. Dopo la scomparsa dei due "capiscuola", Max Kaser e Franz Wieacker, le due scuole hanno percorso vie sempre più lontane della critica testuale tradizionale, esse hanno lasciato perfino le posizioni moderate anteriori e hanno alterato il rapporto equilibrato fra sistema, metodo e critica del testo che aveva caratterizzato i maestri ${ }^{114}$. La corrente, diciamo, kaseriana ha oscillato in un indirizzo sempre più dommatico e meno storico (cadendo negli eccessi "ultraconservatori" che lo stesso Kaser aveva criticato, come dicevamo prima), e aperto alle nuove tendenze dell'europeizzazione del diritto privato, fino al punto di una sorta di neopandettismo, ma di

\footnotetext{
${ }^{111}$ Cfr. D’ORS, Posiciones programáticas, cit. (n. 90), p. 37.

112 "Es gibt kein Zurück hinter die Textkritik" [in WIEACKER, Zur gegenwärtigen Lage, cit. n. 99, p. 1115 = ID., Ausgewäblte Schriften, cit. (n. 99), I, p. 116].

113 "Posso sottoscrivere ciò di tutto cuore. Mi sono già energicamente espresso contro alcuni lavori scientifici dei tempi più recenti, i quali fanno dondolare il pendolo verso l'estremo opposto e trascurano completamente l'intera dottrina della critica del testo, credendo di poter accettare senz'altro la maggior parte dei testi tramandati quali testimonianze del Diritto classico": in KASER, Ein Jabrbundert Interpolationenforschung, cit. (n. 103), p. 144.

${ }^{114}$ Si veda a proposito: BALDUS, C., La critica del testo nella romanistica tedesca a dieci anni della morte di Max Kaser, in MiglietTA - SANTUCCI (a cura di), Problemi e prospettive della critica testuale, cit. (n. 6).
} 
ordine europeo, rappresentato sopra tutti da Reinhard Zimmermann. La corrente wieackeriana, più collegata tradizionamente ai testi, ha messo, però, da parte il metodo ortodosso della "Textstufenforschung" e ha fatto un approccio diretto ad analizzare un'opera specifica o anche tutto il corpus di un dato giurista per cogliere quello che magari cambia nel medesimo (caso delle "Werkmonographien" dirette da Detlef Liebs e Joseph Georg Wolff); a tacer dell'indirizzo che segue formalmente la secta wieackeriana ed è rappresentate dalla linea filosofico-sistematica di Okko Behrends ${ }^{115}$ che si é proposta una spiegazione integrale del diritto romano classico improntata all'idea della continuità della letteratura giurisprudenziale classica fino alla grande recensio giustinianea, dove la questione della critica del testo non ha nessun ruolo rilevante (infatti Behrends ha ritenuto che le posizioni di Kaser e di Wieacker sono ancora troppo collegate alla critica interpolazionista, nella misura in cui essi sono ancora pronti ad accettare l'ipotesi della esistenza di una scuola giuridica postclassica portata alla costruzione teorica del diritto che è presente nelle alterazioni testuali postclassiche e giustinianee, mentre, a suo avviso, tale impostazione era già propria delle sectae classiche e preclassiche $\left.{ }^{116}\right)$. Fuori di queste due correnti, in Germania si devono menzionare anche gli allievi di Wolfgang Kunkel (1902-1981) ${ }^{117}$, che hanno scelto le più svariate strade, spesso esplorando le zone limitrofe tra storia generale e storia giuridica ( $\mathrm{ma}$, ad ogni caso, per vie lontane dalla critica testuale classica).

Nella romanistica italiana, però, sempre più vicina allo studio esegetico delle fonti giuridiche romane, contro la tradizione della vecchia linea dominante di Albertario, si sono levate voci critiche che hanno manifestato il loro scetticismo sull'efficacia di questo indirizzo "conservatore" per rendere conto veramente del contenuto reale del diritto classico presente nelle fonti postclassiche e giustinianee. In questa linea critica con l'anticritica si è mosso, per es., Antonio Guarino. In un lavoro publicato nel 1971 (Sulla credibilità della scienz̧a romanistica moderna) ${ }^{118}$, Guarino cercò di disarmare ognuno degli argomenti di Kaser, da lui esposti nella sua relazione al Congresso di 1967, difendendo il romanista italiano l'ipotesi di un approccio prudente rispetto a l'indagine interpolazionistica, sulla base della celeberrima affermazione di Giustiniano nella constitutio Tanta $\int 10$ ("multa et maxima [...] propter utilitatem rerum transformata sunt") che non si deve sottovalutare. Guarino rifiuta il presunto "classicismo" di Giustiniano in materia di diritto e l'ipotesi che l'imperatore avesse limitato i suoi interventi soltanto ai casi dove $i$ testi classici erano in contraddizzione con la nuova legislazione; egli si oppone all'idea di mantenere le contraddizzioni, discordanze e antinomie che si trovano nei testi tramandati soltanto come qualcosa echeggiante le discussioni e controversie proprie del ius controversum giurisprudenziale dell'epoca classica, e pensa che le polemiche fra i giuristi e le loro personalità furono annegate nel corso dell'epoca classica a causa della pressione sempre crescente del potere imperiale, di modo che le contraddizioni di sostanza e le soluzioni contrastanti presenti nei testi tramandati hanno una migliore spiegazione nelle interpolazioni che attraverso l'ipotetico ius controversum classico. Guarino non crede, dunque, che le parecchie alterazioni dei testi nel periodo "epiclassico" furono semplicemente di carattere formale, in specie quando

115 Sulla posizione metodologica di questo autore, ora: HARKE, J.-D., rec. a BEHRENDS, O., Institut und Prinzip (Göttingen, 2005), in RabelsZ., 72 (2008), pp. 226 ss.

116 BEHRENDS, O., La nuova tradurione tedesca dei 'Digesta' e la critica interpolazionistica, in Index, 25 (1997), pp. 13 ss., 16.

117 Sull'autore, vedasi da ultimo: MIQUEL, J., Wolfgang Kunkel, in DOMINGO, R. (editore), Juristas universales, cit. (n. 77), IV, pp. 396 ss.

${ }_{118}$ Cfr. supra n. 100. Cfr. anche le recensioni di GUARINO alla seconda edizione del Handbuch di Kaser in Labeo, 17 (1971), pp. 348, e Iura, 23 (1972), pp. 172 ss. (vol. I del Römisches Privatrecht), e Labeo, 22 (1976), p. 123 (vol. II dello stesso Handbuch). 
queste alterazioni sembrano in consonanza con la larga legislazione imperiale innovatrice dell'epoca; egli respinge anche la rilevanza dell'ipotetico "volgarismo" delle scuole giurisprudenzali occidentali e il loro influsso sulle manipolazioni formali dei testi e, reciprocamente, non concede moltissimo valore al presunto "classicismo" delle scuole giuriche orientali. Insoma, l'avveduto romanista italiano propugna, dunque, la necessità di continuare nell'uso moderato e prudente del metodo critico-storico, cioè, della critica testuale come la via ottima di realizzare l'essenziale dello studio storico-giuridico, cioè, l'analisi esegetico-critica delle fonti del diritto romano, resa valida e indispensabile per il metodo storico-giuridico, in base ad una serie d'ipotesi di lavoro fondamentali, cioè, la constatazione che $\mathrm{i}$ testi ritenuti come genuini devono presentare comunque taluni indici formali caratteristici, in corrispondenza con l'uniformità dello stile classico collegata a una certa "fungibilità" dei giuristi dell'epoca classica, ma evitando ogni apriorismo, tanto d'indole ipercritica come conformista in eccesso con la credibilità nella genuinità delle fonti a noi pervenute.

Di fronte a queste critiche, Kaser restò nelle sue posizioni "conservatrici"119, sebbene attenuando alquanto talune delle sue osservazioni originarie, poichè, come abbiamo visto sopra, ha riconoscuto certi successi della critica interpolazionistica e ha ammesso il bisogno di continuare con l'analisi critica dei testi. Ma le obiezioni di Guarino vengono rifiutate mediante una riaffermazione nei criteri d'interpretazione delle fonti da lui difesi da prima, sebbene si dica che le differenze fra le due posizioni si riducono soltanto alla questione di una maggiore o minore probabilità di genuinità dei testi: mentre Guarino ammette una maggiore verosimiglianza degli interventi sostanziali dei giuristi postclassici sui testi, Kaser prova a essere cauto e preferisce porre maggiore fiduzia nella trasmissione fedele del contenuto classico delle nostre fonti, allorchè non si possa provare indubbiamente un'alterazione sostanziale. L'autore austriaco fa risaltare i vantaggi di una ricerca basata su una maggiore fiducia nella credibilità delle fonti postclassiche per la scienza romanistica, così: i) essa può apparire a terzi meno insicura e variabile, quindi può acquistare maggior credito nei confronti delle altre discipline storiche; ii) un'impostazione di ricerca più conservativa torna utile anche alla considerazione che il diritto romano riscuote nell'insegnamento universitario del diritto.

Forse per questi motivi utilitaristici, oppure per causa dei rovesciamenti tipici delle mode scientifiche, la verità è che, in fine, malgrado i timori e ammonimenti di Guarino, l'indirizzo "conservatore" ha vinto chiaramente negli ultimi anni anche in Italia, mettendo da parte il metodo inerpolazionistico. Il nuovo indirizzo è andato sempre più accentuandosi nel segno della considerazione dell'individualità dei singoli giuristi sulla considerazione della prevalenza del ius controversum classico, ossia giustamente quello contro il quale reagiva energicamente Guarino. Ma con questa impostazione, come ha detto Talamanca ${ }^{120}$, non solo si é lasciata affatto la metodologia interpolazionistica, ma anche lo stesso problema della critica del testo, una conseguenza della quale era consapevole il medesimo Max Kaser, come abbiamo visto sopra. Oggi, quando una ricerca romanistica intende valutare il caso d'una evidente e innegabile modificazione del testo classico, volta a modificare la sostanza della decisione del giurista, ci sono sovente due strumenti tipici, ambedue non senza pericolo: $\imath$ ) primo, il ricorso all'ambigua categoria della "genuinità sostanziale" del testo, la quale è fra l'altro ancora abbastanza legata ad un modo di pensare "sistematico", cioè, alla ricostruzione dell' "oggettiva" portata del

${ }^{119}$ La prima risposta a Guarino si vede in KASER, Zur Methodologie, cit. (n. 101), e poi nei suoi lavori posteriori. Una reazione di Guarino, invece, si può vedere nel suo articolo Le vie al Diritto classico, in GUARINO, A., Le ragioni del giurista (Napoli, 1983), pp. 389 ss. (= ID., Pagine di Diritto romano, cit., I, n. 100, pp. 433 ss.); c’è ora una traduzione spagnola di questo articolo a cura di E. RUIZ FERNÁNDEZ, Los caminos al derecho romano clásico, in GUARINO, Sobre la credibilidad, cit. (n. 100), pp. 65 ss.

${ }^{120}$ La ricostruzione del testo, cit. (n. 35), pp. 12 ss. 
diritto romano, questa volta classico e non giustinianeo; ii) l'altro, il ricorso all'accorciamento del testo per soppressione del ius controversum, sebbene non sia sempre così sicuro che l'opinione conclusiva sia del giurista cui risale il passo, perchè, nel tagliare il testo, può essere accaduto che all'autore formale del testo sia attribuito il pensiero di un giurista che egli citava.

Entrambi i metodi, insomma, si centrano nella problematica contenutistica guridicosostanziale, lasciando da parte il problema del testo e, quindi, la critica testuale. Così il cerchio è chiuso e si é ritornati al punto iniziale prima della "rivoluzione interpolazionistica" (cioè una sorta di rivoluzione copernicana nell'ambito della romanistica moderna) della fine dell'Ottocento.

\section{LE RECENTISSIME TENDENZE \\ NELLA SCOPERTA DI (PRESUNTE) INTERPOLAZIONI NEL DIGESTO}

1. La critica interpolazionistica è diventata poi un fenomeno marginale nella romanistica più moderna, se addirittura non è morta come metodo rilevante dell'indagine romanistica. Ma questo non significa che l'interesse per l'indagine sull'esistenza di possibili alterazioni dei testi operate dai commissari giustinianei sia affatto scomparsa. Ci sono stati negli ultimi anni taluni indirizzi scientifici e metodi di ricerca, che hanno messo la problematica del testo nel cuore delle loro attività, e dunque la questione delle interpolazioni è ritornato in un certo senso in un primo piano.

Vedremo adesso brevemente alcuni di questi indirizzi.

1. Il primo di questi indirizzi più o meno recenti che prendono in considerazione di nuovo la critica testuale per la ricostruzione del diritto romano dopo il "Konservativismus" kaseriano si è sviluppato in Gran Bretagna attraverso i lavori di Tony Honoré (1921), allievo di Fritz Pringsheim all'università di Oxford, e dunque più vicino all'idea dell'esistenza di alterazioni non solo fomali, bensì anche sostanziali, nei testi tramandatici. Ma egli, in ogni caso, considera che la questione sull'interpolazione o meno di un testo è cosa che non si può decidere "in abstracto". Quindi, nel corso dei suoi studi sul Digesto e sullo stile di alcuni giuristi classici ${ }^{121}$ e di Triboniano ${ }^{122}$, Honoré ha proposto una serie di criteri d'individuazione delle interpolazioni ${ }^{123}$, i quali sono nient'altro che una "rivisitazione" dei vecchi criteri "formali" della critica interpolazionistica classica, ma con alcuni aggiustamenti importanti. Egli ha distinto cinque "regole" o linee direttici che possono essere utili all'indagine delle interpolazioni: due vanno in senso negativo (cioè, dànno indizi per affirmare la classicità di un testo sospetto); due in senso positivo (cioè, forniscono indizi della possibile interpolazione del testo in questione); e, infine, una regola che è di carattere strettamente formale, d'indole sintattica.

i) La prima regola è che se l'espressione in dubbio è tipica o almeno è conforme con lo stile generale dell'autore a cui si attribuisce il testo in questione nel Digesto, sembra improbabile che il testo sia interpolato.

ii) La seconda regola è che, se l'espressione in dubbio è usata nel Digesto dall'autore apparente in modo naturalmente coerente con l'uso normale dell'espressione nella storia dei testi giuridici, è improbabile che l'espressione sia stata interpolata.

iii) La terza dice che, se l'espressione è tipica o consistente con lo stile del compilatore (per

\footnotetext{
121 Gaius (Oxford, 1962); Ulpian [Oxford, 1982; nuova edizione: Ulpian: Pioneer of Human Rights (Oxford, 2002)].

122 Tribonian (London, 1978).

${ }^{123} \mathrm{Si}$ veda: HONORÉ, T., Some suggestions for the study of interpolations in TR., 49 (1981), pp. 225 ss.; ID., Techniques of interpolation: D. 33.4.15-17, in Sodalitas. Scritti in onore di Antonio Guarino (Napoli, 1984), VI, pp. 2723 ss.
} 
es. Triboniano), applicato quanto detto nella regola 2, si deve pensare che l'espressione deve essere stata probabilmente interpolata.

iv) La quarta afferma che, se l'espressione sembra essere strana nel contesto dove essa appare e si può supporre che il compilatore ve l'ha inserita (benché essa non sia parte del suo vocabolario abituale), perchè egli ha trovato per caso un'espressione similare in un testo classico poco prima nel passo, è possibile che l'espressione sia stata interpolata.

v) Finalmente, la quinta regola guarda alla sintassi: le interpolazioni compaiono sovente alla fine di una frase, oppure in un testo integro. La ragione è che c'è più facile aggiungere qualcosa ad un testo che riscriverlo completamente. Per esempio, nel caso di un autore come Ulpiano, che ha l'abitudine di esporre la sua opinione in modo categorico e finire con un'alta notazione, una qualificazione introdotta da, p. es., ut, si modo o nisi alla fine di un testo induce al sospetto che il testo è interpolato.

In ogni caso, tutte queste linee direttrici generali sono soltanto indicative, non servono sempre per il caso specifico. Per Honoré, le più importanti modificazioni dei testi classici sono accadute per l'ommissione del 95\% dei testi letti dai compilatori e queste alterazioni spesso fanno mutare il diritto vigente attraverso le trasposizioni e le riorganizzazioni dei testi classici attribuendo all'autorità dei classici le proposizioni legali che i compilatori volevano introdurre nel ordinamento ${ }^{124}$.

Honoré ha applicato il suo metodo all'indagine d'interpolazioni in diversi passi del Digesto, ma non si può dire che questa indagine sia diventata il fulcro della sua attività scientifica, bensì è rimasta più come una derivazione marginale dei suoi altri lavori ${ }^{125}$.

2. Un'altra linea di attività della romanistica nelle ultime decadi, ove la critica testuale svolge un certo ruolo è il tema della traduzione dei testi giuridici romani. Le recenti nuove traduzioni del Digesto in talune lingue moderne (spagnolo, inglese, olandese, tedesco, italiano) hanno messo in rilievo nuovamente i problemi della intertestualità dei documenti a noi tramandati e la difficoltà di fornire una traduzione moderna, unitaria e comprensibile per il lettore attuale di un testo che, in sé stesso, manca di unità e presenta livelli diversi di scrittura. Ad essere storicamente corretto, il lavoro di traduzione dovrebbe iniziarsi con la separazione del classico dalle aggiunte postclassiche, e in questo senso la "caccia alla interpolazione" dovrebbe essere una parte dell'impegno. È chiaro, però, che se questo fosse così la traduzione diventerebbe un lavoro pressochè impossibile, perchè occorrebbe fare un percorso integrale di tutti i sospetti d'interpolazioni sui testi del Digesto per avere una nuova visuale piena dei problemi delle alterazioni testuali: qualcosa di impraticabile come fare un nuovo Index Interpolationum. Ma certamente una nuova traduzione esauriente della totalità del Digesto obbliga i traduttori a fare un'esegesi rinovata dei singoli frammenti e permette senza dubbio di riflettere nuovamente sui problemi testuali dell'opera da un profilo sistematico. Come ha detto Okko Behrends ${ }^{126}$, uno

124 Vedasi ora: HONORÉ, T., Justinian's Digest. Character and Compilation (Oxford, 2010), pp. 107 s.

125 Infatti, in generale, le tendenze oltranziste della critica interpolazionistica non sono state mai popolari nel mondo anglosassone, vedasi, ad es.: BUCKLAND, W. W., Interpolations in the Digest, in Yale Law Journal, 33 (1924) 4, pp. 343 ss.; ID., Interpolations in the Digest: A criticism of criticism, in Harvard Law Journal, 54 (1941) 8, pp. 1273 ss.; RADIN, M., Handbook of Roman Law (St. Paul, Minn., 1927), pp. 94 ss.; ID., 'Eleganter', in Law Quarterly Review, 46 (1930), pp. 311 ss. (sulla posizione di Radin, vefdasi ora: PETIT, Estudio y edición, cit. n. 30, pp. cii ss.); più recente, JOHNSTON, D., Justinian's Digest. The Interpretation of Interpolation, in Oxford Journal of Legal Studies, 9 (1989) 2, pp. 149 ss. Ciò nonostante, TALAMANCA [La ricostruzione del testo, cit. (n. 35), p. 14] credeva che giustamente in Gran Bretagna, come fosse un'area marginale della romanistica, una ripresa di una ricostruzione del Diritto romano in chiave interpolazionistica sarebbe più probabile, per in un gioco di pendolo provocato, a suo avviso, dall'avvenuta prevenuta repulsa di qualsiasi discussione critica del testo nei paesi centrali della romanistica. Qui non possiamo essere assolutamente convinti dell'esatteza di questa prospettiva.

${ }^{126}$ La nuova tradurione tedesca, cit. (n. 116), p. 55. 
dei quattro autori (finora) della traduzione tedesca, a proposito della loro traduzione: "Naturalmente non è ancora il momento di esprimere, grazie al lavoro svolto di traduzione, valutazioni conclusive sui Digesta e sulle interpolazioni in esse contenute. La traduzione è purtroppo ancora lontana dalla fine ${ }^{127}$. Ma già adesso si può affermare che da qui in avanti sarà difficile considerare i Digesta un'opera che riproduce un diritto classico guastato e sfigurato dallo spirito maligno bizantino o postclassico. Possiamo piuttosto valutarli come una codificazione ben riuscita e apprezzare il fatto che, malgrado tutto quello che dall'antico diritto fu sacrificato e messo da parte a causa del tentativo di creare un ordinamento giuridico unitario, essa si sia mantenuta all'altezza della tradizione della giurisprudenza romana". Ma malgrado questa dichiarazione pienamente inserita nella corrente "conservatrice" più radicale (come è stato già dinanzi accennato, Behrends rende il suo maestro Wieacker ancora molto interpolazionista), egli non solo ha riconoscuto l'esistenza delle alterazioni testuali postclassiche e bizantine nella stesura del Digesto (come no!), ma persino ha suggerito alcune di tali alterazioni e ha proposto la traduzione indicando espressamente che il siffatto testo è un'interpolazione: per es., in D. 6.1 .38 (Cels. 3 dig.), l'espressione 'constituimus' non è tradotta come se fosse un testo del giurista, ma direttamente con l'espressione "wir [Justinian] haben... angeordnet", cioè, come un'aggiunta al testo dell'imperatore medesimo, cioè, dei compilatori ${ }^{128}$; e anche in D. 9,2,27,17 (Ulp., 18 ed.), dove l'intervento di Giustiniano cerca di trovare una media sententia fra la tesi dei Proculiani (difesa da Ulpiano nel testo originale) e la tesi dei Sabiniani pregiulianei, combinando il formalismo dei primi con l'apertura all'interesse patrimoniale degli altri, in una soluzione che risalga a Giuliano: dove il testo originale di Ulpiano diceva "in haec ideo lege Aquilia agi posse", i compilatori hanno scritto "atque ideo lege Aquilia agi posse", ma questo non si può mettere in risalto per i lettori moderni così agevolmente come nel caso anteriore ${ }^{129}$.

Insomma, la realizzazione di una nuova traduzione della totalità del Digesto offre un'eccellente opportunità di fare una accurata riflessione sui problemi d'indole testuale che sono presenti (ma spesso soggiacenti e inavvertiti) nella stesura della recensio giustinianea dei testi classici ${ }^{130}$ e ha aperto anche un'interessante discussione pluridisciplinare intorno al linguaggio dei giuristi romani e le sue peculiarità ${ }^{131}$.

3. Una terza linea in questa direzione di mettere in rilievo l'aspetto testuale delle fonti, molto interessante ma ancora poco sviluppata, è stata iniziata in Spagna per mano dei professori Manuel García Garrido e Fernando Reinoso-Barbero, che nel 1994 hanno publicato un vero opus magnum in 11 volumini intitolato Digestorum similitudines. Questa opera fu presentata ufficialmente con un'allocuzione tenuta dal professore García Garrido il 3 marzo 1995 nell'Istituto di Diritto Romano della Università di Roma "La Sapienza"132. In questa opera si

${ }^{127}$ Finora sono apparsi i seguenti volumi: Corpus iuris civilis. Text und Übersetzung, BEHRENDS, O. - R. KNÜTEL, R. - KUPISCH, B. - SEILER, H. H., I: Institutionen (2 a edizione, Heidelberg, 1997); II: Digesten 1-10 (Heidelberg, 1995); III: Digesten 11-20 (Heidelberg, 1999); IV: Digesten 21-27 (Heidelberg, 2005).

${ }^{128}$ BEHRENDS, La nuova tradurione, cit. (n. 116), pp. 30 ss.

${ }^{129}$ BEHRENDS, op. ult. cit., pp. 43 ss.

${ }^{130}$ Vedasi in questo senso anche: ZIEGLER, Max Kaser e la revisione, cit. (n. 108), i.f.

${ }^{131}$ V. ad es. i volumi: Il latino dei giuristi romani. Atti del Convegno internazionale di studi (Lecce, 5-6 decembre 1994) (a cura di O. BIANCO e S. TAFARO, Galatina, Lecce, 1999) e 'Scientia iuris' e linguaggio nel sistema giuridico romano. Atti del convegno di studi (Sassari, 22-23 novembre 1990) (a cura di F. SINI E R. ORTU, Milano, 2001). Sul tema, v. da ultimo: SCHIPANI, S., Il latino del Diritto nella costruzione della identità dell'Europa, en Studi in onore di Remo Martini, (Milano, 2009), III, pp. 517 ss.

132 Relazione pubblicata in BIDR., 35-36 (1993-1994), pp. 575 ss. [= GARCÍA GARRIDO, M. J., Miscelánea romanistica, presentación y coordinación FERNÁNDEZ DE BUJÁN, F. - REINOSO, F. (Madrid, 2006), I, pp. 429 ss.]. Sul metodo v. la riflessione complessiva di LAZO, P, El método de comparación de casos: examen de resultados, in REHJ., 
raccogliono esaurientemente tutte le geminazioni e similitudines esistenti nel testo del Digesto corrispondenti ai parametri prescelti: qui García Garrido e Reinoso-Barbero intendono per "geminazione" o lex geminata i pasi coincidenti dello stesso giurista autore, opera e libro dentro del Digesto; tutte le altre coincidenze di autori, opere o libri differenti devono esse considerate come similitudines sensu stricto ${ }^{133}$. La ragione di questa precisione terminologica è che così si permetterà nell'ambito palingenetico, dove ci sono molte conclusioni da rivedere, di non dare due o più sistemazioni diverse a uno stesso passo.

L'opera $^{134}$ contiene 27.694 coincidenze, divise in 9.810 gruppi -disposti in ordine alfabetico- di sequenze identiche da quattro ad un numero indeterminato di parole stesse. I gruppi presentano lo stesso ordine: il numero di riferimento, le parole della similitudine in corsivo, e sotto i testi del Digesto dove si trovano, con la corrispondente inscriptio contenente il nome del giurista e dell'opera originaria e del relativo libro, quindi l'indicazione della massa bluhmiana alla quale appartiene, e quando vi siano altre somiglianze una nota con l'indicazione di queste e dei testi in cui si trovano. Si trata sempre di sequenze identiche: se ci sono differenze di parole oppure di terminazioni o tempi verbali sono indicate tutte le forme adoperate.

Non tutte queste coincidenze sono state già scoperte: le similitudines più conosciute sono quelle che cominciano con le stesse parole, già studiate dai glossatori. Gli editori del Digesto, specialmente Mommsen e Krüger rinviano in note a geminazioni dei testi e la critica romanistica, per es. Schulz, ne ha riscontrato delle altre. Questa opera risalta però per il suo carattere universale.

Il criterio per riconoscere una similitudine è la coincidenza minima di 4 parole. Il criterio seguito si basa, secondo García Garrido, in due ragioni fondamentali: utilità e sicurezza, le quali dipendono non tanto del metodo quanto dal sistema di selezione. A suo avviso, fra tutte le possibili alternative, quella che offre un'informazione maggiormente attendibile è la scelta delle quattro parole. Solo a partire di questo numero, infatti, l'informazione resulta utile per la ricerca romanistica. Per dimostrare l'esattezza di siffatta affermazione si deve tener presente che le circa diecimilia similitudines dell'opera sarabbero divenute più di duecentomila se si fossero scelte tre parole come sistema di selezione, delle quali una percentuale molto elevata non presenterebbe interesse. Invece, se la scelta fosse caduta sulle cinque parole, molte geminazioni e coincidenzi sarebbero rimaste fuori della classificazione: per es. molti rilevanti espressioni tecniche come bonorum possessio secundum/contra tabulas, causa in possessionem missus, cautum vel satisdatum est, datur in eorum actio, testamento liberum esse iussit, etc. Per questi motivi, la scelta delle similitudines a partire da quattro parole risulta la migliore. Allo stesso tempo non è in alcun modo limitata: quando fra più similitudines in due testi intercorrono differenze, le somiglianze successive debbono comunque avere almeno quattro parole per venire registrate. Tali requisiti sono richiesti per ottenere risultati sicuri, e perciò si devono escludere somiglianze apparenti, non corrispondenti alla realtà dei testi.

Il modo di utilizzare l'opera è facile. Le similitudines sono state ordinate e numerate con un criterio alfabetico in gruppi di mille in ognuno dei dieci volumi susseguenti al primo, dove appaiono indicate sulla copertina la prima e l'ultima delle similitudini che contengono. Ma i

26 (2004), pp. 41 ss.

133 Sul concetto di 'similitudo', vedasi: GARCÍA GARRIDO, M. J., Redacciones coincidentes (“leges geminatae”) y casos jurisprudenciales semejantes ("capita similia"), en Estudios de Derecho Romano en honor de Álvaro d'Ors (Pamplona, 1987), pp. 517 ss. [= GARCÍA GARRIDO, Miscelánea romanística, cit. (n. 132), I, pp. 327 ss.], e anche, più recente, REINOSOBARBERO, F., Geminaciones ocultas en el Digesto, in Index, 25 (1997), pp. 207 ss. (in particolare, pp. 227 ss., sub n. 1).

${ }^{134}$ Si veda la Praefatio di GArCía GARrido, M. J. - REINOSO-BARbero, F., Digestorum similitudines (Madrid, 1994), I, pp. 3-4. 
criteri di ricerca possono essere diversi per mezzo dei cinque estesi indici del volume primo che si riferiscono ai vocaboli latini e greci, ai frammenti del Digesto, ai giuristi ed alle loro opere. Gli indici si riportano al numero della similitudine, e l'elenco completo di queste si può consultare anche nel volume primo. Per una maggiore informazione si deve consultare il corrispondente volume, dove si trovano citati sotto la singola similitudine i testi del Digesto che la contengono, con l'indicazione del giurista e della sua opera, del relativo libro e della massa bluhminana. Le note rinviano ad altre coincidenze di testi, citati anch'essi con l'indicazione dell'inscriptio e della massa.

Infatti, l'opera è ancora assai recente e non è stata abbastanza utilizzata per porre conclusioni definitive, ma almeno per il momento si può dire che una migliore conoscenza delle similitudines esistenti nel Digesto permette di mostrare nuovi orizzonti per la ricerca critico-testuale e arrivare a nuove scoperte tanto nel campo storico-giuridico quanto nel filologico. Nell'ambito del diritto romano si può dire che l'opera può rendersi molto utile in

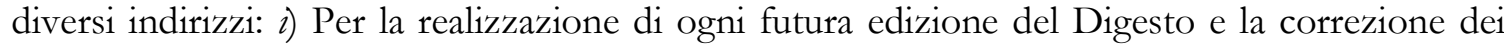
testi giurisprudenziali; ii) Per mostrare la mancanza di originalità di molte decisioni giurisprudenziali; iii) Per fare correzioni palingenetiche; iv) Per segnalare le interrelazioni della letteratura giurisprudenziale; v) Per individuare responsa-tipo che si applicano a diversi casi, che è un mezzo tecnico adoperato dai giuristi, oppure dai compilatori.

In rapporto con le interpolazioni, corruzioni e contaminazioni di testi, si può osservare grazie a questa opera come è pratica frequente nel Digesto quella di estrapolare una decisione concreta per applicarla ad un'altra fattispecie situata in sede diversa da quella originaria. In molti passi è possibile rintracciare la sede originaria per mezzo dello studio palingenetico del libro e dell'opera nella quale la decisione si trova. Sono molto interessanti, quindi, le interpolazioni che appaiono in uno soltanto dei due testi geminati, che non era stato finora possibile scoprire.

Questa opera in supporto cartaceo è stata criticata da alcuni studiosi (singolarmente dal prof. Niccolà Palazzolo ${ }^{135}$ ) inanzi tutto per considerare che è nata antiquata nell'epoca del supporto elettronico e dei "databases", in specie riguardo alla Bibliotheca Iuris Antiqui (BIA). Tuttavia, ci sono talune ragioni formali e sostanziali che fanno $D S$ in alcuni riguardi un'opera più pratica dei "databases". Fra queste ragioni formali sottolineate da García Garrido ${ }^{136}$ sono:

i) I "databases" usuali permettono di cercare una od al massimo due parole, ma non danno la possibilità di trovare frasi o lunghe combinazioni di parole. In $D S$ si individuano molte geminazioni che contengono decine di parole uguali;

ii) Questi “databases" non servono per distinguere differenze di punteggiatura che possono esistere tra due similitudines. Cioè, molte volte le geminazioni e le coincidenze si differenziano per la presenza di virgole, punti, virgolette, che i comuni programmi non possono rintracciare. Queste differenze sono invece individuate nell'opera presente;

iii) I "databases" operano su catene fisse di tipi e non danno risultati se non quando un tipo si ritrova. $D S$, invece, fornisce le somiglianze complete anche se ci sono parole o frasi, lunghe o brevi, non coincidenti. Per ciò talvolta le similitudines riportate hanno periodi separati da puntini di sospensione corrispondenti alle differenze che presentano tra di loro due o più testi. Altre volte si riscontrano differenze che riguardano i casi o desinenze verbali, e anche queste sono indicate.

Fra le ragioni di fondo che impediscono ai "databases" di arrivare alle informazioni che offe

135 Si veda: Palazzolo, N. - Maggio, L., Elementi di informatica romanistica (Catania, 2001), pp. $120 \mathrm{~s}$. $<$ http://www.ittig.cnr.it/Ricerca/Testi/Palazzolo1996Sassari.htm.> [10 luglio 2011]

${ }^{136}$ GARCÍA GARRIDO, Digestorum simulitudines, in ID., Miscelánea romanistica, cit (n. 132), I, pp. $430 \mathrm{s.}$ 
DS sono:

i) I "databases" non seguono, come criteri di selezione, se non quelli relativi al contenuto. Invece, in $D S$ si trovano le coincidenze con una pluralità di mezzi: il testo del Digesto, il giurista e l'opera, i vocaboli latini e greci, l'ordine alfabetico delle similitudines, il numero di queste, etc.

ii) I "databases" non permettono l'ordinata interrelazione delle similitudines tra di loro. DS, nondimeno, fornisce un apparato critico di più di 20.000 note che evidenzia la conessione dei testi del Digesto che contengono le coincidenze.

iii) I "databases" presentano in abbreviazione le inscriptiones dei testi e non permettono quindi di cercare le similitudines nelle forme di iscrizione, il che ha valore per le opere che presentano varie forme di iscrizione (p. es. le forme ad formulam bypothecariam/de formula bypotecaria). Per permettere di individuare queste coincidenze, in DS si è inclusa l'iscrizione completa del testo con la massa bluhmiana alla quale appartiene.

Un raffronto ${ }^{137}$ tra l'uso di $D S$ e del "database" BIA rispetto a più di 40 casi di similitudines presi aleatoriamente ha dimostrato che ci sono taluni casi (7) che non sono stati individuati da BIA, ma lo sono stati da $D S$, mentre negli altri casi della richiesta entrambi i sistemi rendono gli stessi testi, ma in molti di questi casi BIA non risponde propriamente all'istruzione operata (quindi i testi non coincidono esattamente con la domanda) e in altri casi i testi resi non sono del Digesto, ma di un'altra opera: cioè, il "database" presenta quello che nel linguaggo informatico si chiama "rumore" (cioè, dare informazioni che non si domandavano) e anche "silenzio" (cioè, non rendere la precisa informazione che si domandava). In conseguenza, da questo studio comparativo si prova che, malgrado la presentazione "cartacea" apparentemente antiquata dell'opera, $D S$ rende migliori risultati agli effetti della ricerca romanistica che questo esteso "database" (molto utile ad ogni caso; in altre parole, che ambedue opere sono complementari).

In somma, l'utilitá di questa opera consiste fondamentalmente nel suo carattere universale.

4. Per concludere, un quarto indirizzo che mostra un certo rapporto con la tradizionale critica testuale si trova in recenti lavori di ricerca fatti in Germania ${ }^{138}$ che implicano un certo ricupero del genere della "Wortmonographie", ma qui non precisamente nel vecchio senso ipercritico di Beseler, bensì in un senso più concettuale e meno filologico. Lo scopo è l'analisi dell'uso dei termini dai giuristi romani, particolarmente quei termini che alludono a valutazioni d'indole metagiuridica (come, p. es. aequitas, bumanitas, benignitas, etc.), termini che hanno sollevato tradizionalmente il sospetto di essere stati interpolati dai compilatori, ovvero per conseguenza dell'influsso delle scuole postclassiche orientali, pieni di concezioni filosofiche greche. Questi termini appaiono nelle fonti giustinianee come attribuiti ai giuristi classici e adempiono una funzione di correzione dei valori stretti del ius civile, oppure di altri principi giuridici tradizionali, ovvero agiscono pure come depositi di criteri valutativi che possono fornire soluzioni giuridiche per una moltiplicità di casi, a modo delle "clausole generali" dei nostri ordinamenti giuridici moderni. Ma non solo questo tipo di termini è studiato monograficamente, lo sono anche altri termini da tempo sotto il sospetto d'interpolazione, come espressioni generalizzanti (generaliter, consequens, similis, quemadmodum, ut, etiam, non magis quam, omnis, item servandum [...], ut in [...], etc.), che possono fondare vincoli fra un problema giuridico discusso in un testo con altri diversi, in modo che riescano a dare alla proposta di

${ }^{137}$ I risultati sono stati pubblicati in GARCÍA GARRIDO, M. J., Oratio pro opera 'Digestorum similitudines', in Revista General de Derecho Romano, 12 (2009) (http://www.iustel.com).

138 Ad es. KLEITER, T., Entscheidungskorrekturen mit unbestimmter Wertung durch die klassische römische Jurisprudenz (München, 2010). 
soluzione discussa in un caso un significato più ampio e, per conseguenza, giovano ad estendere la norma ai casi futuri e ad ampliare il cerchio valutativo e l'ambito di applicabilità delle soluzioni trovate. Questi termini hanno, dunque, una potenza sistematizzante che vale la pena di indagarsi in specie.

Certamente, queste nuove "Wortmonographien" non possono farsi al modo di Beseler ${ }^{139}$ : primo, oggi non ci sono dubbi che, in generale, questi termini sono classici e sono stati usati dai giuristi classici; secondo, mentre le ricerche di Beseler si svolgevano al livello "soprastrutturale" (cioè, a riguado delle strutture linguistiche, ossia della "Textforschung"), questa nuova ricerca si muove al livello "infrastrutturale" (cioè, al riguardo dei concetti, ossia della "Sachforschung"). Ma allo stesso tempo è anche certo che l'analisi specifica dell'attuazione di questa terminologia esige ad ogni caso una nuova riflessione sulle fonti e sui problemi testuali, una rilettura dei testi compilatori con una visione globale che ponga insieme espressione, concetto e sistema. Ł̀ ovvio, però, che non si può guardare questi termini in abstracto, bensì nel contesto delle catene testuali e delle congiunzioni terminologiche in cui queste voci appaiono e, quindi, anche con riguardo all'argomento stilistico ${ }^{140}$. In questo senso, nell'ambito di questo tipo di studi il ruolo della critica testuale dovrà essere molto significativo, sebbene non si tratti della critica interpolazionistica classica, ma di una sorta di critica più attenta ai fattori concettuali e ideologici, nella linea della svolta della mainstream della romanistica recente più verso il dommatico e lo storico-politico e meno verso il filologico, senza tralasciare neanche gli aspetti rilevanti di natura linguistico-filologica. Ma non si può dubitare che nel corso di queste ricerche, che a mio avviso avranno un ampio sviluppo nei prossimi anni, sarà anche possibile trovare nuovi argumenti per provare possibili interventi postclassici o compilatori sui testi che finora erano stati trascurati, oppure sono passati inavvertiti, o almeno ci saranno motivi per porsi nuove domande intorno alla storia dei testi a noi pervenuti e le ipotetiche dislocazioni fra il pensiero dei giuristi classici e la sua espressione nelle fonti che oggi possiamo leggere e sulle cause di ciò. Ma questa è ancora pure una domanda alla quale solo il tempo potrà veramente rispondere.

\section{BIBLIOGRAFÍA}

Albertario, Emilio, s. v. 'Interpolazione (Diritto)', in Enciclopedia Italiana di Scienze, Lettere ed Arti (Roma, 1939, rist. 1949-50), XIX.

Albertario, Emilio, s. v. Serafini, Filippo, en Enciclopedia Italiana (Roma, 1936; rist. 1949-50), XXXI.

Albertario, Emilio, Glossemi e interpolazioni pregiustinianee, in Atti del Congresso (Pavia, 1934), I [= AlberTARio, E., Studi di Diritto romano, V: Storia. Metodologia. Esegesi (Milano, 1937)].

AlBERTARIO, Emilio, I Tribonianismi avvertiti dal Cuiacio, in ZSS., 31 (1910).

AlBerTARIO, Emilio, Introdurione storica allo studio del Diritto romano giustinianeo, Parte Prima (Milano, 1935).

ALBertArIO, Emilio, s. v. Interpolazione (Diritto), in Enciclopedia Italiana di Scienze, Lettere ed Arti (Roma, 1939, rist. 1949-50), XIX.

AlBertario, Emilio, s. v. 'Interpolazione (Diritto)', in Enciclopedia Italiana di Scienze, Lettere ed Arti

${ }^{139}$ Cfr. BALDus, C., La palabra en los tiempos del cólera. Wortmonographie, Textkritik und Individualforschung, in Studi in onore di Remo Martini, (Milano, 2008), I, pp. 145 ss.

140 Sulla dimensione essenzialmente linguistica dei concetti giuridici v. da ultimo: MANTOVANI, D., Lingua e Diritto. Prospettiva di ricerca fra sociolinguistica e pragmatica, in Studi in onore di Remo Martini (Milano, 2009), II, pp. 673 ss. 
(Roma, 1939, rist. 1949-50), XIX.

ÁlVAREZ SUÁREZ, Ursicino, La jurisprudencia romana en la hora presente (Madrid, 1966).

AMIRANTE, Luigi, Per la storia dei testi giurisprudenziali classici, in Labeo, 7 (1961).

ARANGIO-RUIZ, Vincenzo, rec. a Wieacker, Textstufen, in BIDR., 64 (1961).

ARANGIO-RUIZ, Vincenzo, s. v. 'Alibrandi, Ilario', in Enciclopedia Italiana (Roma, 1936; rist. 19491950), II.

ARCHI, Gian Gualberto, rec. a Wieacker, Textstufen, in Iura, 12 (1961).

BALDUS, Christian, ¿Hacia un nuevo concepto de "Textstufen"? entrambi in Seminarios Complutenses de Derecho Romano, 23-24 (2010-2011).

BALDUS, Christian, Josef Partsch, in DOMINGO, R. (editore), Juristas universales, IV: Juristas del siglo XX (Madrid - Barcelona, 2004).

BALDUS, CHRISTIAN, La critica del testo nella romanistica tedesca a dieci anni della morte di Max Kaser, in MiglietTA - SANTUCCI (a cura di), Problemi e prospettive della critica testuale. Atti del seminario di Diritto romano a Trento, 14-15 dicembre 2007 (Trento, 2011) (opera in corso di stampa).

BALDUS, Christian, La palabra en los tiempos del cólera. Wortmonographie, Textkritik und Individualforschung, in Studi in onore di Remo Martini, (Milano, 2008), I.

BAvierA, Ancora sui Tribonianismi avvertiti da Antonio Fabro, in Archivio Giuridico, 69 (1902), pp. 398 ss.

BEHRENDS, Okko, Das Werk Otto Lenels und die Kontinuität der romanistischen Fragestellungen. Zugleich ein Beitrag zur grundsätzlichen Überwindung der interpolationistischen Methode, in Index, 19 (1991).

BEHRENDS, OKKO, La nuova tradurione tedesca dei 'Digesta' e la critica interpolazionistica, in Index, 25 (1997).

BEHRENDS, OKKO, Otto Lenel, in DOMINGO, R. (editore), Juristas universales, III: Juristas del siglo XIX (Madrid - Barcelona, 2004).

BEKKer, Ernst Emmanuel, Rec. di Cicerus Rede pro Q. Roscio Comedo (ed. H. H. Pflüger, Leipzig, s. d.), in ZSS., 25 (1904).

BOnfante, Pietro, Storia del Diritto romano (4a edizione, Roma, 1934, rist. a cura di G. BONFANTE e G. CRIFÒ, Milano, 1959), II.

BROGGINI Gerardo, Zur Glaubwürdigkeit der römischen Rechtsquellen (über die Grenzen der Interpolationenkritik), in La critica del testo. Atti del II Congresso Internazionale della Società Italiana di Storia del Diritto (Venezia, 18-22 di settembre di 1967) (Firenze, 1971), I.

BUCKLAND, W. W., Interpolations in the Digest, in Yale Law Journal, 33 (1924) 4.

BuCKLAND, W. W., Interpolations in the Digest. A Criticism of Criticism, in Harvard Law Journal, 54 (1941) 8.

CASCIONE, C., "De nuptiis philologiae et iuris". La storiografia wieackeriana dalle "Textstufen" al rapporto tra Diritto romano e "Nachbarndisziplinen der Altertumswissenschafe", in Seminarios Complutenses de Derecho Romano, 23-24 (2010-2011.

CAstresanA, Amelia, Otto Gradenwitz, in DOMINGO, R. (editore), Juristas universales, III: Juristas del siglo XIX (Madrid - Barcelona, 2004)

CHIAZZESE, Lauro, Confronti testuali. Contributo alla dottrina delle interpolazioni giustinianee, in Annali Palermo, 16 (1931)

CHIAZZESE, Lauro, Introdurione allo studio del Diritto romano (3a edizione, Palermo, rist. 1952).

CHIAZZESE, Lauro, Nuovi orientamenti nella storia del Diritto romano, in Archivio Giuridico, 103 (1930).

COGliolo, Pietro, La storia del Diritto romano e le interpolazioni delle Pandette, in Archivio Giuridico, $41(1888)$

COLLINET, Paul, Études historiques sur le Droit de Justinien, I: Le caractère orientale de l'cuvre legislative 
de Justinien et les destinées des Institution classiques en Occident (Paris, 1912).

COllinet, Paul, Études historiques sur le Droit de Justinien. II: Histoire de l'école de droit de Beyrouth (Paris, 1925).

COllinet, Paul, La genèse du Digeste, du Code et des Institutes de Justinien (a cura di R. MONIER e E. VOLTERRA, Paris, 1952).

COMA FORT, J. Ma Índice comentado de las colecciones de fuentes del Corpus iuris civilis (Cizur Menor, 2008).

Const. Deo auctore $₫ 7$

Corpus iuris civilis. Text und Übersetzung, BEHRENDS, O. - R. KNÜTEL, R. - KUPISCH, B. - SEILER, H. H., I: Institutionen (2a edizione, Heidelberg, 1997); II: Digesten 1-10 (Heidelberg, 1995); III: Digesten 11-20 (Heidelberg, 1999); IV: Digesten 21-27 (Heidelberg, 2005).

Cosentini, C., Lezioni di Esegesi delle fonti del Diritto romano (rist. riv., Catania, 1995).

D'Ors, Álvaro, Ludwig Mitteis, in DOMINGO, R. (editore), Juristas universales, III: Juristas del siglo XIX (Madrid - Barcelona, 2004).

D’ORS, Álvaro, rec. a Wieacker, Textstufen, in SDHI., 26 (1960) [= LO STESSO, Crítica romanística (Santiago de Compostela, 1999)].

D’ORS, Álvaro, Presupuestos críticos para el estudio del Derecho romano (Salamanca, 1943).

D'ORS, Xavier, Posiciones programáticas para el estudio del Derecho romano (Santiago de Compostela, 1979).

DE FRANCISCI, Pietro, Emilio Albertario, in SDHI., 15 (1949).

De Marini, F. - LANZA, C., Critica testuale e studio storico del Diritto (3 $3^{a}$ edizione, Torino, 2001).

DI MEDIO, I Tribonianismi avvertiti da Antonio Fabro, in BIDR., 13 (1900), pp. 208 ss.; Di nuovo sui Tribonianismi avvertiti da Antonio Fabro, in BIDR., 14 (1901), pp. 276 ss.

Domingo, Rafael - DomíngueZ, V., François Hotman (Francisco Otomano; Franciscus Hotomanus), in DomingO, R. (editore), Juristas universales (Madrid - Barcelona, 2004), II.

DOMIngO, Rafael, Paul Collinet, in LO STESSO (editore), Juristas universales, III: Juristas del siglo XIX (Madrid - Barcelona, 2004).

DOMINGO, Rafael, Salvatore Riccobono, in LO STESSO (editore), Juristas universales, III: Juristas del siglo XIX (Madrid - Barcelona, 2004).

EISELE, Fridolin, Zur Diagnostike der Interpolationen in den Digesten und im Codex in ZSS., 7 (1886).

FuenteSECA, Pablo, Oriente y Occidente en la Compilación de Justiniano, en Información Jurídica. Revista del Ministerio de Justicia, 109 (1952) [=LO STESSO, Estudios de Derecho romano (Madrid, 2009), pp. 781 ss.].

García CAMiÑas, J., Posiciones metodológicas en el estudio del Derecho romano: el pensamiento de M. Kaser, in Anuario da Facultade de Dereito da Universidade da Coruña, 7 (2003).

García Garrido, Manuel Jesús - REINOSO-BARbero, F., "Praefatio" di Digestorum similitudines (Madrid, 1994), I.

GARCÍA GARRIDO, Manuel Jesús, Miscelánea romanistica, presentación y coordinación FERNÁNDEZ DE BujÁn, F. - REINOSO, F. (Madrid, 2006), I.

García Garrido, Manuel Jesús, Oratio pro opera 'Digestorum similitudines', in Revista General de Derecho Romano, 12 (2009) (http:/ /www.iustel.com).

GARCÍA GARRIDO, Manuel Jesús, Redacciones coincidentes ("leges geminatae”) y casos jurisprudenciales semejantes ("capita similia"), en Estudios de Derecho Romano en honor de Alvaro d'Ors (Pamplona, 1987) [= GARCÍA GARRIDO, Miscelánea romanística, cit. (n. 132), I, pp. 327 ss.].

GARCÍA GARRIDO, Manuel Jesús, Las actuales orientaciones romanisticas, en Revista de Derecho Notarial, IX, 39 (Madrid, 1963).

GAUDEMET, Jean, rec. a Wieacker, Textstufen, in TR., 28 (1960).

Giaro, Tomasz, Max Kaser (1906-1997), in Rechtshistorisches Journal, 16 (1997). 
GIARO, Tomasz, Über methologische Werkmittel der Romanistik, in ZSS., 105 (1988).

GÓMEZ-IGLESIAS, Á., Antoine Favre (Antonius Faber, Antonio Fabro), in DOMINGO, R. (editore), Juristas universales (Madrid - Barcelona, 2004), II.

GRADENWITZ, Otto, Interpolationen in den Pandekten, in ZSS., 7 (1896).

GuARINO, Antonio, Le ragioni del giurista (Napoli, 1983) (=LO STESSO, Pagine di Diritto romano, I); traduzione spagnola a cura di E. RUIZ FERNÁNDEZ, Los caminos al derecho romano clásico, in GUARINO, Sobre la credibilidad de la ciencia romanistica moderna (Granada, 1998)].

GUARINO, Antonio, Giusromanistica elementare (Napoli, 1989).

GUARINO, Antonio,Sulla credibilità della scienza romanistica moderna, in Atti dell'Accademia Pontaniana, N. S., 20 (1971) [= GuARINO, A., Pagine di Diritto romano (Napoli, 1993), I, pp. 403 ss.; traduzione spagnola a cura di E. RUIZ FERNÁNDEZ: Sobre la credibilidad de la ciencia romanistica moderna (Granada, 1998)].

GUZMÁN BRITO, Alejandro, Introducción a los juristas de los siglos XVI y XVII (de Zasio a Montesquieu), in DOMINGO, R. (editore), Juristas universales, II: Juristas modernos (Madrid - Barcelona, 2004).

HARKE, J.-D., rec. a BEHRENDS, O., Institut und Prinæip (Göttingen, 2005), in RabelsZ., 72 (2008).

HONORÉ, Tony, Fritz Pringsheim (1882-1967), in BEATSON, J. - ZIMMERMANN, R. (editori), Jurists Uprooted. German-speaking Emigré Lanyers in Twentieth-century Britain (Oxford, 2004).

HONORÉ, Tony, Gaius (Oxford, 1962).

HONORÉ, Tony, Justinian's Digest. Character and Compilation (Oxford, 2010).

HONORÉ, Tony, Some suggestions for the study of interpolations in TR., 49 (1981).

HONORÉ, Tony, Techniques of interpolation: D. 33.4.15-17, in Sodalitas. Scritti in onore di Antonio Guarino (Napoli, 1984), VI.

HONORÉ, Tony, Tribonian (London, 1978).

HONORÉ, Tony, Ulpian [Oxford, 1982; nuova edizione: Ulpian: Pioneer of Human Rights (Oxford, 2002)].

HUBERT VAN GIFFEN (OBERTUS GIPHANIUS), Commentarius de imperatore Iustiniano (Ingolstadt, 1591).

IHERING, Rudolph von, El Espiritu del Derecho romano en las diversas fases de su desarrollo (trad. esp. di E. Príncipe y Satorre, Madrid, 1895; rist. Granada, 1998).

Il latino dei giuristi romani. Atti del Convegno internazionale di studi (Lecce, 5-6 decembre 1994) (a cura di O. BIANCO e S. TAFARO, Galatina, Lecce, 1999).

JOHNSTON, D., Justinian's Digest. The Interpretation of Interpolation, in Oxford Journal of Legal Studies, 9 (1989) 2.

KASER, Max, Das römische Privatrecht, I: Das altrömische, das vorklassische und klassische Recht (München, 1955); II: Die nachklassischen Entwicklungen (München, 1959).

KASER, Max, Ein Jabrbundert Interpolationenforscbung an den römischen Rechtsquellen, in KASER, M., Römische Rechtsquellen und angewandte Juristenmethode (Wie - Köln - Graz, 1986).

KASER, Max, Ius gentium, Wien - Köln - Graz, 1993).

KASER, Max, Zur heutigen Stand der Interpolationenforschung, in ZSS., 69 (1952).

KASER, Max, Zur Methodologie der römischen Rechtsquellenforschung (Wien - Köln - Graz, 1972).

KLEITER, T., Entscheidungskorrekturen mit unbestimmter Wertung durch die klassische römische Jurisprudenz (München, 2010).

KNÜTEL, R., "Nicht leichter, aber um so reizvollerk". Zum methodologischen Vermächtnis Max Kasers, in ZSS., 115 (1998).

LAMBERTINI, R., Interpolazioni nei Digesta. Dichiarazioni di Giustiniano, esperienza di recerca, in Miglietta, M - SAntUCCI, G. (editori), Problemi e prospettive della critica testuale. Atti del seminario di Diritto romano a Trento, 14-15 dicembre 2007 (Trento, 2011) (opera in corso di 
stampa).

LANDUCCI, F., Filippo Serafini, in Archivio Giuridico, 85 (1921).

LAZO, P., El método de comparación de casos: examen de resultados, en REHJ., 26 (2004).

LEVY, Ernst, Pauli Sententiae. A Palingenesia of the Opening Titles as a Specimen of Research in West Roman Vulgar Law (New York, 1945).

LUSIGNANI, Luigi, Saggio di una raccolta delle interpolazioni presso gli antichi (Parma, 1898).

LUSIGNANI, Luigi, Saggio di una raccolta delle interpolazioni presso gli antichi, cit. (n. 19).

Mantovani, D., Lingua e Diritto. Prospettiva di ricerca fra sociolinguistica e pragmatica, in Studi in onore di Remo Martini (Milano, 2009), II.

MAYER-MALY, Theo, rec. a WIEACKER, Textstufen, in ZSS., 77 (1960).

MIQUEL, Juan, Wolfgang Kunkel, in DOMINGO, R. (editore), Juristas universales, IV: Juristas del siglo XX (Madrid - Barcelona, 2004).

ORESTANO, Riccardo, "Diritto": Incontri e scontri (Bologna, 1981).

ORESTANO, Riccardo, Introducción al estudio del Derecho romano (trad. spagnola M. Abellán Velasco, Madrid, 1997).

PALAZZINI FInTETTI, Luigi, Storia della ricerca delle interpolazioni nel "Corpus iuris civilis" (Milano, 1953).

PAlazzolo, N. - MAgGio, L., Elementi di informatica romanistica (Catania, 2001) [http://www.ittig.cnr.it/Ricerca/Testi/Palazzolo1996Sassari.htm 10 luglio 2011]

PASQUALI. G., s. v. 'Interpolazione', in Enciclopedia Italiana di Scienze, Lettere ed Arti (Roma, 1939, rist. 1949-50), XIX.

PETIT, Carlos, Estudio y edición, con una nota de lectura sobre 'California y el derecho romano', in RADIN, M., Cartas romanisticas (1923-1950) (Napoli, 2001).

RADIN, M., Eleganter, in Law Quarterly Review, 46 (1930).

RADIN, M., Handbook of Roman Law (St. Paul, Minn., 1927).

Rapporto sull'Index Interpolationum, in La critica del testo. Atti del II Congresso Internazionale della Società Italiana di Storia del Diritto (Venezia, 18-22 di settembre di 1967) (Firenze, 1971), I.

REINOSO-BARBERO, F., Geminaciones ocultas en el Digesto, in Index, 25 (1997).

Riccobono, Salvatore, Punti di vista critici e riscostruttivi, a proposito della disertazione di L. Mitteis, "Storia del Diritto antico e studio del Diritto Romano", in Annali Palermo, 12 (1929).

RICCOBOnO, Salvatore, Corso di Diritto romano: Formazione e sviluppo del Diritto romano dalle XII Tavole a Giustiniano (Milano, 1934), Parte II.

RICCOBOnO, Salvatore, Da Diocleziano a Giustiniano, in Conferenze per il XIV Centenario delle Pandette (15 dicembre 530-15 dicembre 1930) (Milano, 1931).

Riccobono, Salvatore, Fasi e fattori dell'evoluzione del Diritto romano, in Mélanges de Droit romain dédiés à G. Cornil (Paris, 1926), II.

RICCOBONO, Salvatore, Il Diritto privato romano nella sua formazione storica e nella sua elaborazione giustinianea, nel Anuario della Università Cattolica di Milano (1926-27).

RICCOBONO, Salvatore, La formazione della teoria generale del contractus nel periodo della giurisprudenza classica, in Studi in onore di P. Bonfante (Milano, 1930), I.

RICCOBOnO, Salvatore, Lineamenti della storia delle fonti e del Diritto romano (Milano, 1949).

RICCOBOnO, Salvatore, Punti vi vista critici e ricostruttivi, in Annali Palermo, 12 (1929).

RICCOBONO, Salvatore, Scritti di Diritto romano (Palermo, 1964), II.

SAVIGNY, Fredich Karl von, De la vocación de nuestro siglo para la legislación y la ciencia del Derecho (trad. spagnola di A. G. POSADA, Buenos Aires, s. d. [ma 1977]).

SCHIPANI, S., Il latino del Diritto nella costruzione della identità dell'Europa, en Studi in onore di Remo Martini, (Milano, 2009), III.

SCHULZ, Fritz, History of Roman Legal Science (2a edizione, Oxford, 1953). 
SCHUlZ, Fritz, Prinzipien des römischen Rechts (Berlin, 1934; rist. 1954).

SCIALOJA, Vittorio, "Prefazione" a Opere giuridiche e storiche del Prof. Ilario Alibrandi (Roma, 1896), I.

SCIALOJA, Vittorio, Ilario Alibrandi, in BIDR., 7 (1895).

Scientia iuris e linguaggio nel sistema giuridico romano. Atti del convegno di studi (Sassari, 22-23 novembre 1996) (a cura di SINI, F. - ORTU, R. Milano, 2001).

SOlAZZI, Siro, Appunti di critica gaiana, in Studi in onore di V. Arangio-Ruiz nel XLV anno del suo insegnamento (Napoli, 1953) (=LO STESSO, Scritti, V).

SOLAZZI, Siro, Glosse a Gaio, In Studi in onore di S. Riccobono nel XL anno del suo insegnamento (Palermo, 1936), pp. 73 ss. [= SOLAZZI, S., Scritti di Diritto romano (Napoli, 1972), VI].

TALAMANCA, Mario, La ricostruzione del testo dalla critica interpolazionistica alle attuali metodologie, in Centro di Studi Romanistici Vincenzo Arangio-Ruiz, Opuscula XVIII (a cura di A. ADAMO, Napoli, 1996) (in corso di ristampa in MIGLIETTA - SANTUCCI (a cura di), Problemi e prospettive della critica testuale. Atti del seminario di Diritto romano a Trento, 14-15 dicembre 2007 (Trento, 2011) (opera in corso di stampa).

TALAMANCA, M., La romanistica italiana fra Otto e Novecento, in Index, 23 (1995).

TAlamancA, Mario, Vittorio Scialoja, en DOMINGO, R. (editore), Juristas universales, III: Juristas del siglo XIX (Madrid - Barcelona, 2004).

TAlamanca, Mario, Otto Lenel e la Palingenesia, Prefazione alla riedizione (a cura di L. CAPOGRossi COlOGNeSI) di LENEL, O., Palingenesia iuris civilis (Roma, 2000), I.

TORRENT, A., Introducción metodológica al estudio del Derecho romano (Oviedo, 1974).

VAlvUEna GarCíA, E., Cien años del Index interpolationum, in e-Legal History Review, 8 (2009) (http://www.iustel.com).

VARELA, E., Jacques Cujas (Jacobus Cuiacius; Cuyacio), in DOMINGO, R. (editore), Juristas universales (Madrid - Barcelona, 2004), II.

VILLERS, R., Gerard de Beseler. Miseres et grandeurs de l'bypercritique, in Mélanges offerts au professeur Louis Faletti. Annales de la faculté de droit et des Sciences Économiques de Lyon (Paris, 1971).

WACKE, Andreas, Max Kaser, in DOMINGO, R. (editore), Juristas universales, IV : Juristas del siglo XX (Madrid - Barcelona, 2004).

WENGER, Leopold, Die Quellen des römischen Rechts (Wien, 1953).

WIEACKER, Franz, Römische Rechtsgeschichte, I: Einleitung, Quellenkunde, Frübzeit und Republike (München, 1988).

WIEACKER, Franz, Lebensläufe klassischer Schriften in nachklassischer Zeit, in ZSS., 67 (1950).

WIEACKER, Franz, Textkritik und Sachforschung, in ZSS., 91 (1974), pp. 1 ss. [= WIEACKER, Ausgewählte Schriften, I.

WIEACKER, Franz, Textstufen klassischer Juristen (Göttingen, 1960).

WIEACKER, Franz, Zur gegenwärtigen Lage der romanistischen Textkritik, in La critica del testo. Atti del II Congresso Internazionale della Società Italiana di Storia del Diritto (Venezia, 18-22 di settembre di 1967) (Firenze, 1971), II [= WIEACKER, F., Ausgewählte Schriften, I: Methodik der Rechtsgeschichte (a cura di D. Simon, Frankfurt am Main, 1983), pp. 103 ss.].

WOLF, J. G., Fran₹ Wieacker, in DOMINGO, R. (editore), Juristas universales, IV: Juristas del siglo XX (Madrid - Barcelona, 2004).

ZEILER, F., Biographische Skizzen zum Lehrkörper der Freiburger Rechtsfakultät in den Jahren 1860$1918 \quad$ (Freiburg, 2008) [http://www.freidok.unifreiburg.de/volltexte/5871/pdf/Biographische_Skizzen.pdf 10 luglio 2011].

ZIEGLER, K.-H., Max Kaser e la revisione della critica romanistica di lengua tedesca dopo il 1967, in MiglietTA - SANTUCCI (a cura di), Problemi e prospettive della critica testuale. Atti del seminario di Diritto romano a Trento, 14-15 dicembre 2007 (Trento, 2011) (opera in corso di stampa). 